University of Wollongong

Research Online

Australian Institute for Innovative Materials -

Papers

Australian Institute for Innovative Materials

$1-1-2019$

Molybdenum and tungsten chalcogenides for lithium/sodium-ion batteries: Beyond MoS2

Junda Huang

Hunan University

Zengxi Wei

Hunan University

Jiaqin Liao

Hunan University

Wei Ni

Panzhihua University

Caiyun Wang

University of Wollongong, caiyun@uow.edu.au

See next page for additional authors

Follow this and additional works at: https://ro.uow.edu.au/aiimpapers

Part of the Engineering Commons, and the Physical Sciences and Mathematics Commons

Research Online is the open access institutional repository for the University of Wollongong. For further information contact the UOW Library: research-pubs@uow.edu.au 


\title{
Molybdenum and tungsten chalcogenides for lithium/sodium-ion batteries: Beyond MoS2
}

\author{
Abstract \\ Molybdenum and tungsten chalcogenides have attracted tremendous attention in energy storage and \\ conversion due to their outstanding physicochemical and electrochemical properties. There are intensive \\ studies on molybdenum and tungsten chalcogenides for energy storage and conversion, however, there is \\ no systematic review on the applications of WS2, MoSe2and WSe2as anode materials for lithium-ion \\ batteries (LIBs) and sodium-ion batteries (SIBs), except MoS2. Considering the importance of these \\ contents, it is extremely necessary to overview the recent development of novel layered WS2, MoSe2and \\ WSe2beyond MoS2in energy storage. Here, we will systematically overview the recent progress of WS2, \\ MoSe2and WSe2as anode materials in LIBs and SIBs. This review will also discuss the opportunities, and \\ perspectives of these materials in the energy storage fields.

\section{Disciplines} \\ Engineering | Physical Sciences and Mathematics

\section{Publication Details} \\ Huang, J., Wei, Z., Liao, J., Ni, W., Wang, C. \& Ma, J. (2019). Molybdenum and tungsten chalcogenides for \\ lithium/sodium-ion batteries: Beyond MoS2. Journal of Energy Chemistry, 33 100-124.

\section{Authors} \\ Junda Huang, Zengxi Wei, Jiaqin Liao, Wei Ni, Caiyun Wang, and Jianmin Ma
}




\section{Review}

\section{Molybdenum and tungsten chalcogenides for lithium/sodium-ion batteries: Beyond $\mathrm{MoS}_{2}$}

Junda Huang ${ }^{\mathrm{a}}$, Zengxi Wei ${ }^{\mathrm{a}}$, Jiaqin Liao $^{\mathrm{a}}$, Wei Ni ${ }^{\mathrm{b}, \mathrm{c}, *}$, Caiyun Wang ${ }^{\mathrm{d}, *}$, Jianmin Ma $^{\mathrm{a}, \mathrm{e}, *}$

${ }^{a}$ School of Physics and Electronics, Hunan University, Changsha 410082, Hunan, China

${ }^{\mathrm{b}}$ Faculty of Technology, University of Oulu, Oulu 90014, Finland

c Panzhihua University, Panzhihua 617000, Sichuan, China

${ }^{\mathrm{d}}$ ARC Centre of Excellence for Electromaterials Science, Intelligent Polymer Research Institute, AIIM

Facility, University of Wollongong, North Wollongong, NSW 2500, Australia

e Institute of Advanced Electrochemical Energy, Xi'an University of Technology, Xi'an 710048,

Shaanxi, China

* Corresponding authors.

E-mail addresses: wei.ni@oulu.fi (W. Ni), caiyun@uow.edu.au (C. Wang), nanoelechem@hnu.edu.cn (J.M. Ma). 


\section{ABSTRACT}

Molybdenum and tungsten chalcogenides have attracted tremendous attention in energy storage and conversion due to their outstanding physicochemical and electrochemical properties. There are intensive studies on molybdenum and tungsten chalcogenides for energy storage and conversion, however, there is no systematic review on the applications of $\mathrm{WS}_{2}, \mathrm{MoSe}_{2}$ and $\mathrm{WSe}_{2}$ as anode materials for lithium-ion batteries (LIBs) and sodium-ion batteries (SIBs), except $\mathrm{MoS}_{2}$. Considering the importance of these contents, it is extremely necessary to overview the recent development of novel layered $\mathrm{WS}_{2}, \mathrm{MoSe}_{2}$ and $\mathrm{WSe}_{2}$ beyond $\mathrm{MoS}_{2}$ in energy storage. Here, we will systematically overview the recent progress of $\mathrm{WS}_{2}, \mathrm{MoSe}_{2}$ and $\mathrm{WSe}_{2}$ as anode materials in LIBs and SIBs. This review will also discuss the opportunities, and perspectives of these materials in the energy storage fields.

Keywords: $\mathrm{MoSe}_{2} ; \mathrm{WS}_{2} ; \mathrm{WSe}_{2}$; Lithium-ion batteries; Sodium-ion batteries 


\section{Introduction}

Being confronted with global energy crisis and environmental issues, the exploring of clean and renewable energy materials as well as their devices is urgentlydemanded [13].Lithium-ion batteries (LIBs) and sodium-ion batteries (SIBs) have shown the uniquepotential and various advantages with good cycle life,high energy density, and low self-discharge features [49]. The achieving of excellent performance for an energy storage device isclosely related to the properties of electrode materials [1015]. Layer-structured transition-metal dichalcogenides (TMDs) are characterized with relatively weaker $\mathrm{M}-\mathrm{X}(\mathrm{M}=$ transition metal, $\mathrm{X}=$ chalcogen $)$ ionic bonds, van der Waals interaction dominated interlayers, and large surface-to-volume ratio. All these features endow them with kinetically favorable performances and have attracted intensive interest due to their immense potential for energy storage and conversion amongst various promising applications [1621]. Tungsten sulfide $\left(\mathrm{WS}_{2}\right)$, molybdenum and tungsten chalcogenides $\left(\mathrm{MoSe}_{2}, \mathrm{WSe} 2\right)$ have recently attracted great attention as anode materials for Na-ion batteries and Li-ion batteries beyond the well-studied two-dimensional (2D) $\mathrm{MoS}_{2}$ analogue, owing to their unique physicochemical characteristics including higher intrinsically electrical conductivity and larger interlayer spacing [2228]. Theyshare the same layered structure with $2 \mathrm{D} \mathrm{MoS}$, and their structural similarities inspire the researchers to develop similar synthetic strategies for $\mathrm{WS}_{2}$, $\mathrm{MoSe}_{2}$ and $\mathrm{WSe}_{2}$ and explore their potential applications in electronics, sensors, and energy conversion/storage[16,17,2942]. For example, it is found that $\mathrm{MX}_{2}(\mathrm{M}=\mathrm{Mo}, \mathrm{W} ; \mathrm{X}=\mathrm{S}, \mathrm{Se})$ as anode materials for LIBs and SIBs showed relatively low voltages and high electronic conductivities during $\mathrm{Li} / \mathrm{Na}$ intercalation. Among them, $\mathrm{WS}_{2}$ and $\mathrm{WSe}_{2}$ demonstrate the lowest $\mathrm{Li} / \mathrm{Na}$ ion migration barriers, affording favorable rate performance for advanced secondary batteries [43]. 
LIBs are one of the most successful examples among various battery technologies $[2,4,21]$. Currently the commercialized anode materials include natural graphite, artificial graphite, mesocarbon microbeads (MCMBs), $\mathrm{Li}_{4} \mathrm{Ti}_{5} \mathrm{O}_{12}$, and silicon/carbon [44]. However, there are still challenges in performance, cost competitiveness, and production technology for these materials (e.g., low capacity, poor conductivity, limited power/energy density, lifetime, safety or all-climate performance issues) to meet the strongly growing market share such as full electrification of the future automotive industry [4446]. TMDs are a recent addition to the growing list of anode materials for next-generation LIBs (Table S1, S3, and S5 in Supplementary materials)[24,30,4749]. Moreover, SIBs have also drawn great attention as promising energy storage devices due to the low cost and abundance of sodium $[6,50,51]$. Although they share the same reaction mechanism with LIBs, however, graphite is not a suitable anode for SIBs since sodium ion could not be inserted into graphite effectively. To solve this problem, apart from the exploration of various oxides and sulfides as anode materials [6,5254], molybdenum and tungsten dichalcogenides $\left(\mathrm{MoS}_{2}, \mathrm{WS}_{2}, \mathrm{MoSe}_{2}\right.$ and $\left.\mathrm{WSe}_{2}\right)$ have been intensively studied and exhibited superior performances associated with the intercalation and conversion during the cycling (Table S2, S4, and S6 in Supplementary materials)[24,30].

Recently, there are some excellent reviews on $\mathrm{MoS}_{2}$ for energy storage and conversion $[38,5558]$, however, there is no systematic review on the applications of $\mathrm{WS}_{2}, \mathrm{MoSe}_{2}$ and $\mathrm{WSe}_{2}$ as anode materials for LIBs and SIBs. Considering the importance of these contents, it is extremely necessary to overview the recent studies on $\mathrm{WS}_{2}, \mathrm{MoSe}_{2}$ and $\mathrm{WSe}_{2}$ as anode materials from synthesis to battery performance. In this review, we will systematically overview the research status of $\mathrm{WS}_{2}, \mathrm{MoSe}_{2}$ and $\mathrm{WSe}_{2}$ from the electrode design, synthetic methods and their battery performance. We will also present our insights 
on the opportunities and challenges of these TMDs in different energy storage systems in the near future.

\section{Lithium-ion batteries}

Owing to the similar layered structures features to graphite yet with larger spacing, TMDs composed of group VI metals (Mo and W) and chalcogens (S and Se) with 2D layered crystalline frameworks have shown great potential as alternative advanced anode materials. As a well-studied representative, $\mathrm{MoS}_{2}$ achieved significant improvements in cycle life and rate performance thanks to numerous efforts devoted to promoting the low intrinsically electrical conductivity as well as creating novel structural and electrode design [5766]. Novel layered $\mathrm{WS}_{2}, \mathrm{MoSe}_{2}$, and $\mathrm{WSe}_{2}$ with the same crystal structure but higher intrinsic electronic conductivity, larger interlayer spacing, and lower potential plateau should possess more advantages for advanced secondary batteries from commercial aspects $[16,17,30,38,6771]$. The Li/Na-ion storage mechanism can be briefly expressed by the following equations [30,72,73],

$\mathrm{MX}_{2}+4 \mathrm{~A}^{+}+4 \mathrm{e}^{-} \leftrightarrow \mathrm{M}+2 \mathrm{~A}_{2} \mathrm{X} \quad(\mathrm{M}=\mathrm{Mo}, \mathrm{W} ; \mathrm{X}=\mathrm{S}, \mathrm{Se} ; \mathrm{A}=\mathrm{Li}, \mathrm{Na})$

or detailed by the following two-step electrochemical reactions,

$\mathrm{MX}_{2}+x \mathrm{~A}^{+}+x \mathrm{e}^{-} \leftrightarrow \mathrm{A}_{x} \mathrm{MX}_{2} \quad(x<2) \quad$ (intercalation)

$\mathrm{A}_{x} \mathrm{MX}_{2}+(4-x) \mathrm{A}^{+}+(4-x) \mathrm{e}^{-} \leftrightarrow \mathrm{M}+2 \mathrm{~A}_{2} \mathrm{X} \quad$ (conversion) 


\section{1. $\mathrm{WS}_{2}$ for lithium-ion batteries}

$\mathrm{WS}_{2}$ with sandwiched $\mathrm{S}-\mathrm{W}-\mathrm{S}$ layers (interlayer spacing $0.618 \mathrm{~nm}$ ) stacked together via weak van der Waals interaction has received tremendous attention for next-generation rechargeable LIBs due to its higher intrinsic electrical conductivity compared to $\mathrm{MoS}_{2}$, competitive theoretical capacity of $433 \mathrm{~mA}$ $\mathrm{h} \mathrm{g}^{-1}$ (based on $4 \mathrm{~mol}$ of Li-ion insertion), and a high density of $7.6 \mathrm{~g} \mathrm{~cm}^{-3}$ resulting in a volumetric energy density 4 times higher than that of graphite $[69,7478]$. However, the electrical conductivity of pristine TMDs and electrode stability need to be further improved for practical application in high power/density energy storage devices.

\subsubsection{Structural control of $W S_{2}$}

Nanostructured electrode materials compared to bulk materials could achieve greatly enhanced electrochemical performance due to their advantages of much higher surface area, reactivity, electric/ionic conductivity as well as reduced dimensions for Li-ion intercalation from shortened transport lengths and separation distances $[69,7988]$. The control of crystalline preferential orientation such as (001) plane of 2D WS 2 nanosheets further improved the diffusion kinetics and electrochemical performance, as an example, an anode by Zhang and coworkers showed an enhanced reversible capacity of $539 \mathrm{~mA} \mathrm{~h} \mathrm{~g}^{-1}$ after 60 cycles at $200 \mathrm{~mA} \mathrm{~g}^{-1}[69]$. The $\mathrm{WS}_{2}$ bundles composed of multiple single sheet crystals can be fabricated from one-dimensional (1D) tungsten oxide nanorods via a "shape-transformation" concept, however, the poor Li storage performance need to be further enhanced due to the limited conductivity [87]. Fang et al. exploited a solid-state reaction route to synthesize graphene-like and plate-like $\mathrm{WS}_{2}$. It is worthy to mention that graphene-like $\mathrm{WS}_{2}$ exhibited a bent pole structure with $1 \mu \mathrm{m}$ in diameter and was comprised of stacked sheets in a thickness of $2-8$ layers. The assembled few-layer or expanded $\mathrm{WS}_{2}$ showed a high capacity of ca. $600 \mathrm{~mA} \mathrm{~h} \mathrm{~g}{ }^{-1}$ after 
100 cycles at $0.05 \mathrm{C}$ and better rate performance than plate-like $\mathrm{WS}_{2}(1-2 \mu \mathrm{m}$ in diameter and $\sim 200$ $\mathrm{nm}$ in thickness) due to the increased surface area and reduced diffusion path [82]. They further explored the Li storage mechanism and claimed that the $\mathrm{W}$ does not participate in the reversible electrochemical redox reaction after it was formed in the initial reduction (lithiation) process, i.e., the redox reaction in a $\mathrm{WS}_{2} / \mathrm{Li}$ cell was similar to that in a $\mathrm{Li}-\mathrm{S}$ battery, inconsistent with a completely reversible conversion reaction $[69,78,89]$. In regard of this, some experts suggested a further sulfuration reprocessing of initial $\mathrm{WS}_{2}$ for repairing sulfur vacancies to improve the electrochemical performance [90]. In addition to the electrodeposition and various gas-phase deposition techniques (e.g., CVD, metal organic CVD, pulsed laser deposition, sputtering), thin film-like $\mathrm{WS}_{2}$ can also prepared by atomic layer deposition (ALD) through the self-saturation growth. When used as thin film anode in LIBs, it showed a stable cycling performance with a high Coulombic efficiency (CE) of over $99 \%[91]$.

Similar to the effect of nanosized materials, mesoporous materials with nanoscale crystalline walls, low intrinsic activation energy, and high electrode-electrolyte interface facilitate shortened Liion diffusion pathway, offer more active sites for Li-ion storage resulting in higher energy/power density $[10,64,79]$. For example, Liu et al. synthesized an ordered mesoporous $\mathrm{WS}_{2}$ with a high surface area $\left(115 \mathrm{~m}^{2} \mathrm{~g}^{-1}\right)$ and narrowed pore size distribution $(3.34 \mathrm{~nm})$ via the replication of a $2 \mathrm{D}$ hexagonal SBA-15 template. When used as an anode for LIBs, it showed a high Li storage capacity of $805 \mathrm{~mA} \mathrm{~h}$ $\mathrm{g}^{-1}$ after 100 cycles (92.5\% capacity retention compared to $2^{\text {nd }}$ cycle) at $0.1 \mathrm{~A} \mathrm{~g}^{-1}$ and an outstanding high rate capability: $661 \mathrm{~mA} \mathrm{~h} \mathrm{~g}^{-1}$ at $1.0 \mathrm{~A} \mathrm{~g}^{-1}(2.25 \mathrm{C})$ and $504 \mathrm{~mA} \mathrm{~h} \mathrm{~g}-1$ at $10 \mathrm{~A} \mathrm{~g}^{-1}(22.5 \mathrm{C})$. It indicates that mesoporous $\mathrm{WS}_{2}$ may be a promising material for high power Li-ion batteries [79]. 


\subsubsection{Hybridizing $W_{2}$ with conducting frameworks}

To enhance the electrical conductivity as well as the electrode stability for promoting the electrochemical performance of pristine $\mathrm{WS}_{2}$, the introduction of conducting frameworks such as amorphous carbon [74,76,90,9298], CNTs [78,99101], and graphene [70,102107] is a facile and effective strategy.

Besides the traditional ball milling and calcination method for incorporating amorphous carbon with layered $\mathrm{WS}_{2}[89,97]$, the spray pyrolysis is another facile route to prepare $\mathrm{WS}_{2} / \mathrm{C}$ composite, and it could deliver a reversible capacity as high as $555 \mathrm{~mA} \mathrm{~h} \mathrm{~g}^{-1}$ after 50 cycles at $100 \mathrm{~mA} \mathrm{~h} \mathrm{~g}^{-1}$ [94]. An integrated $\mathrm{WS}_{2} @ \mathrm{CMK}-3$ nanocomposite with few-layered $\mathrm{WS}_{2}$ nanosheets embedded in ordered mesoporous carbon CMK-3 matrix was prepared by Pang et al. through a facile hydrothermal method, which delivered a reversible capacity of $720 \mathrm{~mA} \mathrm{~h} \mathrm{~g}^{-1}$ after 100 cycles at $100 \mathrm{~mA} \mathrm{~g}^{-1}$ and a high rate capability of 395 and $307 \mathrm{~mA} \mathrm{~h} \mathrm{~g}^{-1}$ at 1.0 and $2.0 \mathrm{~A} \mathrm{~g}^{-1}$, respectively[96]. A WS 2 @NCNFs hybrid structure with $\mathrm{WS}_{2}$ nanosheets uniformly embedded in N-doped carbon nanofibers (NCNFs) was fabricated by Kim's group via an electrospinning method [95]. The interconnected network exhibited an improved capacity of $438 \mathrm{~mA} \mathrm{~h} \mathrm{~g}^{-1}$ after 200 cycles at $500 \mathrm{~mA} \mathrm{~g}^{-1}$, corresponding to a capacity retention rate of $87.2 \%$ at the $2^{\text {nd }}$ cycle. The design of hollow structures is an alternative route of tremendous interest for buffering large volume changes and improving charge transfer during the charge/discharge processes, thus benefiting the long-term cycling stability and rate capability [108110]. For example, a hierarchical nanocomposite, hollow N-doped carbon spheres (HNCSs) uniformly decorated with ultrathin (3-5 layers) $\mathrm{WS}_{2}$ nanosheets (WS $\mathrm{WS}_{2} @ \mathrm{HNCSs}$ ), demonstrated a high specific capacity of $801 \mathrm{~mA} \mathrm{~h} \mathrm{~g}^{-1}$ at $100 \mathrm{~mA} \mathrm{~g}^{-1}$, excellent rate capacity of $546 \mathrm{~mA} \mathrm{~h} \mathrm{~g}^{-1}$ at $2.0 \mathrm{~A} \mathrm{~g}^{-1}$, and a great cycling stability with a capacity retention rate of $95.8 \%$ after 150 cycles at $500 \mathrm{~mA} \mathrm{~g}^{-1}[76]$. 
These 2D layers with high surface energy are inclined to restack or re-aggregate during the processes of Li-ion insertion/extraction, thus resulting in a rapid capacity fade and poor rate capability. To overcome these drawbacks, Zou et al. designed a multi-layer-cake $\mathrm{WS}_{2} / \mathrm{C}$ nanocomposite via an intercalation-transformation method (Fig. 1a), where the few-layered $\mathrm{WS}_{2}$ were sandwiched between the in situ formed amorphous interlayer carbon, forming a unique "regular (phase-pure)" and "alternate (sandwiched)" architecture (Fig. 1b,c). This nanocomposite delivered a high capacity of $829 \mathrm{~mA} \mathrm{~h} \mathrm{~g}^{-1}$ after 140 cycles at $300 \mathrm{~mA} \mathrm{~g}^{-1}$, and demonstrated an excellent rate capacity of $327 \mathrm{~mA} \mathrm{~h} \mathrm{~g}^{-1}$ at $8.0 \mathrm{~A}$ $\mathrm{g}^{-1}$. The improved performance can be ascribed to the synergistic effect: the intercalated carbon layers helped prevent $\mathrm{WS}_{2}$ sheets from restacking and increase the conductivity; few-layered $\mathrm{WS}_{2}$ intrinsically facilitated the transportation of both electrons and Li ions. This intercalation strategy may provide a new facile reference for the design of advanced electrodes of next-generation batteries [74]. Another kind of hybrid sandwiched porous $\mathrm{WS}_{2} / \mathrm{CNT}$ electrodes were fabricated via homogeneously intercalating SWCNTs into lamellar assembled $\mathrm{WS}_{2}$ nanosheets through a facile vacuum filtration affording excellent electrochemical performance: a high specific capacity of $862 \mathrm{~mA} \mathrm{~h} \mathrm{~g}{ }^{-1}$ after 50 cycles at $100 \mathrm{~mA} \mathrm{~g}^{-1}$; a rate capability of 440 and $342 \mathrm{~mA} \mathrm{~h} \mathrm{~g}^{-1}$ at 1.0 and $2.0 \mathrm{~A} \mathrm{~g}^{-1}$ [78]. Moreover, the introduction of the third component positively charged $\mathrm{CuO}$ nanosheet can integrate with negatively charged $\mathrm{WS}_{2}$ nanosheets, the formed ternary $\mathrm{WS}_{2} / \mathrm{CuO} / \mathrm{SWCNT}$ porous laminated hybrid showed an improved performance with an enhanced reversible capacity of $962 \mathrm{~mA} \mathrm{~h} \mathrm{~g} \mathrm{~g}^{-1}$ after 100 cycles at $100 \mathrm{~mA} \mathrm{~g}^{-1}$ and a high rate capacity of $418 \mathrm{~mA} \mathrm{~h} \mathrm{~g}^{-1}$ at $2.0 \mathrm{~A} \mathrm{~g}^{-1}[84,99]$. 
a)
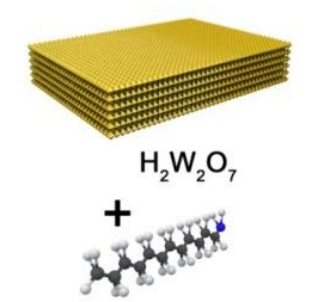

DDA

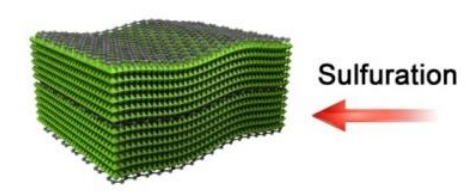

Thousand-Layer-Cake $\mathrm{WS}_{2} / \mathrm{C}$ Nanocomposite

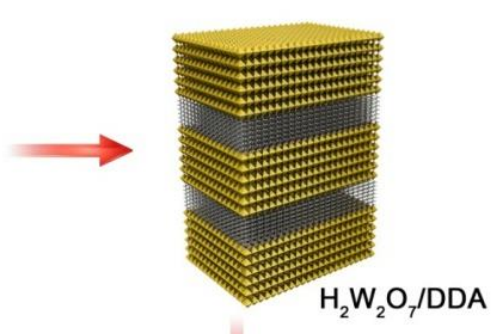

Carbonization

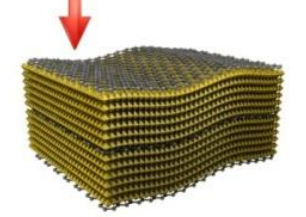

Thousand-Layer-Cake WO $_{3-x} / \mathrm{C}$ Nanocomposite b)

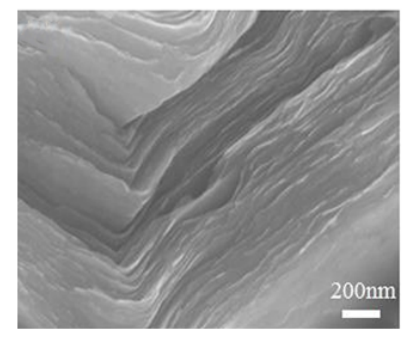

c)

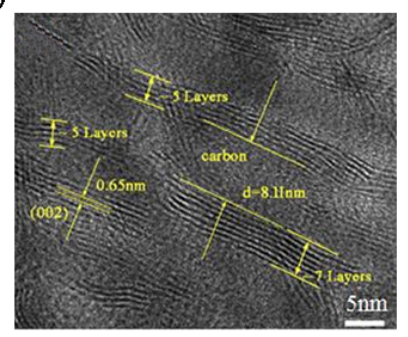

Fig. 1. (a) Schematic illustration of the synthesis process of multi-layer-cake $\mathrm{WS}_{2} / \mathrm{C}$ nanocomposite with a unique "regular" and "alternate" architecture DDA, dodecylamine $\left(\mathrm{C}_{12} \mathrm{H}_{27} \mathrm{~N}\right)$. (b and c) The cross-sectional SEM image and HRTEM image of $\mathrm{WS}_{2} / \mathrm{C}$ nanocomposite. Reproduced from Ref. [74] with permission of Wiley-VCH.

Graphene exhibits outstanding advantages in energy conversion and storage due to its high electric conductivity, large surface area, and good geometrical compatibility with layered TMDs for enhanced electrochemical performances $[89,104,106,111,112]$. For example, Shiva et al. employed a simple hydrothermal process to fabricate uniform graphene-like few-layer $\mathrm{WS}_{2}$ supported on reduced graphene oxide (rGO) with synergistic interactions between them for superior electrochemical performances. When utilized as anode materials for LIBs, the $\mathrm{WS}_{2}-\mathrm{rGO}$ (80:20 and 70:30) composites with a lithiation/delithiation voltage of $\sim 1.0 \mathrm{~V}$ and high interface stability showed a much enhanced capacity of $451 \mathrm{~mA} \mathrm{~h} \mathrm{~g}^{-1}$ (80:20) after 50 cycles at $100 \mathrm{~mA} \mathrm{~g}^{-1}$ and a superior rate capability of 236 $\mathrm{mA} \mathrm{h} \mathrm{g}^{-1}$ (70:30) even at a much higher current density of $4.0 \mathrm{~A} \mathrm{~g}^{-1}$ compared to bare $\mathrm{WS}_{2}(8 \mathrm{~mA} \mathrm{~h}$ 
$\mathrm{g}^{-1}$ at $2.0 \mathrm{~A} \mathrm{~g}^{-1}$ ) and rGO [113]. A thin nanoslice-structured WS $\mathrm{W}_{2} @$ rGO composite fabricated by Li et al. could deliver an improved capacity of $565 \mathrm{~mA} \mathrm{~h} \mathrm{~g}^{-1}$ after 100 cycles at $100 \mathrm{~mA} \mathrm{~g}^{-1}$ and a high rate capacity of $337 \mathrm{~mA} \mathrm{~h} \mathrm{~g}^{-1}$ at $2.0 \mathrm{~A} \mathrm{~g}^{-1}$ [112]. The first-principles calculations revealed that the electronrich environment provided by the graphene network increased the binding energy of Li insertion and favored the delithiation process for $\mathrm{WS}_{2}$; and other advantages such as lowered (diffusion) barrier energy for $\mathrm{Li}^{+}$migration and higher Yong's modulus of the composite in comparison with pristine $\mathrm{WS}_{2}$ were also indicated [112]. Graphene, as a 2D conducting material with high surface area, can bestow the $\mathrm{WS}_{2}$ composite with a very low percolation threshold $[114,115]$. Cho's group prepared a few-layered $\mathrm{WS}_{2}-\mathrm{rGO}$ composite by a simple hydrothermal and subsequent freeze-drying method [103]. The composite with a low content of rGO (only $\sim 3 \mathrm{wt} \%$ ) delivered a good cycling stability of $647 \mathrm{~mA} \mathrm{~g}^{-1}$ after 80 cycles at $350 \mathrm{~mA} \mathrm{~g}^{-1}$ and excellent high-rate capacity of 541 and $296 \mathrm{~mA} \mathrm{~h} \mathrm{~g}^{-1}$ at a current density of 7 and $14 \mathrm{~A} \mathrm{~g}^{-1}$, respectively. The $\mathrm{N}$-doping further improved the electron transport properties and electrochemical activity of graphene or rGO [116,117]. Lee's group integrated fewlayer $\mathrm{WS}_{2}$ with $\mathrm{N}$-doped graphene via a facile surfactant-assisted hydrothermal synthesis. The in-situ nitrogenated graphene/ $\mathrm{WS}_{2}$ delivered a more stable cyclability with a reversible capacity of $830 \mathrm{~mA}$ $\mathrm{h} \mathrm{g}^{-1}$ after 100 cycles at $100 \mathrm{~mA} \mathrm{~g}^{-1}$ and better rate performance of $\sim 700 \mathrm{~mA} \mathrm{~h} \mathrm{~g}^{-1}$ at a high current of $5.0 \mathrm{~A} \mathrm{~g} \mathrm{~g}^{-1}$ (80\% of the initial capacity at $\left.0.1 \mathrm{~A} \mathrm{~g}^{-1}\right)$, which may be a promising material for poweroriented applications [70]. For some carbon-based frameworks, they may also help in suppressing the "shuttle effect" of sulfur-containing electrodes via adsorbing polysulfide intermediates. The co-doping of carbon component not only increases the electrical conductivity but also enhances the interaction between $\mathrm{WS}_{2}$ and carbon framework. For example, the $\mathrm{WS}_{2}$ hybrid with N,S co-doped graphene could show a much higher and stable reversible capacity of $509 \mathrm{~mA} \mathrm{~h} \mathrm{~g}^{-1}$ after 500 cycles at $2.0 \mathrm{~A} \mathrm{~g}^{-1}$, which 
was mainly attributed to the pseudocapacitive charge storage [118]. In regard of further improvement of gravimetric energy density, Chen et al. designed a double transition-metal chalcogenide hybrid via composition-optimized composition of $\mathrm{WS}_{2}, \mathrm{MoS}_{2}$, and N-doped graphene the ternary hybrid (W/Mo $=1: 1)$ exhibited a very high and stable reversible capacity of $1032 \mathrm{~mA} \mathrm{~h} \mathrm{~g}{ }^{-1}$ after 100 cycles at 100 $\mathrm{mA} \mathrm{g}^{-1}$ with a higher initial Coulombic efficiency (ICE) of $90 \%$ and an excellent rate performance of $\sim 770 \mathrm{~mA} \mathrm{~h} \mathrm{~g}^{-1}$ at $5.0 \mathrm{~A} \mathrm{~g}^{-1}$, a capacity retention of $75 \%$ when the current density increased 50 fold from 0.1 to $5.0 \mathrm{~A} \mathrm{~g}^{-1}[119]$.

\subsubsection{Free-standing $\mathrm{WS}_{2}$ electrodes}

Flexible energy storage devices have recently attracted increasing interest as power supplies for wearable smart electronics in modern life [120126]. The design of flexible electrodes with high conductivity, stable structure, superior electrochemical performance and robust mechanical property is of strong demand [106]. The incorporation with carbon fiber cloth is a facile and effective route, which includes carbon cloth, biomaterial-derived carbon paper or electrospun nonwoven conductive matrices $[75,77,127]$. For example, Hao's group designed a flexible anode for LIBs with metallic $1 \mathrm{~T} @ 2 \mathrm{H} \mathrm{WS} 2$ nanosheet arrays stably anchored on cotton cloth-derived interlinked carbon fiber cloth (CFC). Compared to the semiconducting $(2 \mathrm{H})$ phase $\mathrm{WS}_{2}$ (trigonal prismatic coordination), the metallic (1T) phase $\mathrm{WS}_{2}$ (octahedral coordination) exhibits higher conductivity via the transversal displacement of one of $\mathrm{S}$ atomic layer. Through displacement of $\mathrm{S}$ atoms in $\mathrm{WS}_{2}$ induced by incorporation of $\mathrm{N}$ atoms and the formation of $\mathrm{N}-\mathrm{W}$ covalent bonds within the matrix, the metallic 1T phase $\mathrm{WS}_{2}$ transformed from $2 \mathrm{H}$ phase was stably ensured. The as-prepared 1T@2H WS $@$ @FC flexible anode showed a smaller initial discharge capacity loss (a higher ICE of 87.4\%) and a higher reversible capacity $\left(1130 \mathrm{~mA} \mathrm{~h} \mathrm{~g}^{-1}\right.$ after 200 cycles at $0.1 \mathrm{~A} \mathrm{~g}^{-1}$ and $510 \mathrm{~mA} \mathrm{~h} \mathrm{~g}^{-1}$ after 800 cycles at 
2.0 $\mathrm{A} \mathrm{g} \mathrm{g}^{-1}$ ) than that with pure $2 \mathrm{H}$ phase, mainly due to the improvement of conductivity and outstanding electrochemical performances via capacitance-controlled fast charge storage and longterm cyclability [75]. Zhang et al. developed a flexible hierarchical electrode of few-layer $\mathrm{WS}_{2}$ nanosheets uniformly grown on graphene-wrapped electrospun carbon fibers (Fig. 2) for remarkably improved electrical conductivity. Benefiting from the synergistic effect of hybrid carbon nanofibers and $\mathrm{WS}_{2}$ nanosheets, this self-supported membrane possessed a porous and interconnected structure with large surface area, high electrical conductivity and good structural integrity for rapid Liions/electrons transfer and overall electrochemical stability. The optimized hybrid binder-free electrode showed a high initial capacity of $1128 \mathrm{~mA} \mathrm{~h} \mathrm{~g}^{-1}$ at $100 \mathrm{~mA} \mathrm{~g}^{-1}$, excellent long-term stability with $95 \%$ of the capacity retained after 100 cycles, and an outstanding rate capability of $624 \mathrm{~mA} \mathrm{~h} \mathrm{~g}^{-1}$ at $2.0 \mathrm{~A} \mathrm{~g}^{-1}[128]$. Kong et al. fabricated a similar hybrid electrode of $\mathrm{WS}_{2}$ nanoplates encapsulated in porous graphitic nanofibers $\left(\mathrm{WS}_{2} @ \mathrm{G}\right)$ via electrospinning in combination with chemical vapor deposition (CVD) methods, creating an efficiently conductive and electrolyte-accessible framework (Fig. 3). This integrated highly conductive electrode not only alleviated the volume expansion during the cycling but also enabled a mechanically robust feature. Therefore it demonstrated an excellent cycle life with high capacity of $c a .500 \mathrm{~mA} \mathrm{~h} \mathrm{~g}^{-1}$ after 300 cycles at $0.5 \mathrm{~A} \mathrm{~g}^{-1}$, and showed a superior rate capability of $455 \mathrm{~mA} \mathrm{~h} \mathrm{~g}^{-1}$ at $1.0 \mathrm{~A} \mathrm{~g}^{-1}[129]$. 


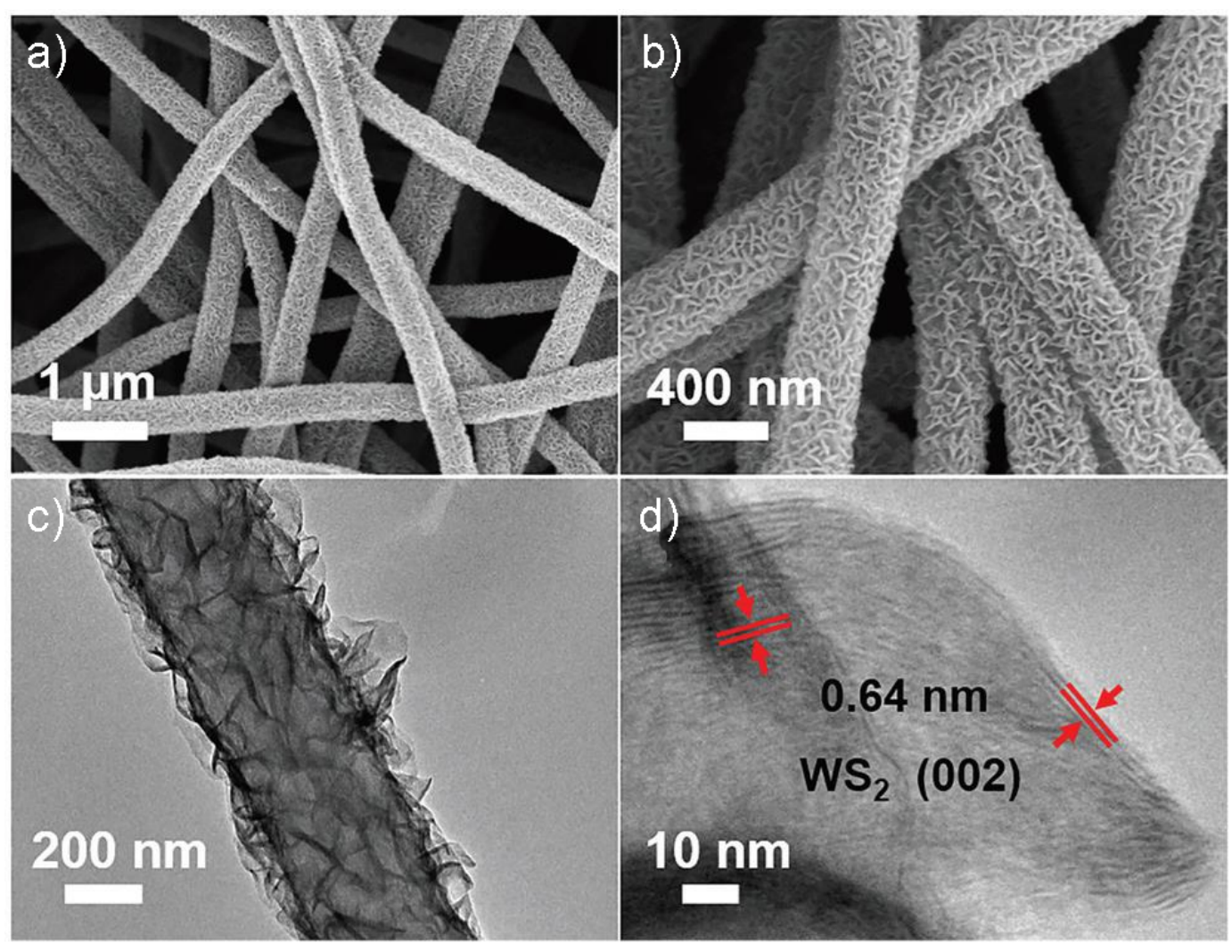

Fig. 2. Microstructure of flexible $\mathrm{WS}_{2} / \mathrm{GCNF}$ hybrid membrane with $\mathrm{WS}_{2}$ nanosheets grown on graphenewrapped electrospun carbon nanofibers: (a and b) SEM, (c) TEM and (d) HRTEM images. Reproduced from Ref. [128]with permission of Royal Society of Chemistry. 

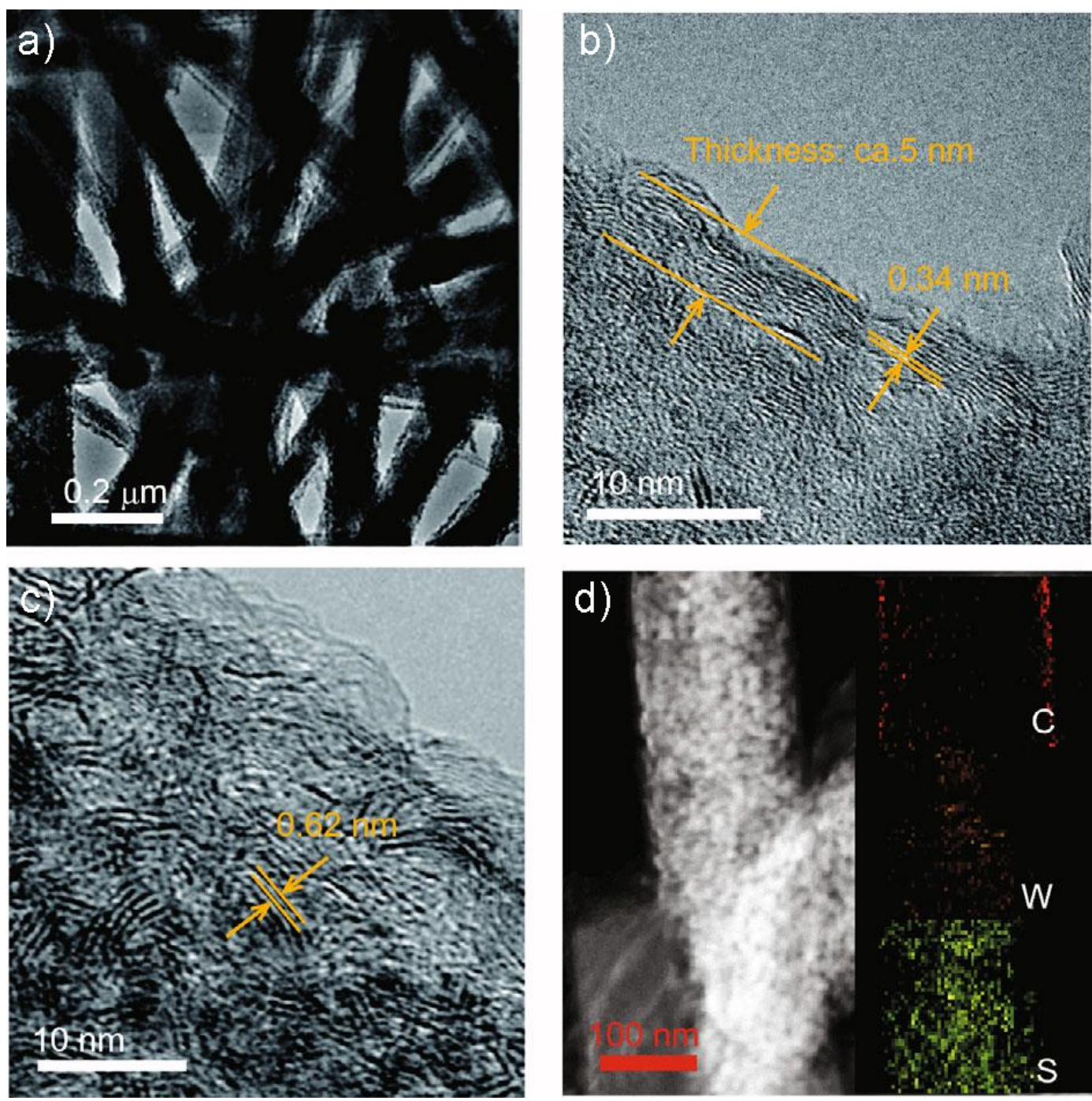

Fig. 3. (a) TEM, (b and c) HRTEM images, and (d) dark field TEM image and mapping of the nanocable-like $\mathrm{WS}_{2} @ \mathrm{G}$ with layered $\mathrm{WS}_{2}$ nanoplates embeded in electrospun graphitic carbon nanotubes for dual anode material. Reproduced from Ref. [129]with permission of Science China Press and Springer.

The design of flexible free-standing electrode is one of the hottest research topics for higher energy/power density energy-storage devices and the ever-growing market of wearable electronics $[120,123]$. For example, through embedding $\mathrm{WS}_{2}$ nanosheets into an interconnected framework of electrospun carbon nanofibers (CNFs) mat, the binder-free $\mathrm{WS}_{2} @ \mathrm{CNFs}$ exhibited a high reversible capacity of $545 \mathrm{~mA} \mathrm{~h} \mathrm{~g}^{-1}$ after 800 cycles at $500 \mathrm{~mA} \mathrm{~g}^{-1}$ and a high rate capability $(62.4 \%$ of the 
capacity delivered at $0.1 \mathrm{~A} \mathrm{~g}^{-1}$ was retained at $2.0 \mathrm{~A} \mathrm{~g}^{-1}$ ). Flexible electrodes can also be fabricated by introducing carbon nanotubes (CNTs) as potential elastic three-dimensional (3D) conductive network, which will not only enhance the electrical conductivity, ion diffusion, but also buffer the volume change, suppress the restacking of $\mathrm{WS}_{2}$ layers [130]. Ren and coworkers designed a free-standing 3D SWCNTs/WS 2 -nanosheets foam as LIB anode via a simple hydrothermal method coupled with a freeze-drying process, which showed an ultra-long-life performance with a high reversible capacity of $688 \mathrm{~mA} \mathrm{~h} \mathrm{~g}^{-1}$ after 1000 cycles at $1.0 \mathrm{~A} \mathrm{~g}^{-1}$ as well as a high specific capacity of $1050 \mathrm{~mA} \mathrm{~h} \mathrm{~g}^{-1}$ at $100 \mathrm{~mA} \mathrm{~g}^{-1}$ [130]. Impressively, it also exhibited a good low-temperature performance with a specific capacity of $840 \mathrm{~mA} \mathrm{~h} \mathrm{~g}^{-1}$ at $0{ }^{\circ} \mathrm{C}$ and $689 \mathrm{~mA} \mathrm{~h} \mathrm{~g}^{-1}$ at $-20{ }^{\circ} \mathrm{C}$, corresponding to $69 \%$ and $57 \%$ of the capacity delivered at room-temperature [78]. Besides the chemical methods, Pan et al.exploited a direct sonication assisted liquid-phase exfoliation of commercial $\mathrm{WS}_{2}$ powder to obtain $2 \mathrm{D} \mathrm{WS}_{2}$ nanosheets with large quantity, low cost, and without pollution. The facile and green route allows large-scale water-borne exfoliation exclusively employing stabilizers for impurity-free few-layered $\mathrm{WS}_{2}$ rectangular nanosheets of substantial fraction. The $\mathrm{WS}_{2}$-based film anode for LIBs via vacuum filtration showed an enhanced reversible capacity of $406 \mathrm{~mA} \mathrm{~h} \mathrm{~g}^{-1}$ at $200 \mathrm{~mA} \mathrm{~g}^{-1}$ after 100 cycles, and when integrated with SWCNTs to increase the conductivity and isolate the $2 \mathrm{D} \mathrm{WS}_{2}$ from restacking, it could achieve a higher capacity of $577 \mathrm{~mA} \mathrm{~h} \mathrm{~g}^{-1}$ after 100 cycles with $42 \%$ increment as well as higher rate capacity of 435 and $363 \mathrm{~mA} \mathrm{~h} \mathrm{~g}^{-1}$ at 1.0 and $2.0 \mathrm{~A} \mathrm{~g}^{-1}$, respectively. The route herein opens up new opportunities for easy and clean processing of $\mathrm{WS}_{2}$-based film devices with promising potential in energy storage and functional nanocomposites [131].

The incorporation with graphene for laminar or 3D flexible electrode will be very promising to extend the synergetic advantages of graphene and TMDs $[12,75,122,132]$. The construction of hybrid 
structures with conductive and mechanically strong reduced graphene oxide (rGO) nanosheets is an effective strategy to enhance the conductivity and reduce the restacking effect for both $\mathrm{WS}_{2}$ and graphene [133]. Liu et al. challenged a like-charged (both negative-charged) $\mathrm{WS}_{2}$ and GO nanosheets in aqueous dispersion rather than those with opposite charges for easily assembling homogeneous hybrid lamellar films via a vacuum filtration process to produce highly efficient flexible anodes for LIBs. The binder-free $\mathrm{WS}_{2} / \mathrm{rGO}$ lamellar electrode showed excellent cycling stability, good rate capability and a high reversible capacity of $698 \mathrm{~mA} \mathrm{~h} \mathrm{~g}^{-1}$ after 100 cycles at $100 \mathrm{~mA} \mathrm{~g}^{-1}$, which was much higher than that of pure $\mathrm{WS}_{2}$ nanosheets $\left(89 \mathrm{~mA} \mathrm{~h} \mathrm{~g}^{-1}\right)$ and $\mathrm{rGO}\left(60 \mathrm{~mA} \mathrm{~h}^{-1}\right)$. This substantially enhanced electrochemical performance can be ascribed to the uniformly alternated lamellar structures, where rGO nanosheets prevented the restacking of $\mathrm{WS}_{2}$ sheets, enhanced the conductivity, and tolerated the volume variations during Li-ion insertion/extraction [133]. The 3D graphene (3DG) frameworks with interconnected conductive network will further reduce the contact resistance among numerous active nanosheets beyond the advantages such as large surface area, extraordinary physicochemical stability, and good compatibility with other integrated active materials $[68,111,134]$. A free-standing hierarchical architecture of $\mathrm{WS}_{2}$ nanotubes/rGO hybrid via a simple one-pot hydrothermal reaction was reported by Chen et al. It delivered a high reversible rate capacity of 319 $\mathrm{mA} \mathrm{h} \mathrm{g}{ }^{-1}$ over 500 cycles at $1.0 \mathrm{~A} \mathrm{~g}^{-1}$, benefiting from the enhanced conductivity, more reactive sites, large electrolyte/electrode interface for Li-ion diffusion and accommodated volume changes [68]. Yang's group further designed an ice-templated 3D WS $2 / \mathrm{CNT}-\mathrm{rGO}$ hybrid nanoarchitecture aerogel (Fig. 4a) consisting of $\mathrm{WS}_{2}$ nanosheets, CNTs, and $\mathrm{rGO}$ with ordered microchannels (Fig. 4b-f), which not only provided good electronic transportation routes, but also offered excellent ionic conductive channels. This hybrid aerogel used as free-standing anode materials for LIBs could deliver a high and 
quite stable capacity of $572 \mathrm{~mA} \mathrm{~h} \mathrm{~g}^{-1}$ after 100 cycles at $200 \mathrm{~mA} \mathrm{~g}^{-1}$ (Fig. 4g), and an excellent rate capability of 536, 414, and 337 at 1,5 , and $10 \mathrm{~A} \mathrm{~g}^{-1}$, respectively [67]. The improved electrochemical performance can be ascribed to the synergistic effect between the rationally arranged CNT-rGO framework and $\mathrm{WS}_{2}$ nanosheets [68]. However, the low ICE of CNT-rGO component, with irreversible lithium consumption proportional to the active surface area of modified carbons [135], often induces a decreased ICE of the composite electrode. The low ICE, which is inferior for a full cell or batteries, may be further improved by annealing or a pre-lithiation process (i.e., pre-occupying the defects of graphene-based frameworks or additives) [21,136]. It should be noted that although some flexible or free-standing electrodes derived from graphene or CNTs showed potential for wearable energy storage devices, the mechanical properties usually fall short of expectations for practical application, thus the design of robust flexible advanced electrodes is still in high demand [129].

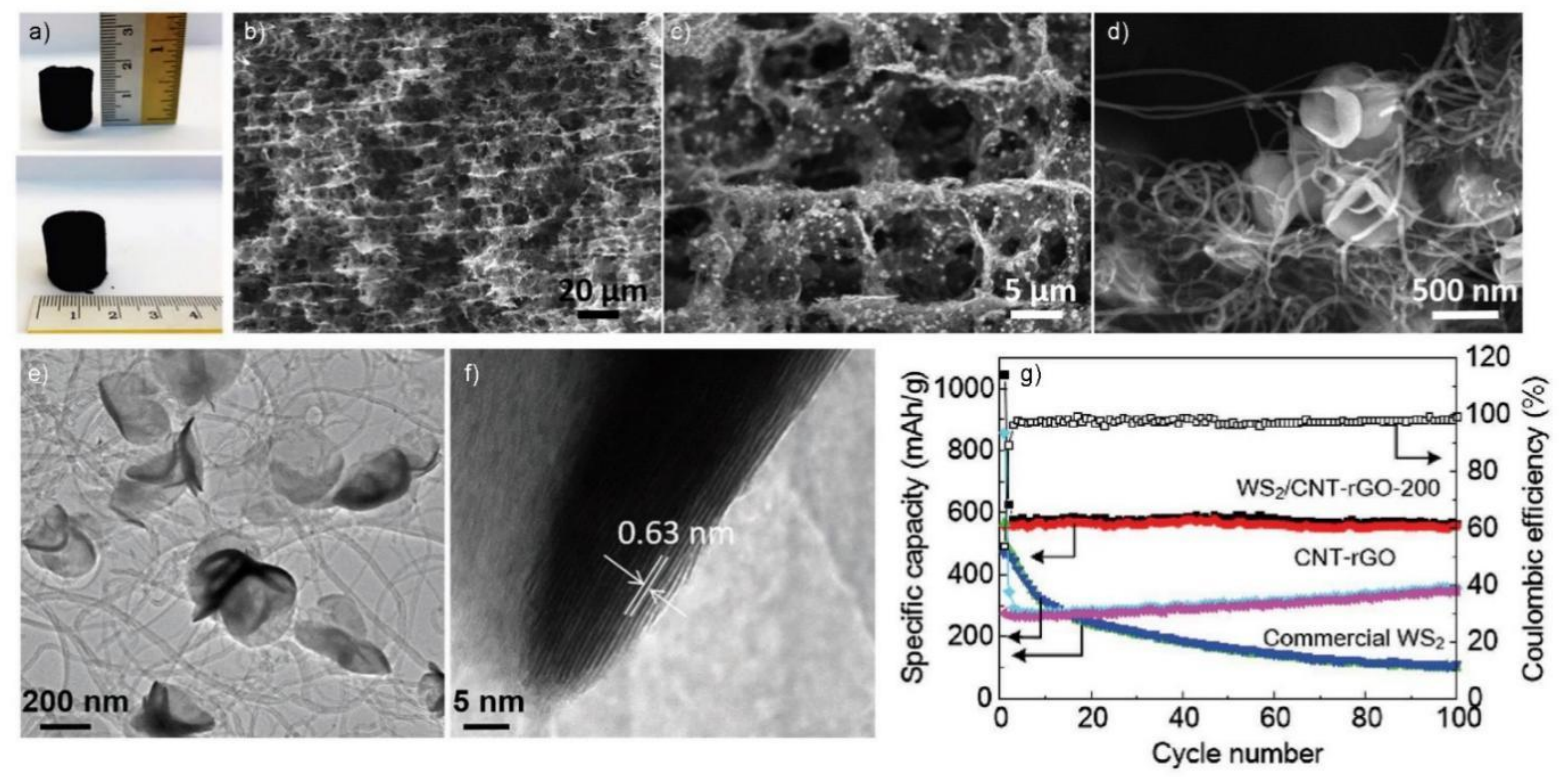

Fig. 4. (a) Photo of the 3D WS $2 /$ CNT-rGO aerogel. (b-d) Various SEM images at different magnifications and (e and f) TEM and HRTEM images of ordered $\mathrm{WS}_{2} / \mathrm{CNT}-\mathrm{rGO}$ aerogel. (g) Cycling performance of WS $/$ CNTrGO aerogel, $\mathrm{WS}_{2}$ commercial powder, and CNT-rGO aerogel anodes for LIBs at a current density of $200 \mathrm{~mA}$ 
$\mathrm{g}^{-1}$, and the corresponding coulombic efficiency of $\mathrm{WS}_{2} / \mathrm{CNT}-\mathrm{rGO}$ aerogel electrode. Reproduced from Ref. [67] with permission of Wiley-VCH.

\section{2. $\mathrm{MoSe}_{2}$ for lithium-ion batteries}

$\mathrm{MoSe}_{2}$ is an interesting narrow-band-gap semiconductor with a lamellar crystal structure of Se-MoSe sandwich layers, making it a good candidate for LIBs and SIBs by electrochemical intercalation. $\mathrm{MoS}_{2}$ with a high theoretical capacity and excellent cycling performance has been under focused research, a close analogue $\mathrm{MoSe}_{2}$ may show more advantages due to the higher electrical conductivity of Se than that of $\mathrm{S}[41,137,138]$. On the basis of crystal structure, $\mathrm{MoSe}_{2}$ has two phases: semiconductive trigonal $2 \mathrm{H}-\mathrm{MoSe}_{2}$ phase and metallic octahedral $1 \mathrm{~T}-\mathrm{MoSe}_{2}$ phase. The $1 \mathrm{~T}-\mathrm{MoSe}_{2}$ structure possesses a high intrinsic electronic conductivity and has overcome the sensitivity to air atmosphere (via replacing a conventional Li intercalation-exfoliation method with a $\mathrm{NH}_{4}{ }^{+}$intercalation one), thus it is a promising material for practical applications $[139,140]$. However, the $2 \mathrm{H}-\mathrm{MoSe}_{2}$ electrode usually suffers from low cycling stability and inferior rate capability due to the instability and intrinsic low electronic conductivity (note: the following crystal phases refer to $2 \mathrm{H}$ phase unless otherwise specified) [141143].

\subsubsection{Structural control of $\mathrm{MoSe}_{2}$}

To further enhance the ionic/electronic conductivity and inhibit the stacking problem as well as the "shuttle effect" of intermediate polyselenides for LIBs, many efforts have been made including nanostructure design [137,144146], incorporating with carbon-based conductive frameworks (e.g., amorphous carbon, CNTs, graphene) [141,147154], and fabrication of integrated electrodes [139,140]. For example, Shi et al. synthesized a highly ordered hexagonal mesoporous crystalline $\mathrm{MoSe}_{2}$ via a 
nanocasting method using silica SBA-15 as a hard template. The obtained $\mathrm{MoSe}_{2}$ with a direct bandgap of $1.37 \mathrm{eV}$ demonstrated a high reversible Li storage capacity of $630 \mathrm{~mA} \mathrm{~h} \mathrm{~g}^{-1}$ and showed a rate performance better than the analogous mesoporous $\mathrm{MoS}_{2}$, making it a promising anode for LIBs due to the increased structural stability and conductivity. Through tuning the mesoporous structure, a high reversible Li storage capacity of $744 \mathrm{~mA} \mathrm{~h} \mathrm{~g}^{-1}$ at $0.1 \mathrm{C}$ and excellent rate capability up to $2 \mathrm{C}$ could be achieved [137]. In addition, such nano-replication method for mesoporous TMDs was successfully applied to fabricate other analogues including $\mathrm{MoS}_{2}, \mathrm{WS}_{2}$, and $\mathrm{WSe}_{2}$ [64]. It exhibited a reversible capacity exceeding the theoretical reversible capacity of $\mathrm{MoSe}_{2}\left(422 \mathrm{~mA} \mathrm{~h} \mathrm{~g}{ }^{-1}\right.$, based on the conversion reaction with $\mathrm{Li}^{+}$followed by forming Mo nanoparticles in the insoluble $\mathrm{Li}_{2} \mathrm{Se}$ matrix [150]), which seems to be a common and highly beneficial phenomenon for layer-structured materials due to the additional interfacial Li storage, thus forming a bridge between batteries and capacitors at the mesoscopic scale $[88,102,137]$. Despite that $\mathrm{MoSe}_{2}$ with various nanosheet-assembled nanostructures, such as nanocaterpillars, nanosheets, and nanotubes can be synthesized by a general solvothermal method, the incorporation of heteroatoms can be adopted to further endow those layered $\mathrm{MoSe}_{2}$ with even more exposed active and unsaturated sites as well as enhanced conductivity. The hierarchical S-doped $\mathrm{MoSe}_{2-x}$ hybrid nanotubes showed an enhanced reversible capacity as anode material for LIBs [144]. Related electrochemical mechanism need to be further studied for in-depth insight. Surface modification or tuning the band gap via formation of heterostructures to enhance the conductivity is another approach for advancing layered $\mathrm{MoSe}_{2}$ as anode materials. Zhang et al. conceptually designed a strategy to narrow the band gap of $\mathrm{MoSe}_{2}$ to obtain conductive red $\mathrm{MoSe}_{2}$ nanosheets by constructing the Mo-O bonding on the surface of $\mathrm{MoSe}_{2}$ nanosheets for enhanced electronic conductivity (Fig. 5a). This material demonstrated a significantly improved Li storage 
performance and high-rate capability thereof. The red $\mathrm{MoSe}_{2}$ nanosheets as anode material for LIBs exhibited a superior reversible capacity of $1126 \mathrm{~mA} \mathrm{~h} \mathrm{~g}^{-1}$ after 500 cycles at $1.0 \mathrm{~A} \mathrm{~g}^{-1}$ (Fig. 5b), an outstanding high-rate and long-term capacity of $650 \mathrm{~mA} \mathrm{~h} \mathrm{~g}^{-1}$ at $5.0 \mathrm{~A} \mathrm{~g}^{-1}$ over 4,000 cycles (Fig. 5c) [146]. The design of tunable band gap may extend to other layered TMDs. It is also noteworthy that $\mathrm{MoSe}_{2}$ may also undergo a phase transition during the initial discharge process, i.e., from $2 \mathrm{H}-\mathrm{MoSe}_{2}$ to $\mathrm{O}-\mathrm{MoSe}_{2}$, based on a Li-ion vacancy-hopping diffusion mechanism. Nanocrystalline $\mathrm{MoSe}_{2}$ holds lower charge transfer resistance, better electrochemical performance, and greater potential as anode materials thereof compared with the amorphous one (i.e., calcined at lower temperature), although they may present a same phase transition process after the initial discharge/charge process [155].

a)

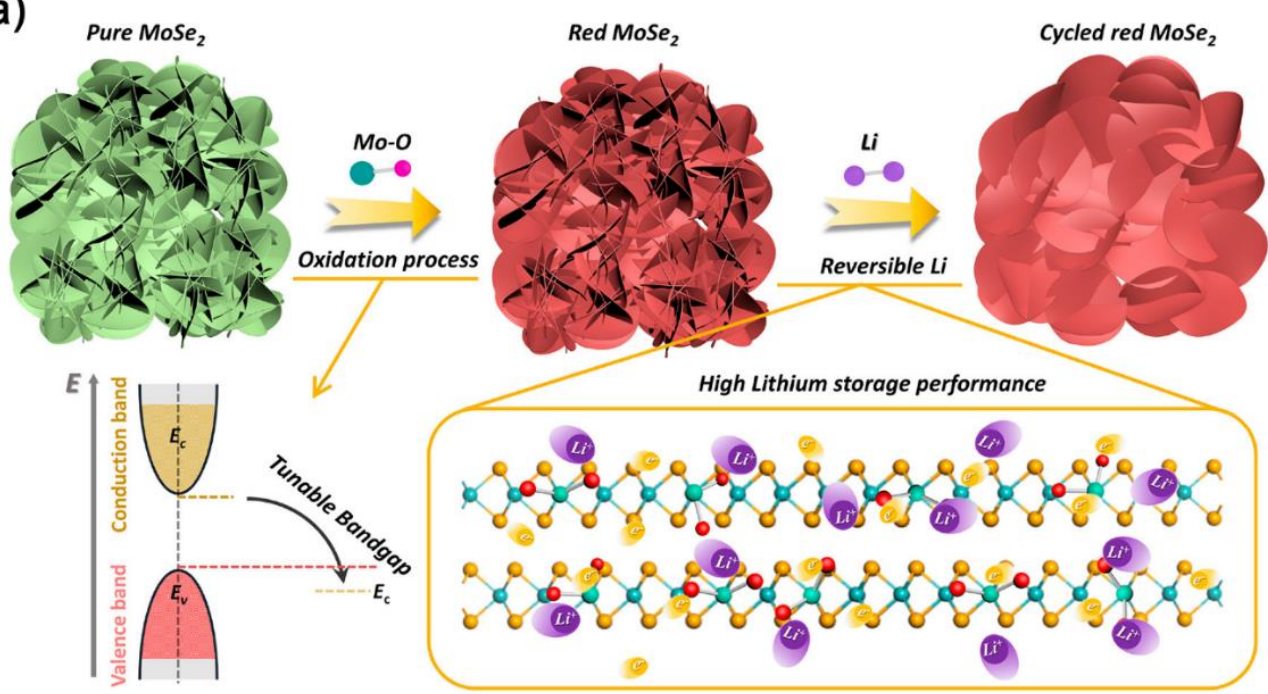

b)

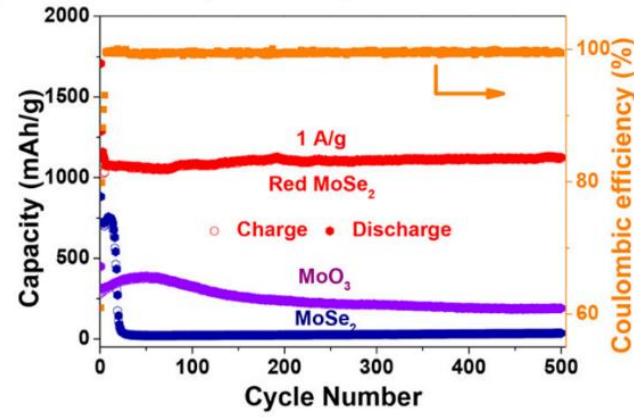

c)

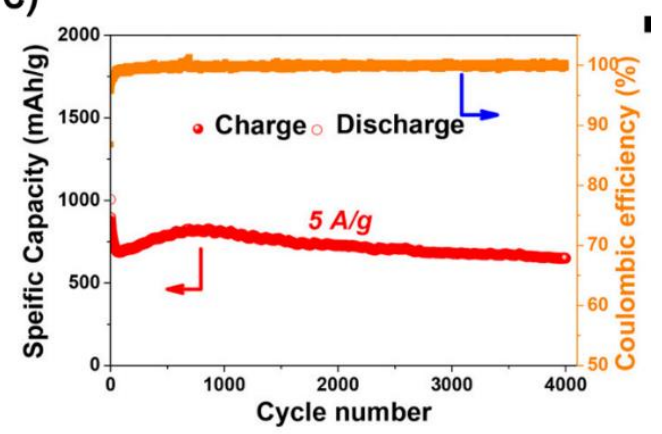


Fig. 5. (a) Schematic illustration of the synthesis of conductive red $\mathrm{MoSe}_{2}$ with a tunable band gap and its application for LIBs. (b) Cycling performance of red $\mathrm{MoSe}_{2}$, black $\mathrm{MoSe}_{2}$, and $\mathrm{MoO}_{3}$ anodes at a current density of $1 \mathrm{~A} \mathrm{~g}^{-1}$. (c) Cycling performance of red $\mathrm{MoSe}_{2}$ anode at $5 \mathrm{Ag}^{-1}$. Reproduced from Ref. [146] with permission of American Chemical Society.

\subsubsection{Hybridizing $\mathrm{MoSe}_{2}$ with conductive frameworks}

Amorphous carbon is a cost-effective and versatile framework for various composite structures [156159]. Through tuning the glucose-derived carbon ratio in the hydrothermally prepared $\mathrm{MoSe}_{2}-\mathrm{C}$ hybrid materials, the optimal one with $15 \%$ carbon could deliver a higher reversible capacity of 1165 $\mathrm{mA} \mathrm{h} \mathrm{g}^{-1}$ after 150 cycles at $200 \mathrm{~mA} \mathrm{~g}^{-1}$ and $860 \mathrm{~mA} \mathrm{~h} \mathrm{~g}^{-1}$ after 150 cycles at $1000 \mathrm{~mA} \mathrm{~g}^{-1}$, as well as an excellent rate capability of $734 \mathrm{~mA} \mathrm{~h} \mathrm{~g}^{-1}$ at $10 \mathrm{~A} \mathrm{~g}^{-1}[150]$. This type of hybrid materials with an optimal carbon layer displayed not only increased electric conductivity but also electrode integrity. Wei's group fabricated a MoSe $/$ CMK-5 composite with layered $\mathrm{MoSe}_{2}$ encapsulated in ordered tubular mesoporous carbon CMK-5 via a nanocasting route. As a conductive framework with a massive internal surface area, CMK-5 not only increases electric conductivity, shortens ion diffusion pathway but also well accommodates the volume change of $\mathrm{MoSe}_{2}$ during (de)lithiation process. When this nanocomposite utilized as an anode for LIBs, it delivered an outstanding reversible capacity of $788 \mathrm{~mA} \mathrm{~h} \mathrm{~g}^{-1}$ after 100 cycles at $100 \mathrm{~mA} \mathrm{~g}^{-1}$ with a low self-discharge feature, superior rate performance as well as more stable long-term cycling capability $\left(451 \mathrm{~mA} \mathrm{~h} \mathrm{~g}^{-1}\right.$ attained after 1000 cycles at a current density of $2.0 \mathrm{~A} \mathrm{~g}^{-1}$ ) [149]. Another kind of hierarchical $\mathrm{MoSe}_{2}$ microspheres (composed of interconnected nanoflakes) coated with homogeneous thin N-doped carbon (N-C) layer was constructed by Tu and coworkers via a facile two-step method of hydrothermal process followed by thermal polymerization of dopamine. The $\mathrm{MoSe}_{2} / \mathrm{N}-\mathrm{C}$ composite as LIB anode material exhibited 
smaller polarization resistance, better reversibility, and enhanced electrochemical reactivity compared to the unmodified $\mathrm{MoSe}_{2}$. This composite delivered a high reversible capacity of $698 \mathrm{~mA} \mathrm{~h} \mathrm{~g}^{-1}$ after 100 cycles at $100 \mathrm{~mA} \mathrm{~g}^{-1}$, high rate capacity of $471 \mathrm{~mA} \mathrm{~h} \mathrm{~g}^{-1}$ at $2.0 \mathrm{~A} \mathrm{~g}^{-1}[148]$. It also showed an enhanced long-term cycling stability compared to the glucose-derived carbon coating route [141]. The improved electrochemical properties can be ascribed to incorporation of $\mathrm{N}$-doped carbon coating and the hierarchical microsphere structure with more reactive sites and faster ionic/electronic transfer characteristics. Furthermore, for the incorporation with 1D nanofiber frameworks [152], Yang et al. designed a coaxial-cable $\mathrm{MoSe}_{2} /$ hollow carbon nanofiber (HCF) composite with few-layered ultrasmall $\mathrm{MoSe}_{2}$ nanosheets decorated HCFs. The $\mathrm{MoSe}_{2} / \mathrm{HCFs}$ composite delivered a high and stable specific capacity of 658 and $577 \mathrm{~mA} \mathrm{~h} \mathrm{~g}^{-1}$ at 0.5 and $1.0 \mathrm{~A} \mathrm{~g}^{-1}$ after 100 cycles, with an almost $100 \%$ capacity retention rate and a high-rate capacity of $524 \mathrm{~mA} \mathrm{~h} \mathrm{~g}$ at $3.0 \mathrm{~A} \mathrm{~g}^{-1}$. The enhanced electrochemical performance can be ascribed to the rational design and the synergistic effect between conductive $\mathrm{HCF}$ and smart $\mathrm{MoSe}_{2}$ nanoarrays that facilitates electronic/ionic conductivity and electrode structural stability [160]. Wang et al. further fabricated a $\mathrm{N}$-doped carbon/MoSe 2 core/branch nanostructure via calcinating a mixture of polyaniline (PANI)-intercalated $\mathrm{MoO}_{3}$ nanorod hybrid and Se powder in Ar atmosphere. This nanohybrid could deliver a high reversible capacity of $906 \mathrm{~mA} \mathrm{~h}$ $\mathrm{g}^{-1}$ with a capacity retention rate of $97.6 \%$ at $100 \mathrm{~mA} \mathrm{~g}^{-1}$ after 100 cycles and an enhanced rate capability of $560 \mathrm{~mA} \mathrm{~h} \mathrm{~g}^{-1}$ at $1.0 \mathrm{~A} \mathrm{~g}^{-1}$, due to the unique structure of $\mathrm{N}$-doped carbon nanorod cores and the $\mathrm{MoSe}_{2}$ nanosheet branches [151].

The design of hollow structure together with introducing conductive carbon frameworks facilitates fast electron/ion transfer and alleviates the stress caused by huge volume changes during charge/discharge process [109,110,142,161163]. Yang et al. synthesized porous hollow carbon spheres 
(PHCS) decorated uniformly and conformally with $\mathrm{MoSe}_{2}$ nanosheets, which could deliver a reversible Li storage capacity of $681 \mathrm{~mA} \mathrm{~h} \mathrm{~g}^{-1}$ after 100 cycles at $1.0 \mathrm{~A} \mathrm{~g}^{-1}$. The enhanced performance can be explained by that the mechanically robust carbon hollow conductive support accommodated stress from cycling, benefited the conductivity and shortened ion pathway [142]. Pan's group designed similar $\mathrm{MoSe}_{2} / \mathrm{C}$ hybrid hollow spheres via a colloid template/glucose assisted hydrothermal route followed by annealing treatment. This hollow hybrid demonstrated an excellent reversible capacity of $795 \mathrm{~mA} \mathrm{~h} \mathrm{~g}^{-1}$ after 250 cycles at $200 \mathrm{~mA} \mathrm{~g}^{-1}$, and $744 \mathrm{~mA} \mathrm{~h} \mathrm{~g}{ }^{-1}$ after 300 cycles at $1000 \mathrm{~mA} \mathrm{~g}^{-1}$; and showed a superior rate capacity of $370 \mathrm{~mA} \mathrm{~h} \mathrm{~g}^{-1}$ at a very high current density of $10 \mathrm{~A} \mathrm{~g}^{-1}[161]$. To further enhance the conductivity of the carbonaceous frameworks, Zhao et al. synthesized a 3D hierarchical hollow $\mathrm{MoSe}_{2} / \mathrm{N}$-doped carbon microsphere $\left(\mathrm{MoSe}_{2} / \mathrm{N}-\mathrm{C}\right)$ composite via dopamineassisted chemical precipitation followed by an annealing treatment. The hollow spherical $\mathrm{MoSe}_{2} / \mathrm{N}-\mathrm{C}$ composite exhibited a superior capacity of $1313 \mathrm{~mA} \mathrm{~h} \mathrm{~g}^{-1}$ at $1.0 \mathrm{~A} \mathrm{~g}^{-1}$ after 100 cycles, and an excellent rate capacity of $597 \mathrm{~mA} \mathrm{~h} \mathrm{~g}^{-1}$ at a current density at $10 \mathrm{~A} \mathrm{~g}^{-1}[162]$.

The optimized synergistic effect of layered $\mathrm{MoSe}_{2}$ and the most promising matrix graphene will enhance the electronic/ionic conductivity and integrity of the electrode $[143,164]$. For example, fewlayered $\mathrm{MoSe}_{2} / \mathrm{rGO}$ hybrid with ultrathin $\mathrm{MoSe}_{2}$ well dispersed and anchored on the flexible graphene nanosheets could be synthesized by a facile ionic liquid-assisted hydrothermal route, which exhibited a high reversibility of $\sim 1100 \mathrm{~mA} \mathrm{~h} \mathrm{~g}^{-1}$ after 100 cycles at $100 \mathrm{~mA} \mathrm{~g}^{-1}$ and greatly improved cycling stability [143]. The similar hierarchical $\mathrm{MoSe}_{2} / \mathrm{rGO}$ composite obtained via a hydrothermal/solvothermal route also showed enhanced electrochemical performance: Zhang et al.'s work on $\mathrm{MoSe}_{2} / \mathrm{rGO}$ hybrid exhibited an excellent rate performance and cycling capacity of $917 \mathrm{~mA}$ $\mathrm{h} \mathrm{g}^{-1}$ at $0.5 \mathrm{~A} \mathrm{~g}^{-1}\left(750 \mathrm{~mA} \mathrm{~h} \mathrm{~g}^{-1}\right.$ at $\left.1.0 \mathrm{~A} \mathrm{~g}^{-1}\right)$ after 100 cycles [164]; Yao et al. reported a 3D 
$\mathrm{MoSe}_{2} / \mathrm{rGO}$ foam composed of nanolayered $\mathrm{MoSe}_{2}$ affording a long-term cycling stability with a $89.1 \%$ capacity retention rate $\left(>470 \mathrm{~mA} \mathrm{~h} \mathrm{~g}^{-1}\right)$ after 600 cycles at $0.5 \mathrm{C}$ [153]; a kind of 2D hybrid nanosheets with high-density few-layered $\mathrm{MoSe}_{2}$ arrays vertically and uniformly grown on both sides of rGO sheets (ca. 90\% loading content) exhibited an excellent cycling stability up to 1000 cycles with an attainable capacity of $637 \mathrm{~mA} \mathrm{~h} \mathrm{~g}^{-1}$ at $1.0 \mathrm{~A} \mathrm{~g}^{-1}[154]$. The incorporation of graphene effectively enhances the structural integrity of $\mathrm{MoSe}_{2}$ and improves its electrochemical performance, and thus holds great potential as advanced anode material for LIBs.

\subsection{3. $\mathrm{MoSe}_{2}$-based heterostructures and alloys}

Heterostructures of TMDs, combining merits of different TMDs, have been regard as a promising strategy tuning the electronic properties thereof with great potential in energy conversion and storage, catalysis and electronics [13,43,165169]. For example, Zhao et al. designed a carbon-free hybrid nanostructure of lamellar $\mathrm{MoSe}_{2}$ nanosheets embedded with $\mathrm{MoO}_{2}$ nanoparticles $\left(\mathrm{MoO}_{2} @ \mathrm{MoSe}_{2}\right)$ via a simple hydrothermal method followed by freeze-drying in vacuum, where the $\mathrm{MoSe}_{2}$ nanosheets provide a flexible substrate and the $\mathrm{MoO}_{2}$ nanoparticles act as spacers to inhibit restacking and provide higher active surface area for electrolyte. In addition, the heterojunctions at the interface (i.e., heterointerfaces) between $\mathrm{MoSe}_{2}$ and $\mathrm{MoO}_{2}$ introduce a self-built electric field for promoted lithiation/delithiation process. As a result, this lamellar hybrid could deliver a long-term cycling capacity of $520 \mathrm{~mA} \mathrm{~h} \mathrm{~g}^{-1}$ at a high current density of $2.0 \mathrm{~A} \mathrm{~g}^{-1}$ over 400 cycles (with CE approaching $100 \%$ ) and an excellent rate performance [170]. Yang et al. designed a facile, low-cost, and high-yield solution-phase strategy for creating $\mathrm{MoS}_{2}-\mathrm{MoSe}_{2} \mathrm{p}-\mathrm{n}$ heterostructures with vertically grown $\mathrm{MoSe}_{2}$ (p-type) nanosheet array on layered $\mathrm{MoS}_{2}$ (n-type) followed by a coating process with amorphous carbon. This heterostructure delivered a superior electrochemical activity and excellent Li-ion storage 
properties with a high reversible capacity of $676 \mathrm{~mA} \mathrm{~h} \mathrm{~g}^{-1}$ after 200 cycles at $200 \mathrm{~mA} \mathrm{~g}^{-1}$. The unique compositional and structural features include porous architecture for shortened Li-ion diffusion channels and optimized interfaces between electrode and electrolyte, edge-to-edge configuration with more exposed active sites, and high-quality heterointerface within the heterostructures for fast interfacial charge transfer; all these contribute to the enhanced electrochemical activity and efficiency [165]. And the advantages were also verified by the first-principles calculations where the $\mathrm{MoS}_{2} / \mathrm{MoSe}_{2}$ heterointerface could effectively reduce the band gap, diversify Li adsorption sites and enhance the electrochemical properties in heterostructure [167]. The incorporation of $\mathrm{TiO}_{2}$ with a relatively high (de)lithiation voltage can efficiently avoid the formation of solid electrolyte interface (SEI) layers and thus enhance the safety performance of the batteries. Taking the decoration of fewlayered $\mathrm{MoSe}_{2}$ nanosheets on $\mathrm{C} / \mathrm{TiO}_{2}$ nanobelts as an example via a glucose-assisted hydrothermal process, the $\mathrm{MoSe}_{2} @ \mathrm{C} / \mathrm{TiO}_{2}$ heterostructure as LIB anode material showed an enhanced reversible capacity of $987 \mathrm{~mA} \mathrm{~h} \mathrm{~g}^{-1}$ after 100 cycles at $500 \mathrm{~mA} \mathrm{~g}^{-1}$ and an outstanding rate capacity of $860 \mathrm{~mA}$ $\mathrm{h} \mathrm{g}^{-1}$ at a current rate of $3.0 \mathrm{~A} \mathrm{~g}^{-1}$, much better than its individual components [171].

Theoretical and experimental studies have revealed that the introduction of Se into molybdenum sulfides by forming $\mathrm{MoS}_{2(1-x)} \mathrm{Se}_{2 x}$ alloys may not only widen the interlayer spacing for more effective diffusion of ions/electrons during charge/discharge process, but also decrease the energy barriers to pass through the layers due to the slight distortion and polarized electric field in the basal planes caused by the incorporation of Se with bigger radius [172174]. As an example, the optimized 2D layered mesoporous $\mathrm{MoS}_{2(1-x)} \mathrm{Se}_{2 x} / \mathrm{rGO}$ electrode prepared by Wang et al. could deliver a high capacity of 830 $\mathrm{mA} \mathrm{h} \mathrm{g}{ }^{-1}$ at $100 \mathrm{~mA} \mathrm{~g}^{-1}$ after 150 cycles, and an enhanced capacity of $415 \mathrm{~mA} \mathrm{~h} \mathrm{~g}^{-1}$ at $1000 \mathrm{~mA}$ $\mathrm{g}^{-1}[172]$. $\mathrm{MoSe}_{2}$ can also be used to enhance the cycling and rate performances of other transition- 
metal chalcogenides (TMCs). For example, the material $\mathrm{Cu}_{2-x} \mathrm{Se} @ \mathrm{C}$ nanosheets coated with $\mathrm{MoSe}_{2}$ nanoparticles showed an improved reversible capacity of $432 \mathrm{~mA} \mathrm{~h} \mathrm{~g}^{-1}$ after 100 cycles at $100 \mathrm{~mA} \mathrm{~g}^{-1}$ as well as enhanced rate capacity, much higher than that of $\mathrm{Cu}_{2-x} \mathrm{Se} @ \mathrm{C}$ or pure phase $\mathrm{Cu}_{2-x} \mathrm{Se}$ nanosheets (166 and $82 \mathrm{~mA} \mathrm{~h} \mathrm{~g}^{-1}$, respectively). The sandwich-like structure not only enhances the electrical conductivity but also buffers the volume change and increases the structural stability during cycling [175]. In addition, $\mathrm{MoSe}_{2}$ may be also utilized to enhance the electrochemical stability of elemental Se as anode for LIBs by buffering volume changes and inhibiting aggregation during cycling, thus the combination of $\mathrm{MoSe}_{2}$ and Se is expected to provide a higher reversible capacity and excellent rate capability. As an example, the CNTs@C@MoSe $2 @$ Se hybrid could deliver a specific capacity of $1010 \mathrm{~mA} \mathrm{~h} \mathrm{~g}^{-1}$ after 100 cycles at $100 \mathrm{~mA} \mathrm{~g}^{-1}$ and a high-rate capacity of $508 \mathrm{~mA} \mathrm{~h} \mathrm{~g}^{-1}$ at $5.0 \mathrm{~A} \mathrm{~g}^{-1}$ after 500 cycles [176].

\subsubsection{Flexible $\mathrm{MoSe}_{2}$ electrodes}

Recent progressive techniques in flexible portable electronic apparatuses triggered the intensive interests for flexible electrodes and soft batteries as energy sources with features of light weight and high specific capacity $[120,121,139]$. For flexible $\mathrm{MoSe}_{2}$ anode in advanced LIBs, Zhu et al. constructed a N-doped 1D carbon backbones supported $\mathrm{MoSe}_{2}$ nanosheets $\left(\mathrm{MoSe}_{2} / \mathrm{N}-\mathrm{CNFs}\right)$ for superior flexible electrodes (Fig. 6) via combining the techniques of electrospinning, hydrothermal treatment, and calcination. It delivered an initial discharge capacity of $863 \mathrm{~mA} \mathrm{~h} \mathrm{~g}^{-1}$ at $100 \mathrm{~mA} \mathrm{~g}^{-1}$ with an ICE of $76.3 \%$, a reversible capacity of $611 \mathrm{~mA} \mathrm{~h} \mathrm{~g}^{-1}$ after 100 cycles, corresponding to a CE higher than $98 \%$. This flexible hybrid electrode also demonstrated a good rate performance with reversible specific capacities of 532, 452, and $302 \mathrm{~mA} \mathrm{~h} \mathrm{~g}^{-1}$ at $0.5,1.0$, and $2.0 \mathrm{~A} \mathrm{~g}^{-1}$, respectively [140]. Xiang et al. fabricated a 2D stable metallic $1 \mathrm{~T}-\mathrm{MoSe}_{2}$ with an expanded interlayer spacing of 
$10.0 \AA$ that was in situ vertically grown on CVD-derived SWCNTs (1T-MoSe $2 / S W C N T s)$ film (Fig. 7a-c) via a solvothermal route for hybridized flexible anode of LIBs (Fig. 7d inset). This binder-free electrode delivered an outstanding capacity of $971 \mathrm{~mA} \mathrm{~h} \mathrm{~g}^{-1}$ after 100 cycles at $300 \mathrm{~mA} \mathrm{~h} \mathrm{~g}^{-1}$ and an excellent rate capability of 630 at $3.0 \mathrm{~A} \mathrm{~g}^{-1}$ (Fig. $7 \mathrm{~d}-\mathrm{f}$ ). It is confirmed by an X-ray absorption nearedge characterization that a strong electrical and chemical coupling (i.e., C-O-Mo bonding) was formed between SWCNT and 1T-MoSe 2 nanosheets, which remarkably enhanced the electron/ion transport (Fig. 7g) and structural stability for high Li storage performance thereof. The flexible full cell assembled with a $\mathrm{LiFePO}_{4}$ cathode showed excellent cycling reversibility and mechanical flexibility, i.e., a good overlapping in CV curves and galvanostatic charge/discharge process and a negligible decrease after 50 bendings compared to the original flat battery [139]. The synthetic strategy shown here may provide inspiration for fabricating other flexible energy storage devices. 

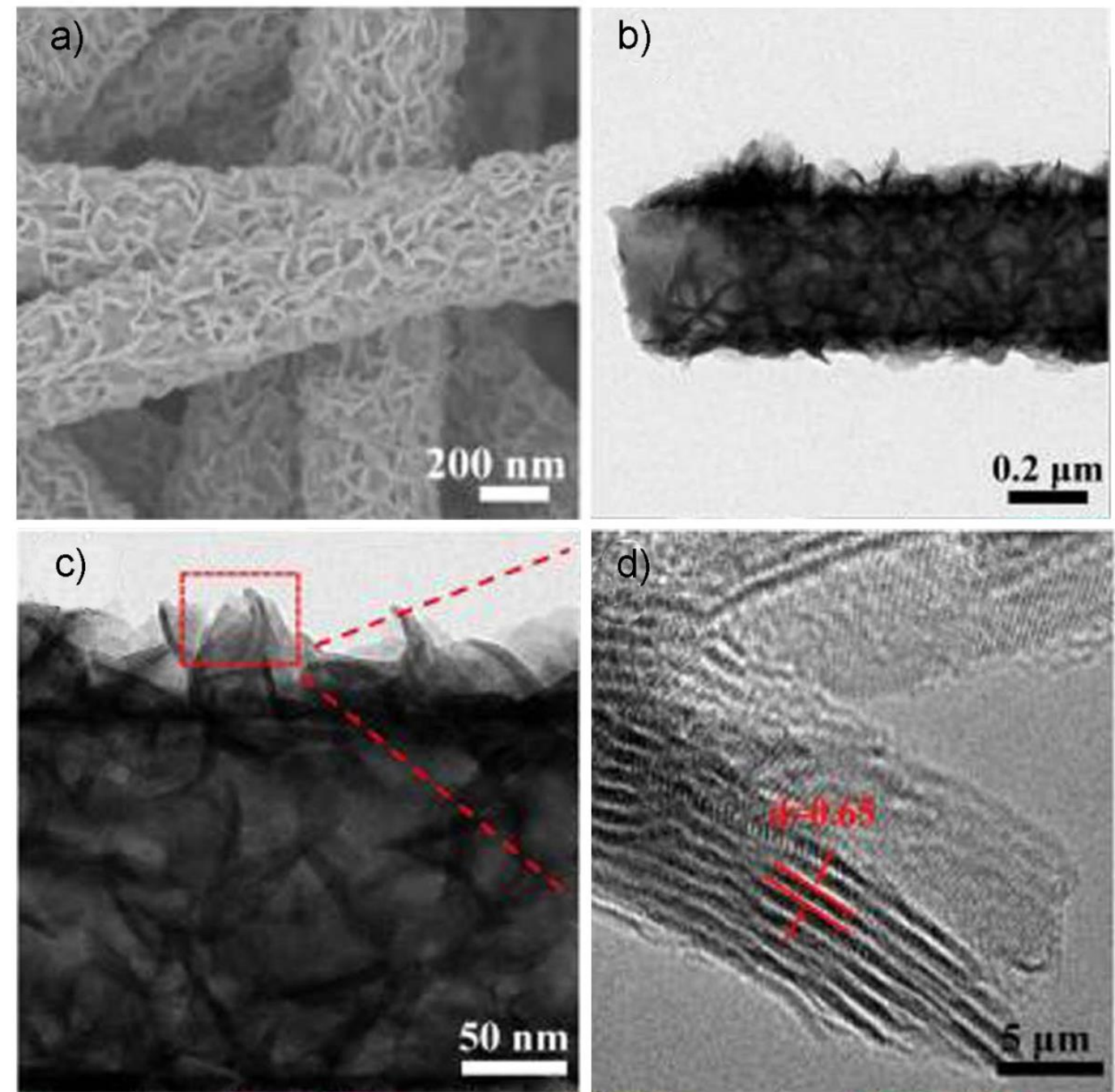

Fig. 6. (a) SEM, (b and c) TEM and (d) HRTEM images of flexible $\mathrm{MoSe}_{2} / \mathrm{HPCFs}$ with $\mathrm{MoSe}_{2}$ nanosheets anchored on N-doped 1D carbonaceous backbones as binder-free electrodes. Reproduced from Ref. [140] with permission of Elsevier. 


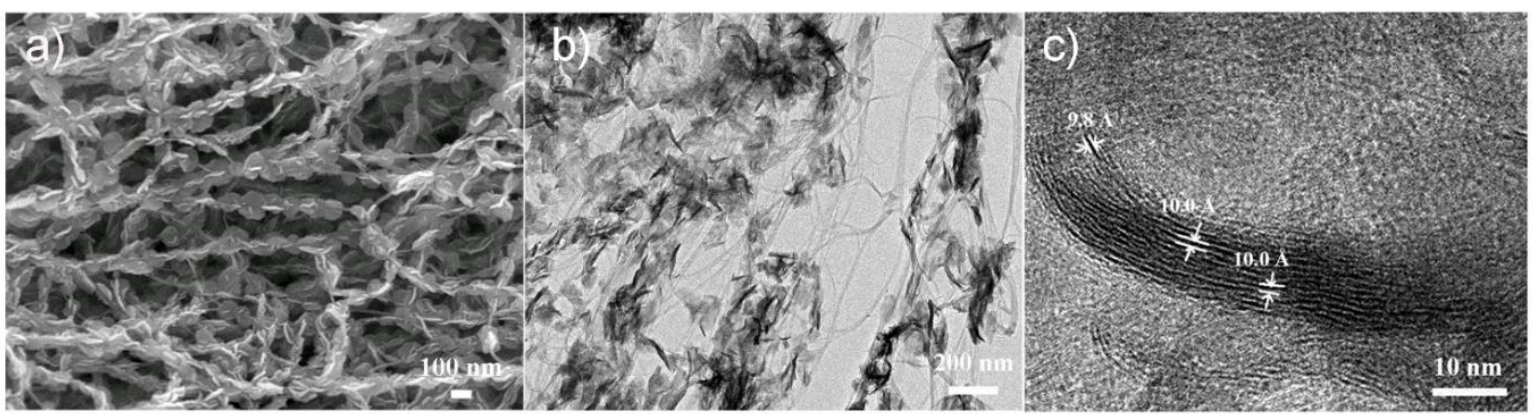

d)
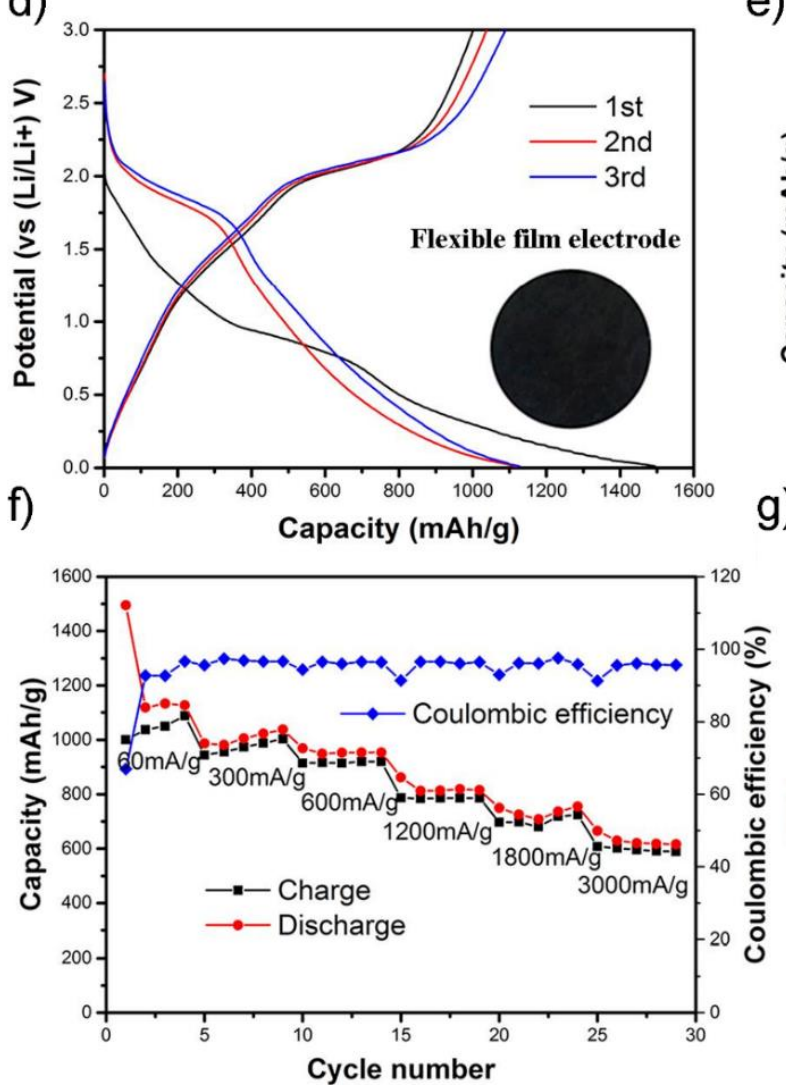

e) g)
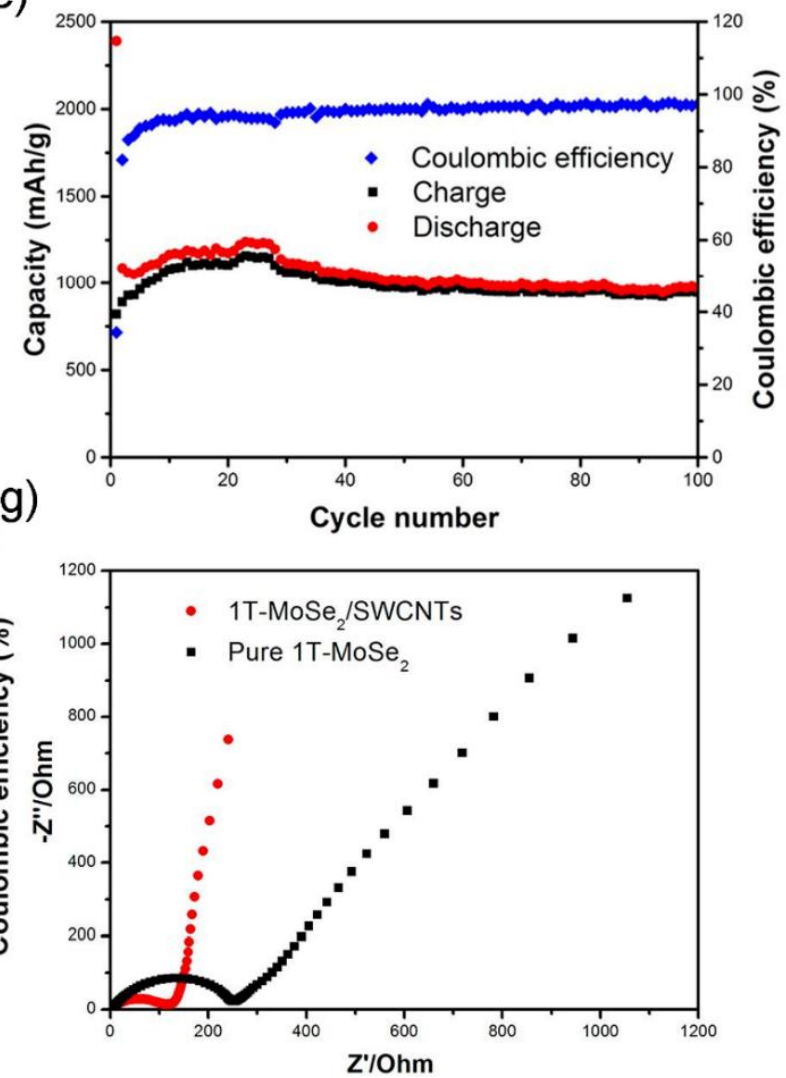

Fig. 7. (a) SEM, (b) TEM, and (c) HRTEM images of the $1 \mathrm{~T}-\mathrm{MoSe}_{2} / \mathrm{SWCNT}$ s hybridized flexible binder-free electrode with $\mathrm{MoSe}_{2}$ nanosheets (characterized by an enlarged interlayer distance of $10.0 \AA$ ) intimately anchored on the surface of SWCNT bundles. Electrochemical performance evaluations of 1T-MoSe $/ \mathrm{SWCNTs}$ hybrids: (d) charge and discharge curves (inset: film electrode), (e) cycling performance at $300 \mathrm{~mA} \mathrm{~g}^{-1}$, (f) rate performance, and (g) the Nyquist plots. Reproduced from Ref. [139] with permission of American Chemical Society. 


\section{3. $\mathrm{WSe}_{2}$ for lithium-ion batteries}

$\mathrm{WSe}_{2}$ is a vital member of TMDs and has raised intensively interests owing to its unique properties with a small band gap of $1.6 \mathrm{eV}$ and a large adjacent layer spacing of $0.648 \mathrm{~nm}$ (two times larger than that of graphite), which can effectively facilitate reversible ion intercalation and extraction [177]. Thanks to its very high density of $9.32 \mathrm{~g} \mathrm{~cm}^{-3}, \mathrm{WSe}_{2}$ has a high volumetric capacity [178]. To overcome the common defects of TMDs for enhanced electrical conductivity and suppressed volume changes during the electrochemical reaction processes, effective methods have been attempted including structural design and hybridizing with other conductive components [177180]. For instance, Wei and coworkers fabricated an orderly mesoporous WSe 2 CMK-5 nanocomposite through a nanocasting route by introducing the unique mesoporous carbon CMK-5 as a nanoreactor. Benefiting from the synergetic effect of few-layered $\mathrm{WSe}_{2}$ and mesoporous carbon for improved redox kinetics and structural stability, this hybrid showed an enhanced rate capability of 400 and $320 \mathrm{~mA} \mathrm{~h} \mathrm{~g}^{-1}$ at 1.0 and $2.0 \mathrm{~A} \mathrm{~g}^{-1}$, respectively; an outstanding long-term cycling stability with a specific capacity of 490 $\mathrm{mA} \mathrm{h} \mathrm{g}{ }^{-1}$ after 600 cycles at $500 \mathrm{~mA} \mathrm{~h} \mathrm{~g}^{-1}$ and a CE of above $99 \%$ [177]. It should be noted that the introduction of carbon conductive framework enhanced the electrochemical properties such as reversibility, cycling stability and rate capability, however, it usually reduced the ICE [178]. For example, CMK-5 exhibited an initial discharge-charge capacities of 1559 and $496 \mathrm{~mA} \mathrm{~h} \mathrm{~g} \mathrm{~g}^{-1}$ with a CE of merely $31.8 \%$ due to the formation of SEI film [177]. Thus a pre-lithiation treatment of the anode materials will be very beneficial for a practical application in the full cells or batteries.

\section{Sodium-ion batteries}

Sodium-ion batteries (SIBs) have attracted great attention and have been considered as a promising alternative for LIBs in cost-effective electrochemical energy storage, however, it is stillchallenging 
but greatly desired to design and develop novel electrode materials with high reversible capacity, long cycling life, and good rate capabilitytoward high-performance SIBs[57,50]. Sodiation/desodiation with $\mathrm{Na}$ ions in layered TMDs is based onan intercalation followed by conversion reaction, which not only is able to deliverhigher capacity than the intercalation reaction, but alsoprovide capacitive storage.The structural design of electrodes and introduction of conductive matrices for TMDs/C composites can substantially improveNa storage behavior by accommodating large volumechanges and facilitating fast ion diffusion $[6,29,50,56]$.

\section{1. $\mathrm{WS}_{2}$ for sodium-ion batteries}

2D semiconductive $\mathrm{WS}_{2}$ has a large interlayer spacing $(d=6.2 \AA$ for (002) facial) with weak van der Waals interaction in-between layers [181]. Theoretically, it affords easier and rapid Na-ion transport during the sodiation/desodiation processes compared with metal oxides. However, pristine or pure $\mathrm{WS}_{2}$ usually suffers from relatively low electroconductive response, not affordable for rapid charging/discharging processes of SIBs $[84,182]$. Recent studies have shown the benefits from the morphology control or nanostructuring $[67,183]$, the incorporation with conductive substrates such as carbon (including CNTs, graphene) $[96,97,134]$. Greatly improved electrochemical performance can be achieved due to the enhanced Na-ion/electron conductivities, shortened diffusion/transfer pathway, and the improved electrode structural stability $[96,97,184]$.

\subsubsection{Structural control of $W_{2}$}

Firstly, nanostructures play a significant role in improving the electrochemical performance of $\mathrm{WS}_{2}$. As an example, Zhou et al. exploited a scalable synthesis route for high-quality $\mathrm{WS}_{2}$ nanosheets via a $\mathrm{NaCl}$ template-assisted in situ CVD process [80]. The as-prepared $\mathrm{WS}_{2}$ nanosheets with a singlecrystalline structure showed higher structural stability and conductivity. When utilized as SIB anode, 
it delivered a high reversible capacity of $461 \mathrm{~mA} \mathrm{~h} \mathrm{~g}^{-1}$ at $100 \mathrm{~mA} \mathrm{~g}^{-1}$ after 60 cycles and exhibited a greatly enhanced rate capacity of 389,371 , and $351 \mathrm{~mA} \mathrm{~h} \mathrm{~g}^{-1}$ at 1,2 , and $5 \mathrm{~A} \mathrm{~g}^{-1}$, respectively. It is claimed that the excellent rate performance was attributed to the enhanced Na-ion reaction kinetics that were mainly controlled by the capacitive process. This synthesis method is applicable to produce other TMDs, such as $\mathrm{MoS}_{2}, \mathrm{MoSe}_{2}$, and WSe 2 nanosheets. Secondly, in addition to the influence of different sulfur sources or nanostructures just discussed above [185], Wang et al. further revealed that the (002)-oriented $\mathrm{WS}_{2}$ nanosheets with large interlayer spacing by controlled sulfuration time can deliver a better cycling stability and higher rate performance than other (100)-oriented $\mathrm{WS}_{2}[183]$. However, due to the relatively sluggish electrode kinetics of SIBs, the Na storage capacity of the same electrode is usually smaller than that of LIBs [96]. Thirdly, expanding adjacent layers of bare $\mathrm{WS}_{2}$ is a promising approach to improve the Na storage. Liu et al. synthesized thin $\mathrm{WS}_{2}$ nanowires (diameter $\sim 25 \mathrm{~nm}$ ) with expanded interlayer spacing of $0.83 \mathrm{~nm}$ via a facile solvothermal route followed by a heat treatment, which not only provided more active sites and open channels for the intercalation of $\mathrm{Na}^{+}$ions but also facilitated the electron and ion diffusion. When evaluated as a SIB anode it showed a higher reversible capacity of $483 \mathrm{~mA} \mathrm{~h} \mathrm{~g}^{-1}$ after 50 cycles at $100 \mathrm{~mA} \mathrm{~g}^{-1}$ and a good rate capability of 430, 368, and $236 \mathrm{~mA} \mathrm{~h} \mathrm{~g}^{-1}$ at $1,2,5 \mathrm{~A} \mathrm{~g}^{-1}$, respectively, over the potential window of $0.5-3.0 \mathrm{~V}$; and this potential range was chosen to suppress the irreversible conversion reaction and maintain the reversible intercalation-type mechanism. It also exhibited an ultra-long cycle life of 1400 cycles with a capacity of $\sim 330$ at $1.0 \mathrm{~A} \mathrm{~g} \mathrm{~g}^{-1}$ and a high CE of $>99 \%$. Through the HRTEM observation of the intermediate it was revealed that the $\mathrm{WS}_{2}$ layers were further expanded during cycling, e.g., with an interlayer spacing of $1.28 \mathrm{~nm}$ after 10 cycles and almost separated into single layers after 100 cycles. When paired up with a $\mathrm{NaVPO}_{4} \mathrm{~F} / \mathrm{C}$ cathode (theoretical capacity of $128 \mathrm{~mA} \mathrm{~h} \mathrm{~g}^{-1}$ ), the Na-ion full 
cell delivered an initial capacity of $\sim 330 \mathrm{~mA} \mathrm{~h} \mathrm{~g}^{-1}$ and relatively good stability with a $76 \%$ retention rate after 20 cycles (based on the mass of $\mathrm{WS}_{2}$ anode) when tested between $3.01 .0 \mathrm{~V}$ at $100 \mathrm{~mA}$ $\mathrm{g}^{-1}[186]$.

\subsubsection{Hybridizing $W_{2}$ with conducting frameworks}

As for LIBs, similar efforts have been made to improve the electrochemical performance of $\mathrm{WS}_{2}$ for SIBs by incorporating with electrical conducting matrices [101]. For example, N-doped conductive carbon was involved into $\mathrm{WS}_{2}$ nanosheets for a higher conductivity, the as-prepared $\mathrm{WS}_{2}-\mathrm{NC}$ nanocomposite showed an enhanced reversible capacity of $\sim 360 \mathrm{~mA} \mathrm{~h} \mathrm{~g}^{-1}$ at $100 \mathrm{~mA} \mathrm{~g}^{-1}$ and $200 \mathrm{~mA}$ h $\mathrm{g}^{-1}$ at $1.0 \mathrm{~A} \mathrm{~g}^{-1}[187]$. The $\mathrm{WS}_{2} @ \mathrm{CMK}-3$ hybrid fabricated by Pang et al. based on ordered mesoporous carbon matrix showed an enhanced capacity of $333 \mathrm{~mA} \mathrm{~h} \mathrm{~g}^{-1}$ at $100 \mathrm{~mA} \mathrm{~g}^{-1}$ without any fading over 70 cycles, and a rate capability of $230 \mathrm{~mA} \mathrm{~h} \mathrm{~g}^{-1}$ at $2.0 \mathrm{~A} \mathrm{~g}^{-1}[96,129]$. For the carbonincorporated 2D-TMDs materials, MOF-derived well-defined morphology and nanostructures is an alternative choice of great advantages as a highly conductive matrix [188]. Prussian blue (PB), a subset material of MOF families, can be directly pyrolyzed to produce nanoporous carbon framework with well-defined nanocubic morphology as well as high surface area and interconnected pores useful for improved electrochemical performance of active materials. By incorporation with an outer shell of few-layered $\mathrm{WS}_{2}$ nanosheets, Yang and coworkers designed a unique cubic-shaped $\mathrm{WS}_{2} @ \mathrm{NC}$ hybrid nanostructure with $\mathrm{WS}_{2}$ nanopetals on PB-derived N-doped carbon framework (Fig. 8). This material possesses several advantages such as improved electronic conductivity, buffered volumetric change, reduced ion diffusion length, and a larger surface area for sodiation/desodiation. The incorporating of PB-derived N-doped carbon framework greatly improved the rate capability of $\mathrm{WS}_{2}$, and this hybrid exhibited a stable cycling performance with a specific capacity of $320 \mathrm{~mA} \mathrm{~h} \mathrm{~g}^{-1}$ after 200 cycles at a 
current density of $200 \mathrm{~mA} \mathrm{~g}^{-1}$ and with one of the highest ICE reported of 79.8\% [184]. Developing a facile and up-scalable strategy to construct desirable TMDs/C hybrids with open and unstacked active nano-building blocks and strong interconnection with the conductive matrix would be very promising for practical application. Yu and coworkers designed a one-step in situ solid-state hybridization strategy to construct $\mathrm{WS}_{2}$ nanowall arrays anchored on N-doped carbon layers (NCLs) as shown in Fig. 9a[73]. The exposed active edge sites will be maximized and the exchange current density of 2D TMDs will be enhanced compared to the structure parallel to the substrates $[189,190]$. This lamellar hybrid architecture demonstrated largely improved Na storage performance as SIB anode materials. The $\mathrm{WS}_{2} / \mathrm{C}$ in such structure delivered a stable reversible capacity of $180 \mathrm{~mA} \mathrm{~h} \mathrm{~g}^{-1}$ over the potential range of $0.4-3.0 \mathrm{~V} v s . \mathrm{Na}^{+} / \mathrm{Na}$ after 1200 cycles at $1.0 \mathrm{~A} \mathrm{~g}^{-1}$ with a mean capacity loss as low as 0.015 $\mathrm{mA} \mathrm{h} \mathrm{g}{ }^{-1}$ per cycle (Fig. 9b left). It implies that the unique 2D@2D hybrid structure accounts for the excellent Na-ion storage properties, as illustrated in Fig. 9b (right). This structure allows the direct and full contact of open nanowalls of expanded interlayers with electrolyte without "dead volume" for increased ion diffusion kinetics, more active sites, reduced internal resistance and structural strain during the electrochemical reactions as well as intimate coupling with the NCLs substrates [73]. 
a)
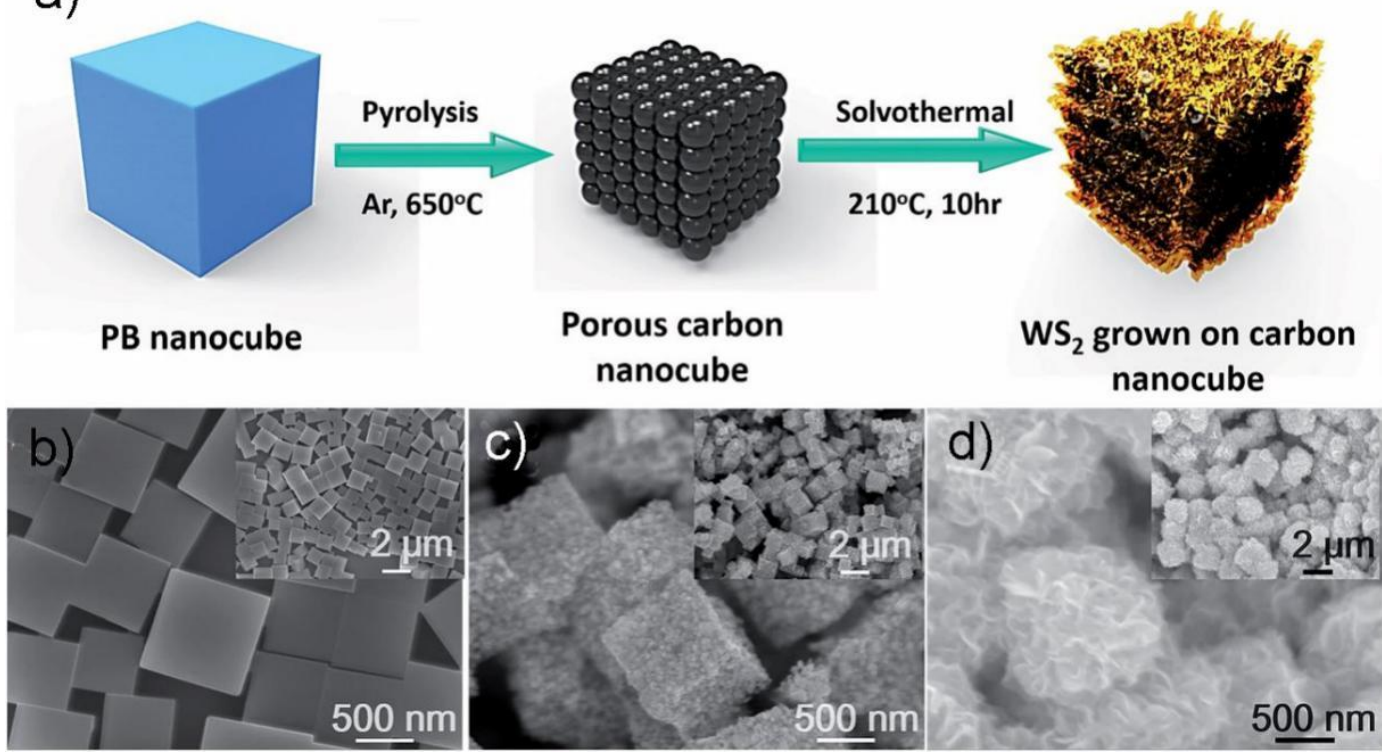

Fig. 8. (a) Schematic illustration of the $\mathrm{WS}_{2} @ \mathrm{NC}$ synthesis process derived from Prussian blue (PB) nanocubes. SEM images of (b) PB nanocubes, (c) derived porous N-doped carbon nanocubes (NC) and (d) WS $\mathrm{WN}_{2} \mathrm{NC}$ samples. Insets show SEM images at lower magnification. Reproduced from Ref.[184] with permission of Royal Society of Chemistry. 
a)

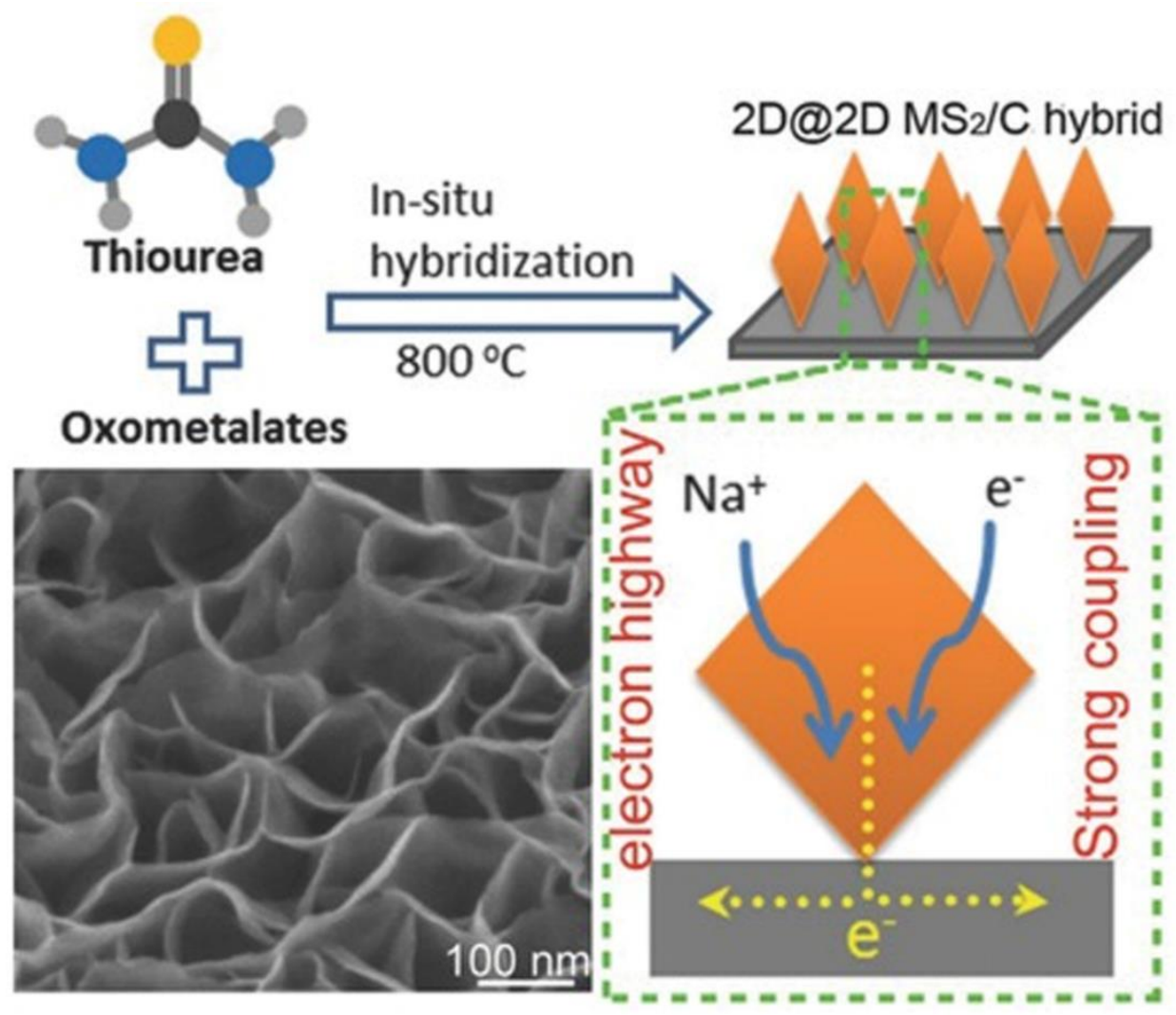

b)

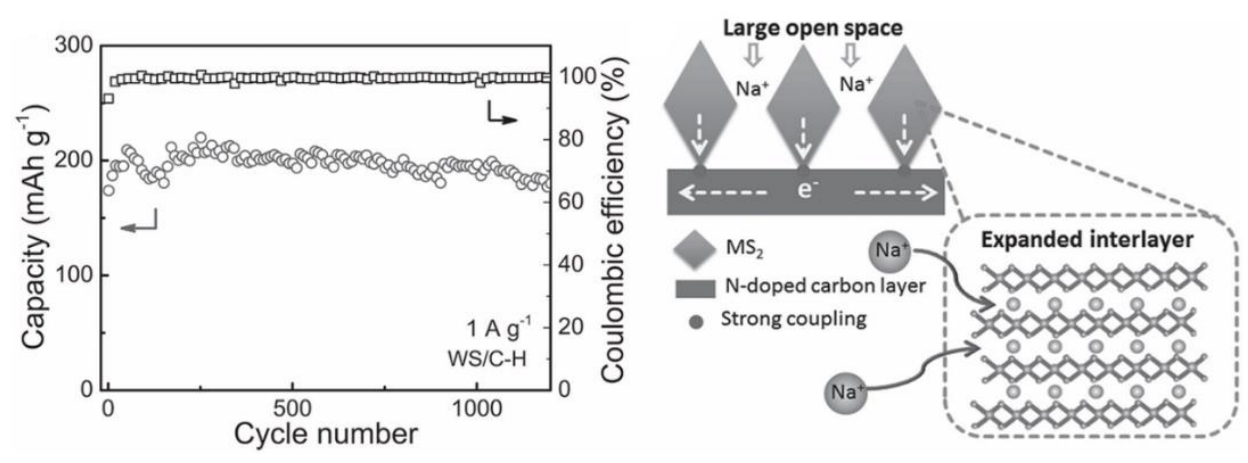

Fig. 9. (a) Schematic illustration of the procedure to fabricate the lamellar hybrid structure (lower left: SEM image $)$ of $\mathrm{MS}_{2} / \mathrm{C}(\mathrm{M}=\mathrm{Mo}, \mathrm{W})$ with $\mathrm{MS}_{2}$ nanowall arrays anchored on a carbon layer by an in-situ hybridization strategy and the $\mathrm{Na}^{+}$intercalation in the obtained $\mathrm{MS}_{2} / \mathrm{C}$ hybrid electrode. (b) Cycling performance of the obtained $\mathrm{WS}_{2} / \mathrm{C}$ hybrid at $1 \mathrm{~A} \mathrm{~g}^{-1}$ (left), and schematic diagram of fast $\mathrm{Na}^{+} /$electron transport in the hybrid electrode with expanded $\mathrm{WS}_{2}$ interlayers (right). Reproduced from Ref. [73] with permission of Wiley-VCH.

Recently, graphene-based TMDs have been developed with significantly improved Na-ion storage properties, since the 2D graphene nanosheets with excellent physical and chemical features 
can effectively enhance the electrochemical conductivity and buffer the volumetric expansion as well $[12,22]$. Dou and coworkers fabricated a WS $2 @$ graphene nanocomposite by a hydrothermal route, which showed a long-cycle reversible capacity of $329 \mathrm{~mA} \mathrm{~h} \mathrm{~g}{ }^{-1}$ over 500 cycles at $20 \mathrm{~mA} \mathrm{~g}^{-1}$, much higher than that of bare $\mathrm{WS}_{2}\left(32 \mathrm{~mA} \mathrm{~h} \mathrm{~g}^{-1}\right)$ [191]. Furthermore, those 3D graphene structures fabricated from 2D sheets can not only exhibit the merits of graphene including fast electronic transport and preventing aggregation of active materials, but also demonstrate excellent mechanical strength for potential flexible energy storage and conversion devices. Choi and Kang prepared a hybrid structure of layered $\mathrm{WS}_{2}$ nanosheet-decorated 3D rGO microspheres $\left(\mathrm{WS}_{2}-3 \mathrm{D} \mathrm{rGO}\right)$ using a facile two-step ultrasonic spray pyrolysis combined with a sulfidation process (Fig. 10a). The as-prepared $\mathrm{WS}_{2}-3 \mathrm{D}$ rGO microsphere material showed superior Na-ion storage properties to the metal oxide analogue (i.e., $\mathrm{WO}_{3}-3 \mathrm{D}$ rGO microspheres), although the theoretical capacity of $\mathrm{WO}_{3}$ is higher than that of $\mathrm{WS}_{2}$. When evaluated by galvanostatic measurements, the $\mathrm{WS}_{2}-3 \mathrm{D}$ rGO material showed an enhanced rate capability and a discharge capacity of $334 \mathrm{~mA} \mathrm{~h} \mathrm{~g}^{-1}$ after 200 cycles at a current density of $200 \mathrm{~mA}$ $\mathrm{g}^{-1}$ with the CE high than $99.9 \%$, in sharp contrast to that merely $118 \mathrm{~mA} \mathrm{~h} \mathrm{~g}^{-1}$ for $\mathrm{WO}_{3}-3 \mathrm{D}$ rGO under the same conditions (Fig. 10b). It is noteworthy that although the as-prepared $\mathrm{WS}_{2}-3 \mathrm{D}$ rGO microspheres material delivered a much superior capacity and long-term cycling performance compared to pure $\mathrm{WS}_{2}$, it suffered from a low ICE since the rGO incorporated has a relative low ICE of $23.2 \%$ related with the large irreversible capacity. Thus the ICE of the hybrid electrode needs be further improved for practical application [192]. 
a)

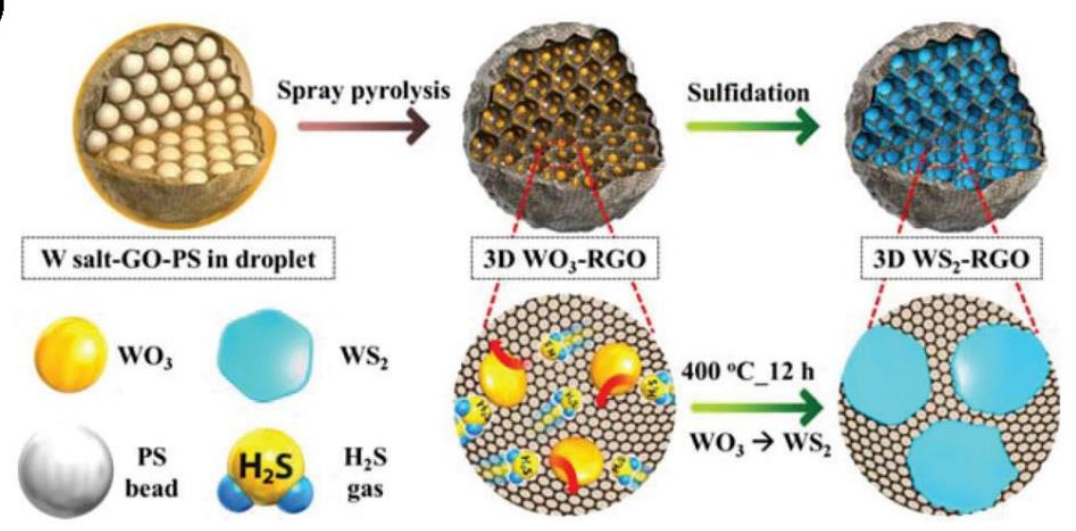

b)

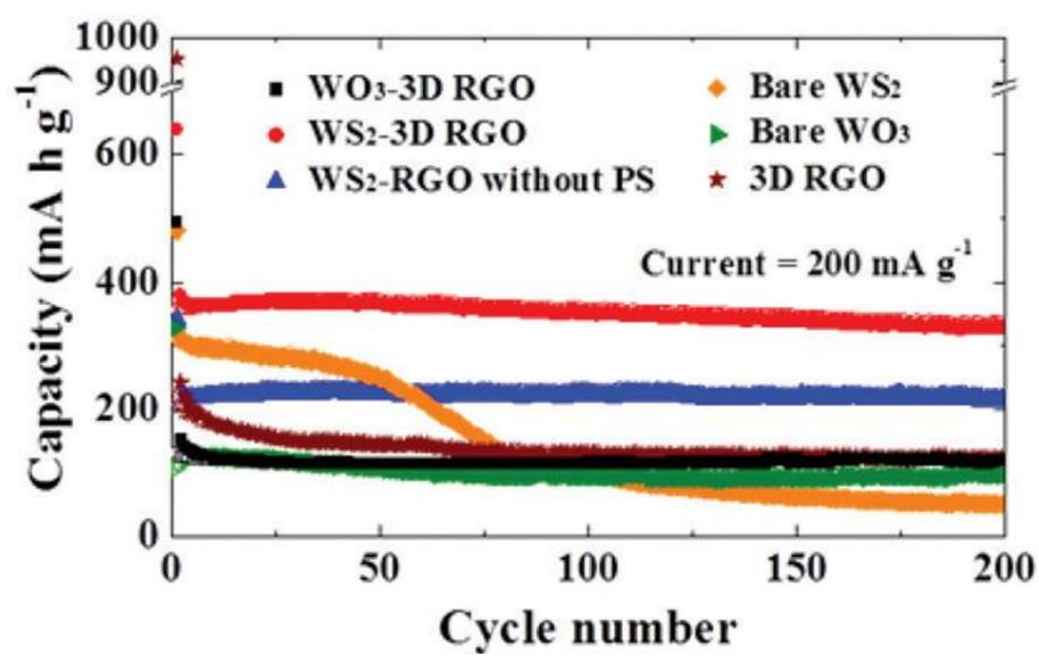

Fig. 10. (a) Schematic diagram for the formation mechanism of $3 \mathrm{D} \mathrm{WS}_{2}-\mathrm{rGO}$ microsphere. (b) The cycling performances of as-prepared microspheres and counterparts for Na-ion storage at a current density of $200 \mathrm{~mA}$ $\mathrm{g}^{-1}$. Reproduced from Ref. [192] with permission of Royal Society of Chemistry.

\subsection{3. $\mathrm{WS}_{2}$-based heterostructures}

Although TMDs have been recently considered as a class of high-capacity alternative anode materials to metal oxides due to the large interlayer space, reversible conversion reaction and higher conductivity of $\mathrm{Na}_{2} \mathrm{~S}$ products, they may also encounter with the "shuttle effect" that occurs in the $\mathrm{Li}-$ $\mathrm{S}$ battery system, namely, the sulfur dissolution problem originating from soluble polysulfide intermediates during the $\mathrm{Na}_{2} \mathrm{~S}$ formation/decomposition process resulting in loss of active sulfur 
components and a fading capacity. In this regard, the introduction of a protective layer such as carbon or metal oxide on the surface is preferably adopted, Taylor's group exploited a more facile and advanced coating process to precisely control the surface layer on the metal sulfide nanomaterial [72]. The as-designed heterogeneous $\mathrm{WS}_{x} / \mathrm{WO}_{3}$ core-shell hybrid with thorn-bush nanofiber (NF) structures via electrospinning and post-thermal treatment with metal oxide coating on the $\mathrm{WS}_{x} \mathrm{NF}(2<x<3)$ showed an enhanced Na-ion storage performance (Fig. 11a). Compared to pristine $\mathrm{WS}_{x} \mathrm{NF}$ electrode ( $44 \%$ capacity retention), $\mathrm{WS}_{x} / \mathrm{WO}_{3} \mathrm{NFs}$ retained $74 \%$ of the capacity obtained at the $2^{\text {nd }}$ discharge capacity after 100 cycles at $100 \mathrm{~mA} \mathrm{~g}^{-1}$ (Fig. 11b), and comparable rate capability at high current densities. Using the ex situ XRD characterization of the disassembled Na electrode, it was confirmed that the modification of metal sulfide electrode with oxide passivation surface layer effectively alleviated sulfur dissolution for achieving both high capacity and improved cycle performance [72]. 
a)

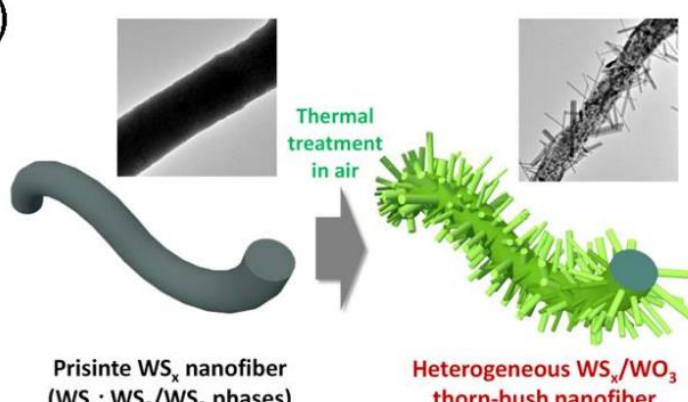

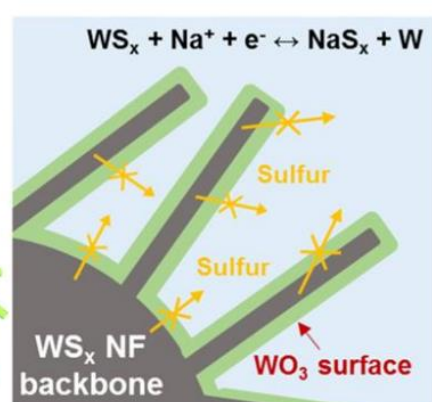

b)

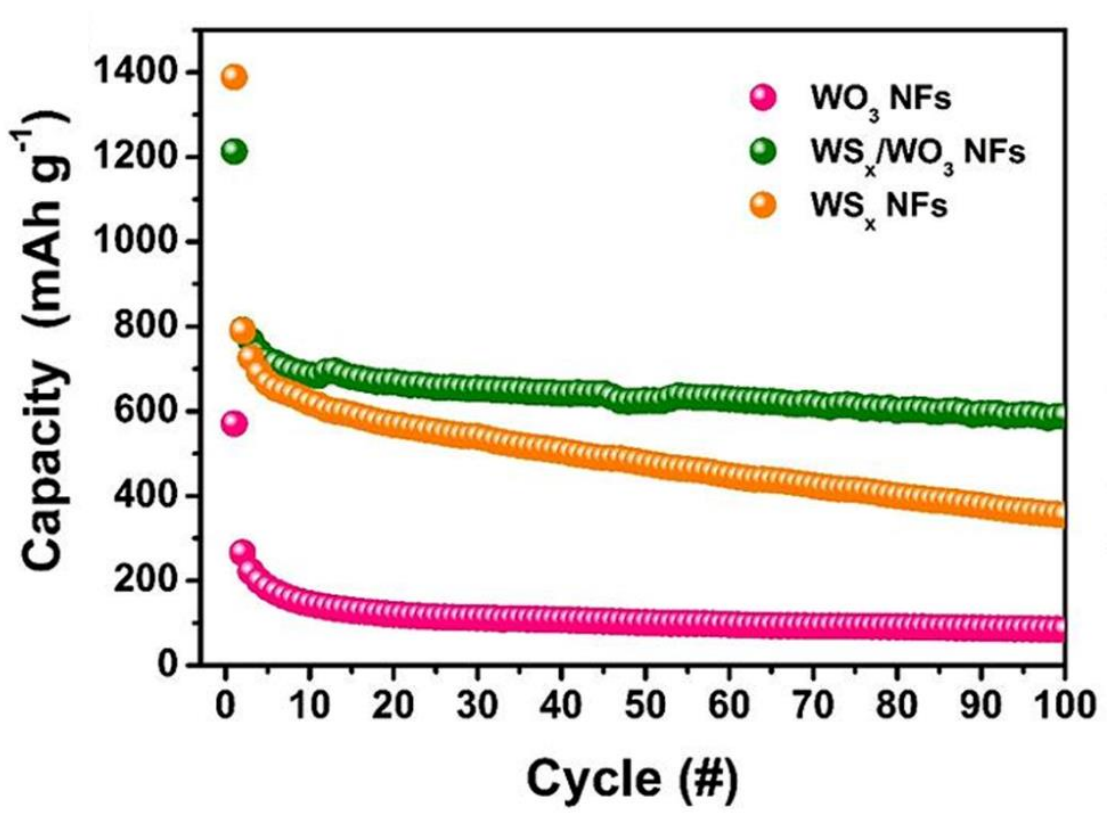

Fig. 11. (a) Schematic illustration of the synthetic strategy for heterogeneous $\mathrm{WS}_{x} / \mathrm{WO}_{3}$ thorn-bush (core-shell) nanofibers and the corresponding Na-ion storage reaction mechanism during cell operation. (b) Cycle performance of $\mathrm{WS}_{x}$ nanofibers and the post-calcined $\mathrm{WS}_{x}$ nanofibers $\left(\mathrm{WS}_{x} / \mathrm{WO}_{3}\right.$ or $\left.\mathrm{WO}_{3}\right)$ over a voltage window of 3.0-0.01 V at a current density of $100 \mathrm{~mA} \mathrm{~g}^{-1}$. Reproduced from Ref. [72] with permission of American Chemical Society.

\subsubsection{Flexible $\mathrm{WS}_{2}$ electrodes}

Flexible $\mathrm{WS}_{2}$ electrodes for SIBs have also been demonstrated [193,194]. Yu and coworkers prepared a 3D porous interconnected $\mathrm{WS}_{2} / \mathrm{C}$ nanocomposite on a Ti foil via a facile electrostatic spray deposition (EDS) technique, which is comprised of 0D WS $2(\sim 10 \mathrm{~nm}), 1 \mathrm{D}$ CNTs and $2 \mathrm{D}$ rGO. This 
annealed $\mathrm{WS}_{2} / \mathrm{C}$ nanocomposite electrode showed an excellent rate performance (with capacities of $393,270,199$, and $81 \mathrm{~mA} \mathrm{~h} \mathrm{~g}^{-1}$ at $100,500,1000$, and $5000 \mathrm{~mA} \mathrm{~g}^{-1}$, respectively) and long cycling stability (267 and $219 \mathrm{~mA} \mathrm{~h} \mathrm{~g}^{-1}$ at $500 \mathrm{~mA} \mathrm{~g}^{-1}$ after 200 and 300 cycles, respectively). The EDS technique for porous interconnected nanocomposite structures offers an alternative solution for high rate and long cycling SIB anodes, and may be expanded to produce materials for thin film batteries [195]. In addition, as a free-standing dual anode for SIBs besides LIBs, a hybrid film of $\mathrm{WS}_{2}$ nanoplates embedded in graphitic carbon nanotubes $\left(\mathrm{WS}_{2} @ \mathrm{G}\right)$ abovementioned could deliver a stable reversible Na-ion storage capacity of more than $340 \mathrm{~mA} \mathrm{~h} \mathrm{~g}^{-1}$ over 600 cycles at $500 \mathrm{~mA} \mathrm{~g}^{-1}$ and a high rate capacity of $289 \mathrm{~mA} \mathrm{~h} \mathrm{~g}^{-1}$ at $3.0 \mathrm{~A} \mathrm{~g}^{-1}[129]$. The $\mathrm{WS}_{2} / \mathrm{CNT}-\mathrm{rGO}$ hybrid aerogel abovementioned delivered a Na-ion storage capacity of $253 \mathrm{~mA} \mathrm{~h} \mathrm{~g}^{-1}$ after 100 cycles at $200 \mathrm{~mA} \mathrm{~g}^{-1}$, higher than those of commercial $\mathrm{WS}_{2}$ powder (23 $\left.\mathrm{mA} \mathrm{h} \mathrm{g}^{-1}\right)$ and pure CNT-rGO aerogel $\left(61 \mathrm{~mA} \mathrm{~h} \mathrm{~g}^{-1}\right)$ [67]. Wang et al. designed a 3D carbon foam supported $\mathrm{WS}_{2}$ nanosheets with decorated $\mathrm{N}$-doped graphene quantum dots (NGQDs-WS $2 / 3 D C F)$ for cable-shaped flexible SIBs. Benefiting from the 3D robust porous interpenetrating scaffold and the NGQDs modification, the free-standing electrode of hybrid nanoarchitecture could deliver a high capacity of $392 \mathrm{~mA} \mathrm{~h} \mathrm{~g}^{-1}$ at $200 \mathrm{~mA} \mathrm{~g}^{-1}$ after 1000 cycles with an extraordinary capacity retention of $97.1 \%$ versus that of the first cycle, and an enhanced rate capability of $268 \mathrm{~mA} \mathrm{~h} \mathrm{~g}^{-1}$ at $2.0 \mathrm{~A} \mathrm{~g}^{-1}$. When developed as a cable-shaped flexible full SIB, it also exhibited high capacity and fine flexibility [194].

\section{2. $\mathrm{MoSe}_{2}$ for sodium-ion batteries}

\subsubsection{Structural control of $\mathrm{MoSe}_{2}$}

Compared with $\mathrm{MoS}_{2}$, the analogue $\mathrm{MoSe}_{2}$ exhibits some advantages for SIBs due to its larger interlayer spacing $(0.646 \mathrm{~nm})$ and higher electric conductivity originating from the small band gap, 
which both enable fast charge transfer and enhanced reversible electrochemical charge/discharge processes [196,197]. The design of (porous) nanostructured anode materials, in consideration of larger radius and slower reaction kinetics for $\mathrm{Na}$ ions compared to $\mathrm{Li}$ ions, will benefit high reversible capacity and prolonged cycle life [198202]. The porous/hollow structures with high surface area will show an improved performance than solid analogues since the activation barrier for Na-ion transportation on the surface $(0.344 \mathrm{~V})$ is much lower than that of interlayers $(1.28 \mathrm{~V})$ of $\mathrm{MoSe}_{2}$, i.e., a larger Na-ion diffusion coefficient on the surface [202]. For example, a hierarchical yolk-shellstructured $\mathrm{MoSe}_{2}$ microspheres synthesized by a facile selenization of $\mathrm{MoO}_{3}$ precursor could deliver an initial capacity of $527 \mathrm{~mA} \mathrm{~h} \mathrm{~g}^{-1}$ and a better cycling capacity of $433 \mathrm{~mA} \mathrm{~h} \mathrm{~g}^{-1}$ after 50 cycles at 200 $\mathrm{mA} \mathrm{g}^{-1}$ as well as a high rate capability of 364 and $345 \mathrm{~mA} \mathrm{~h} \mathrm{~g}^{-1}$ at 1.0 and $1.5 \mathrm{~A} \mathrm{~g}^{-1}$ [203]. Furthermore, the accurate control of various hollow structures and their evolution process is of great interest and challenge. Cao's group developed a new strategy on Hansen solubility parameter (HSP)-guided solvent selection to initiate Ostwald ripening for accurate synthesis of interior space-tunable $\mathrm{MoSe}_{2}$ spherical structures (i.e., solid, core-shell, yolk-shell and hollow spheres; see Fig. 12a,b) with outer shells composed of few-layer nanosheets (Fig. 12c-e), which showed architecture-dependent electrochemical performances. The as-obtained hollow spheres showed a superior initial discharge capacity of $710 \mathrm{~mA} \mathrm{~h} \mathrm{~g}^{-1}$ at $100 \mathrm{~mA} \mathrm{~g}^{-1}$ with an impressively high ICE of $91.3 \%$ as well as outstanding stable cycling performance (694 $\mathrm{mA} \mathrm{h} \mathrm{g}^{-1}$ after 100 cycles with CE over 98\%) and rate capability, much higher than those of yolk-shell and solid spheres (Fig. 12f,g). The enhanced performance is attributed to the synergistic effects including enhanced electrical conductivity by increasing crystallinity, more electrochemical active sites due to higher specific surface area, and fast mass transfer kinetics with enlargement of interior space [204]. Similarly, Zhang et al.prepared a rod-like 
hollow structure composed of interlayer-expanded $\mathrm{MoSe}_{2}$ nanosheets with a 54.8\% expansion of (002) planes up to $10.0 \AA$. The hierarchically nanotubular architecture was a result of oriented attachment/assembly and Ostwald ripening effects during the one-pot solvothermal route. When utilized as a SIB anode in a controlled cut-off voltage range of $0.5-3.0 \mathrm{~V}$ within an intercalation mechanism, it exhibited a highly durable and stable cycling performance with a discharge capacity of $228 \mathrm{~mA} \mathrm{~h} \mathrm{~g}^{-1}$ after 1500 cycles at $1.0 \mathrm{~A} \mathrm{~g}^{-1}$. It is also noteworthy that for the controlled potential range of $0.5-3.0 \mathrm{~V}$, although showing herein a lower capacity than those obtained in the potential range of 0.01-3.0 V, it did exhibit a much better cycling performance due to the integrity of the layered structure of the electrode based on a limited intercalation-type reaction [201]. Shi et al. synthesized an in-situ carbon-doped $\mathrm{Mo}\left(\mathrm{Se}_{0.85} \mathrm{~S}_{0.15}\right)_{2}$ hierarchical nanotubes (diameter of $300 \mathrm{~nm}$, wall thickness of $50 \mathrm{~nm}$ ) composed of 2D layered nanosheets via a solvothermal method followed by selenizing the precursor of $\mathrm{MoS}_{2}: \mathrm{C}$ nanotubes at $900{ }^{\circ} \mathrm{C}$. The $\mathrm{Mo}\left(\mathrm{Se}_{0.85} \mathrm{~S}_{0.15}\right)_{2}: \mathrm{C}$ hierarchical hybrid performed as a robust host material for Na-ion storage. It could deliver an enhanced capacity of $421 \mathrm{~mA} \mathrm{~h} \mathrm{~g}^{-1}$ (close to the theoretical capacity of $\mathrm{MoSe}_{2}$ ) at $200 \mathrm{~mA} \mathrm{~g}^{-1}$ after 100 cycles with a high ICE of $82.3 \%$. Moreover, it showed a remarkable and stable capacity of $360 \mathrm{~mA} \mathrm{~h} \mathrm{~g}^{-1}$ at a high current density of $2.0 \mathrm{~A} \mathrm{~g}^{-1}$ over 100 cycles and a superior rate capability (e.g., with a capacity retention of $81.8 \%$ compared to that at $50 \mathrm{~mA} \mathrm{~g}^{-1}$ ). The combined structural features are beneficial for the fast $\mathrm{Na}^{+}$ion and electron kinetics and excellent performances thereof [199]. On the other hand, some S-doped 2H-MoSe 2 porous nanospheres assembled from few-layered nanosheets also showed enhanced electrical conductivity, expanded layer spacing, and improved Na-ion storage performance thereof [176,200,204]. 
a)
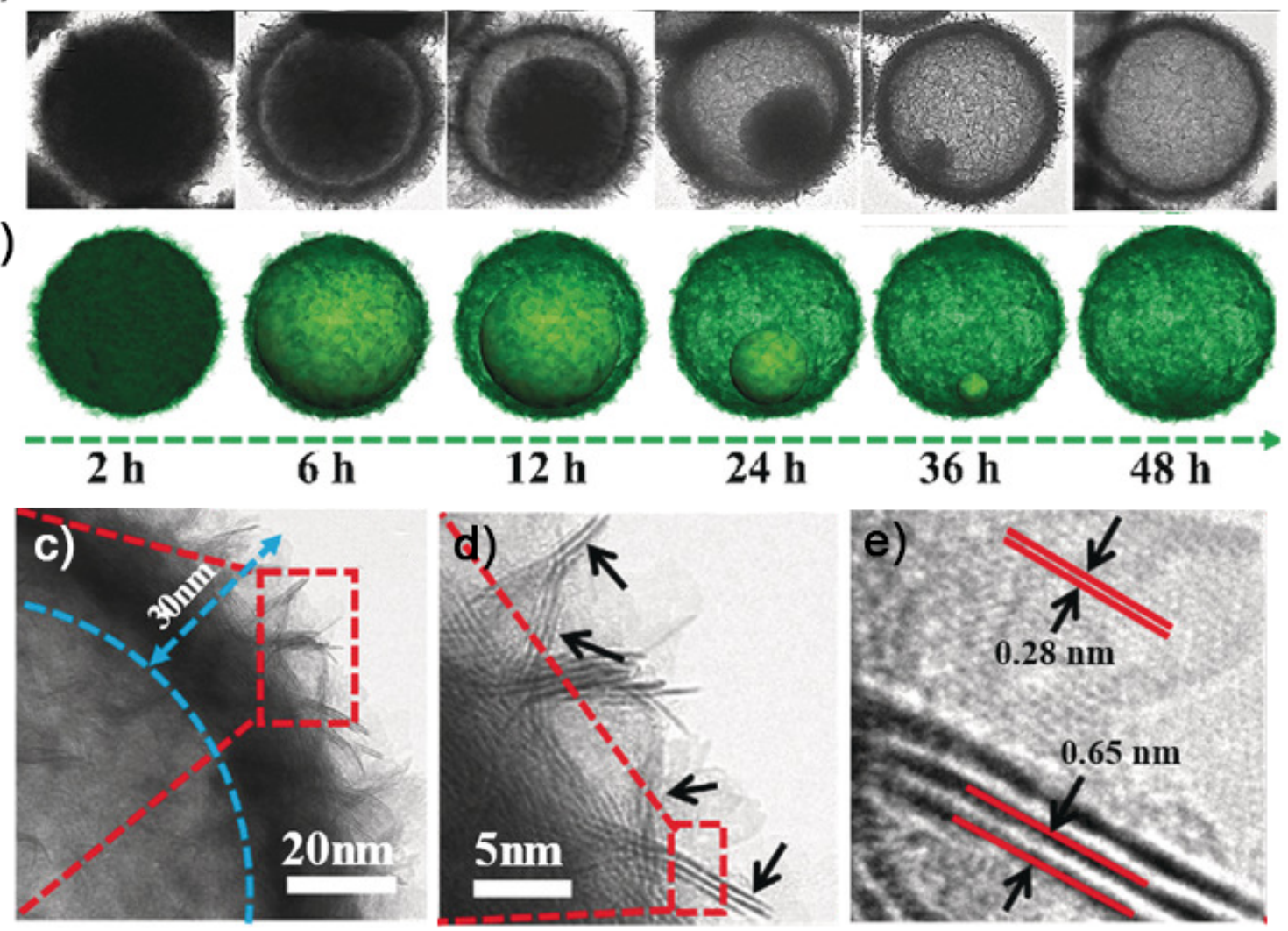

f)
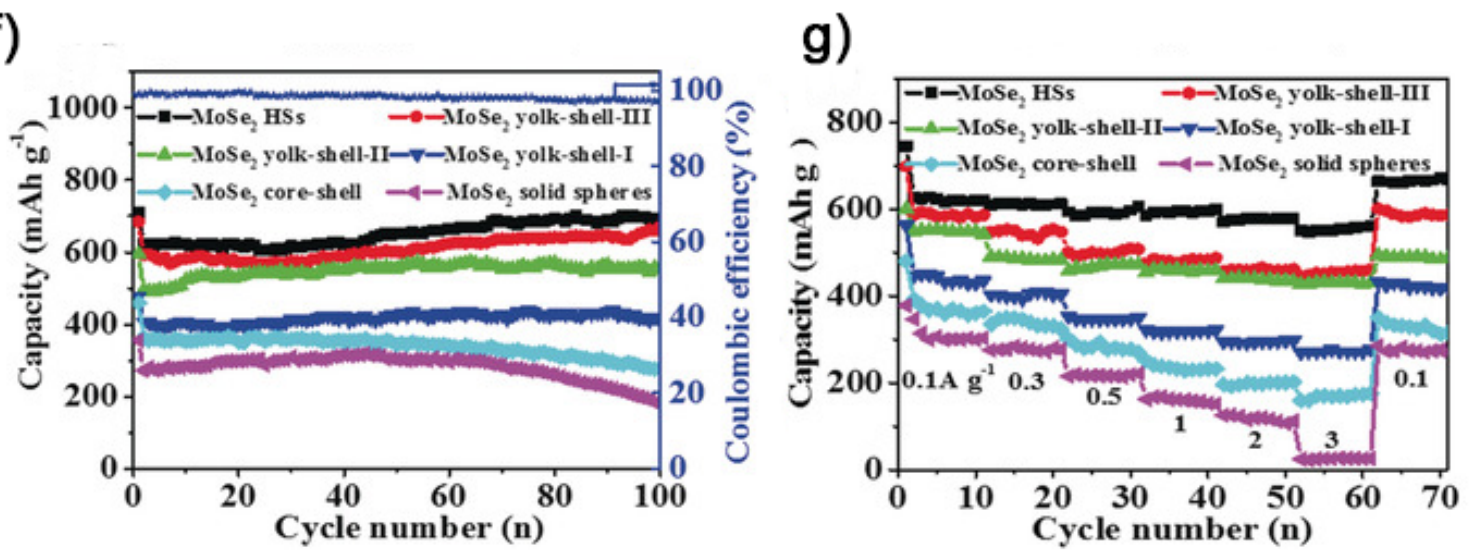

Fig. 12. (a) The evolution process of $\mathrm{MoSe}_{2}$ solid spheres to hollow spheres (HSs) and (b) corresponding schematic graphs with different reaction times in DMF (2-48 h). (c-e) TEM and HRTEM images of MoSe $\mathrm{MSS}_{2}$. (f) Cycling performances of different $\mathrm{MoSe}_{2}$ electrodes for SIBs over the voltage window of $0.01-3.0 \mathrm{~V}$ and the coulombic efficiency of $\mathrm{MoSe}_{2} \mathrm{HSs}$ at $100 \mathrm{mAg}^{-1} .(\mathrm{g})$ Rate capability of different $\mathrm{MoSe}_{2}$ electrodes for SIBs. Reproduced from Ref. [204] with permission ofWiley-VCH. 


\subsubsection{Hybridizing $\mathrm{MoSe}_{2}$ with conductive frameworks}

For the improved electrochemical performance of $\mathrm{MoSe}_{2}$, coupling with electrically conductive matrices such as carbon is a popular and effective strategy [142,162,164,205,206]. For example, Qiu's group synthesized one type of carbon-stabilized interlayer-expanded few-layer $\mathrm{MoSe}_{2}$ nanosheets via a combined process of oleic acid/dopamine-assisted solvothermal, self-polymerization and calcination. The incorporation of $\mathrm{N}$-doped carbon $(\mathrm{N}-\mathrm{C})$ expands the interlayer spacing of $\mathrm{MoSe}_{2}$ from 6.4 to 7.0 $\AA$, facilitates the permeation of electrolyte into the interlayers and enhances electronic/ionic conductivity as well as buffers volume changes during charge/discharge processes. When used as a SIB anode, the $\mathrm{MoSe}_{2} @ \mathrm{~N}-\mathrm{C}$ can delivered a high reversible capacity of $445 \mathrm{~mA} \mathrm{~h} \mathrm{~g}{ }^{-1}$ at $1.0 \mathrm{~A} \mathrm{~g}^{-1}$ after 100 cycles and a significantly improved rate capability of $367 \mathrm{~mA} \mathrm{~h} \mathrm{~g}^{-1}$ at $5.0 \mathrm{~A} \mathrm{~g}^{-1}$. When assembled into full SIBs with $\mathrm{Na}_{3} \mathrm{~V}_{2}\left(\mathrm{PO}_{4}\right)_{3}$ cathode, the hybrid anode exhibited an impressively high capacity of $421 \mathrm{~mA} \mathrm{~h} \mathrm{~g}^{-1}$ at $200 \mathrm{~mA} \mathrm{~g}^{-1}$ after 100 cycles [205]. Using an alternative carbon resource such as cassava starch, the interlayer spacing could be further expanded up to $10 \AA$ for the expanded (002) planes of few-layered $\mathrm{MoSe}_{2}$ in the flower-like $\mathrm{MoSe}_{2} / \mathrm{C}$ composite, which could deliver a longterm reversible capacity of $c a .360 \mathrm{~mA} \mathrm{~h} \mathrm{~g}^{-1}$ after 350 cycles at $500 \mathrm{~mA} \mathrm{~h} \mathrm{~g}^{-1}$ and a high rate capacity of $266 \mathrm{~mA} \mathrm{~h} \mathrm{~g}^{-1}$ even at $4.0 \mathrm{~A} \mathrm{~g}^{-1}[205,207]$. Well-defined nanostructures such as hollow structures have attached great interest due to their unique advantages especially for the enhanced tolerance for volume expansion or structural strain $[108,109,208]$. The introduction of core in this encapsulationtype structure will further increase the volumetric energy density of SIBs [108-110]. Liu et al. designed such a type of $\mathrm{MoSe}_{2} @$ hollow carbon nanosphere (HCNS) with confined few-layer $\mathrm{MoSe}_{2}$ nanosheets of exposed (002) planes, the layer spacing of which was expanded to $1.02 \mathrm{~nm}$ compared to the intrinsic value of $0.646 \mathrm{~nm}$ for pristine $\mathrm{MoSe}_{2}$ (Fig. 13a-e) [196]. This hybrid $\mathrm{MoSe}_{2} @ \mathrm{HCNS}$ as anode 
materials for SIBs showed excellent rate capabilities, ultralong cycling life with high Coulombic efficiency: it maintained a capacity of 501 and $471 \mathrm{~mA} \mathrm{~h} \mathrm{~g}^{-1}$ after 1000 cycles at 1.0 and $3.0 \mathrm{~A} \mathrm{~g}^{-1}$ (Fig. 13f), respectively, with a rate capacity retention of $382 \mathrm{~mA} \mathrm{~h} \mathrm{~g}^{-1}$ at $10 \mathrm{~A} \mathrm{~g}^{-1}$. Such high performance can be attributed to the 2D few-layer nanosheets with expanded (002) planes and the unique conductive hybrid shell structure for improving electrons/ions transfer, buffering volume changes and promoting the reversible desodiation-sodiation processes. The aforementioned $\mathrm{MoSe}_{2} @ \mathrm{PHCS}$ hollow structures as dual anodes also exhibited an enhanced reversible Na storage capacity of $580 \mathrm{~mA} \mathrm{~h} \mathrm{~g}^{-1}$ after 100 cycles at $200 \mathrm{~mA} \mathrm{~g}^{-1}$ due to the optimized synergic effects of the carbon hollow structure and thin $\mathrm{MoSe}_{2}$ nanosheets [142]. A debatable issue about the capacity degradation mechanism is the shuttle effect of polyselenides, similar to that of polysulfides in $\mathrm{Li}-\mathrm{S}$ batteries, leading to the loss of active materials and fast capacity fading [197]. The fabrication of conductive core/shell structures can alleviate volume changes of active materials (e.g. $\mathrm{MoSe}_{2}$ ) and prevent them from "shuttle effect" and enhance the electrical conductivity. However, in some cases, only the conductivity of surficial active materials adhered to the conductive shell is improved, the conductivity of the core part is still low if the hybrid structure has relatively large dimensions. Fan and coworkers proposed a unique urchin-like $\mathrm{MoSe}_{2} @ \mathrm{~N}-\mathrm{C}$ composite structure with few-layer $\mathrm{MoSe}_{2}$ nanosheets uniformly distributed on highly conductive N-doped carbon $(\mathrm{N}-\mathrm{C})$ matrix to meet these considerations for SIBs. The as-prepared $\mathrm{MoSe}_{2} / \mathrm{N}-\mathrm{C}$ composite spheres showed much improved rate capability and cycling stability compared with pure $\mathrm{MoSe}_{2}$ sample. The high capacity retention up to 500 cycles $\left(89.8 \%\right.$ from the $2^{\text {nd }}$ cycle at $\left.500 \mathrm{~mA} \mathrm{~g}^{-1}\right)$ was mainly based on the alloying reaction, which benefits from the enhanced conductivity and accommodation of large volume expansion [197]. 

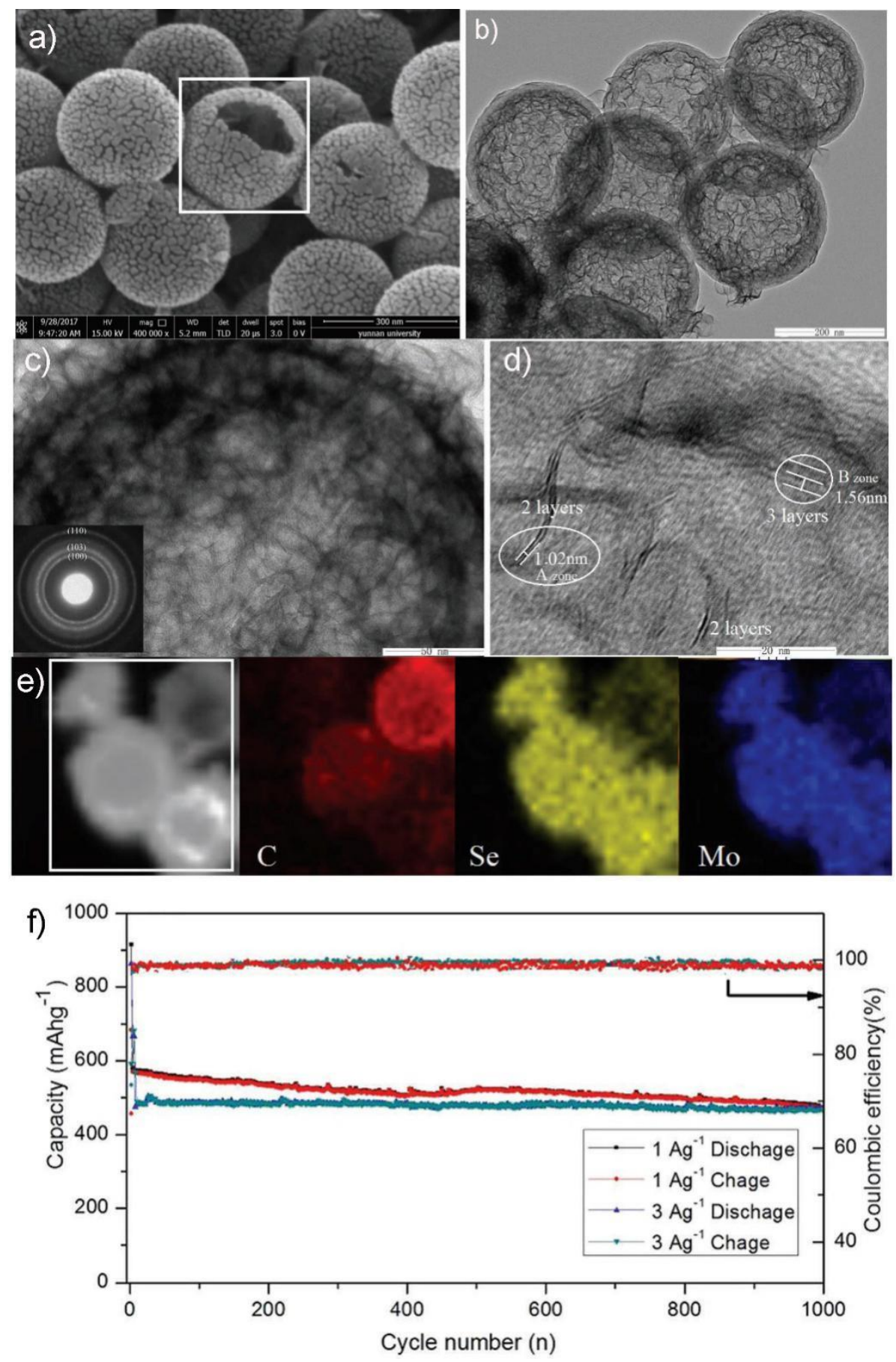

Fig. 13. (a) SEM, (b and c) TEM, and (d) HRTEM images of encapsulation-type $\mathrm{MoSe}_{2} @ \mathrm{HCNS}$ with expanded (002) planes confined in hollow carbon nanospheres (HCNS), and SAED (inset in (c)). (e) EDX mapping images (elements C, Se, Mo) of the fabricated few-layer MoSe ${ }_{2} @ H C N S$ samples. (f) Cycling capability of $\mathrm{MoSe}_{2} @ \mathrm{HCNS}$ with prolonged cycle life (1000 cycles) for ultrahigh-performance SIBs at 1 and $3 \mathrm{~A} \mathrm{~g}^{-1}$. Reproduced from Ref. [196] with permission of Wiley-VCH. 
Beyond traditional amorphous carbon, nanostructured carbon materials such as carbon nanotubes (CNTs) $[160,209,210]$ and graphene $[154,164]$ have been extensively used to improve the performance of $\mathrm{MoSe}_{2}$ as anode materials for $\mathrm{SIBs}$ by minimizing the restacking of $\mathrm{MoSe}_{2}$ layers, providing abundant active sites and enhancing the electrical conductivity. For example, a composite ultrathin $\mathrm{MoSe}_{2}$ nanosheets firmly anchored on the surface of MWCNTs was synthesized via a one-step hydrothermal route, and could deliver an enhanced reversible specific capacity of $459 \mathrm{~mA} \mathrm{~h} \mathrm{~g}^{-1}$ at 200 $\mathrm{mA} \mathrm{g}^{-1}$ after 90 cycles, and a rate capacity of $385 \mathrm{~mA} \mathrm{~g}^{-1}$ at $2.0 \mathrm{~A} \mathrm{~g}^{-1}$, much better than those of $\mathrm{MoSe}_{2}$ nanosheets [210]. As a dual anode material, the coaxial-cable $\mathrm{MoSe}_{2} / \mathrm{HCFs}$ composite also showed an enhanced and stable specific capacity of 423 and $395 \mathrm{~mA} \mathrm{~h} \mathrm{~g}^{-1}$ at 0.5 and $1.0 \mathrm{~A} \mathrm{~g}^{-1}$ after 100 cycles, and a high rate capacity of 337 at $3.0 \mathrm{~A} \mathrm{~g}^{-1}[160]$. Choi and Kang synthesized 3D porous CNTmicrospheres embedded with ultrafine $\mathrm{MoSe}_{2}$ nanocrystals via a spray pyrolysis followed by a selenization process, which showed excellent Na-ion storage properties with a long-term cycling capacity of $296 \mathrm{~mA} \mathrm{~h} \mathrm{~g}^{-1}$ after 250 cycles at a high current density of $1.0 \mathrm{~A} \mathrm{~g}^{-1}$, and delivered high rate capabilities of 280 and $255 \mathrm{~mA} \mathrm{~h} \mathrm{~g}^{-1}$ at 3.0 and $5.0 \mathrm{~A} \mathrm{~g}^{-1}$, respectively [211].

Graphene, as the most promising conductive matrix, can effectively buffer the volume expansion/contraction of active materials, enhance the electrical conductivity, and shorten the ionic pathway due to the large contact area between electrode and electrolyte [12,164,212214]. For example, a hierarchical $\mathrm{MoSe}_{2} / \mathrm{rGO}$ dual anode composite could deliver an enhanced cycling capacity of 430 $\mathrm{mA} \mathrm{h} \mathrm{g}^{-1}$ at $0.5 \mathrm{~A} \mathrm{~g}^{-1}\left(380 \mathrm{~mA} \mathrm{~h} \mathrm{~g}^{-1}\right.$ at $\left.1.0 \mathrm{~A} \mathrm{~g}^{-1}\right)$ after 200 cycles with a $\mathrm{CE}$ of $99 \%$ [164]. To control the dispersity of $\mathrm{MoSe}_{2}$ on graphene, Du's group constructed a high quality $\mathrm{MoSe}_{2} / \mathrm{rGO}$ hybrid nanostructure with monodispersed flower-like $\mathrm{MoSe}_{2}$ anchored rGO framework. This hybrid showed an improved electrochemical performance as anode materials for SIBs both in half cell and full cell 
systems [215]. To further enhance the conductivity and the interaction with active species, Niu et al. designed a hybrid few-layered $\mathrm{MoSe}_{2}$ on N,P-codoped rGO nanosheets (MoSe $2 / \mathrm{N}, \mathrm{P}-\mathrm{rGO}$ ) via a solvothermal reaction followed by calcination. This hybrid showed a greatly improved electrochemical performance including outstanding long-term cycling stability with a specific capacity of $378 \mathrm{~mA} \mathrm{~h}$ $\mathrm{g}^{-1}$ after 1000 cycles at $500 \mathrm{~mA} \mathrm{~g}^{-1}$ (87\% capacity retention compared to that at the $2^{\text {nd }}$ cycle), excellent rate capabilities even at a very high current density up to $15 \mathrm{~A} \mathrm{~g}^{-1}$ due to the enhanced capacitive contribution. The superior cycling stability of the electrode could be attributed to the strong interaction of dual-doped carbon with (poly)selenides, as supported by a theoretical simulation. The insight into the conversion mechanism was revealed by ex situ Raman spectra and HRTEM analyses, i.e., the element Se rather than $\mathrm{MoSe}_{2}$ was formed after the charging process. When paired with $\mathrm{Na}_{3} \mathrm{~V}_{2}\left(\mathrm{PO}_{4}\right)_{3} / \mathrm{C}$ cathode, it demonstrated an excellent performance in the full cell with highly stable cycling behavior and competitive energy density of $57.6 \mathrm{Wh} \mathrm{kg}^{-1}$ at $1.68 \mathrm{~kW} \mathrm{~kg}^{-1}$ (voltage window of 3.4-1.0 V), showing a promising potential for advanced SIBs [216].

Dual carbon frameworks may further improve the conductivity, electrode stability and long-term cycling performance thereof. Tu and coworkers designed a facile one-step hydrothermal strategy to fabricate a 3D C-coated $\mathrm{MoSe}_{2} / \mathrm{rGO}$ composite with both high porosity and large surface area by introducing rGO as a conductive skeleton and glucose-derived carbon as a protective layer. This composite could deliver an ultrastable reversible capacity of $445 \mathrm{~mA} \mathrm{~h} \mathrm{~g}^{-1}$ after 350 cycles at $200 \mathrm{~mA}$ $\mathrm{g}^{-1}$ and a high rate capability of $228 \mathrm{~mA} \mathrm{~h} \mathrm{~g}^{-1}$ at $4.0 \mathrm{~A} \mathrm{~g}^{-1}$, much better than those of C-MoSe 2 nanosheets. By further ex-situ XPS and TEM analyses, it was claimed that the reaction mechanism between $\mathrm{MoSe}_{2}$ and $\mathrm{Na}^{+}$did not follow the typical route but similar to that of a Se/C anode: after the charging process, a mixture electrode of Se (or polyselenide) and Mo were formed rather than 
$\mathrm{MoSe}_{2}$ [217]. Cui et al. synthesized MoSe $@$ @C@graphene hybrid nanofibers via electrospinning followed by calcination to further optimize the electrochemical performance of $\mathrm{MoSe}_{2} @ \mathrm{C}$ hybrid nanofibers by introducing low-content 2D graphene for boosting the Na-ion storage performance. The 1D nanofiber showed enhanced structural stability due to the sufficient tolerance to stress, and the additional graphene improved the surface properties for higher conductivity as well as enhanced electrode reaction kinetics and rate performance thereof. It can deliver a high reversible capacity of $367 \mathrm{~mA} \mathrm{~h} \mathrm{~g}^{-1}$ after 200 cycles at $200 \mathrm{~mA} \mathrm{~g}^{-1}$ and a stable rate capability of 353 and $320 \mathrm{~mA} \mathrm{~h} \mathrm{~g}^{-1}$ at 1.0 and 2.0 $\mathrm{A} \mathrm{g} \mathrm{g}^{-1}$, respectively [218]. Kang's group further exploited an efficient procedure for largescale production of highly porous $\mathrm{MoSe}_{2}$ hybrid powder ( $\mathrm{MoSe}_{2}-\mathrm{rGO}-\mathrm{CNT}$ ) containing ultrafine $\mathrm{MoSe}_{2}$ nanocrystals embedded in synergistic rGO and CNTs matrix (Fig. 14a) via a spray pyrolysis and annealing route. The as-prepared trinary hybrid exhibited an excellent cycling discharge capacity of $393 \mathrm{~mA} \mathrm{~h} \mathrm{~g}^{-1}$ after 200 cycles and $335 \mathrm{~mA} \mathrm{~h} \mathrm{~g}^{-1}$ after 400 cycles at $1.0 \mathrm{~A} \mathrm{~g}^{-1}$, and a competitive rate capability of 275,225 , and $173 \mathrm{~mA} \mathrm{~h} \mathrm{~g}^{-1}$ at 5,15 , and $30 \mathrm{~A} \mathrm{~g}^{-1}$, respectively, which are superior to the analogue binary hybrids or pristine $\mathrm{MoSe}_{2}$ (Fig. 14b-d) [209]. 
a)

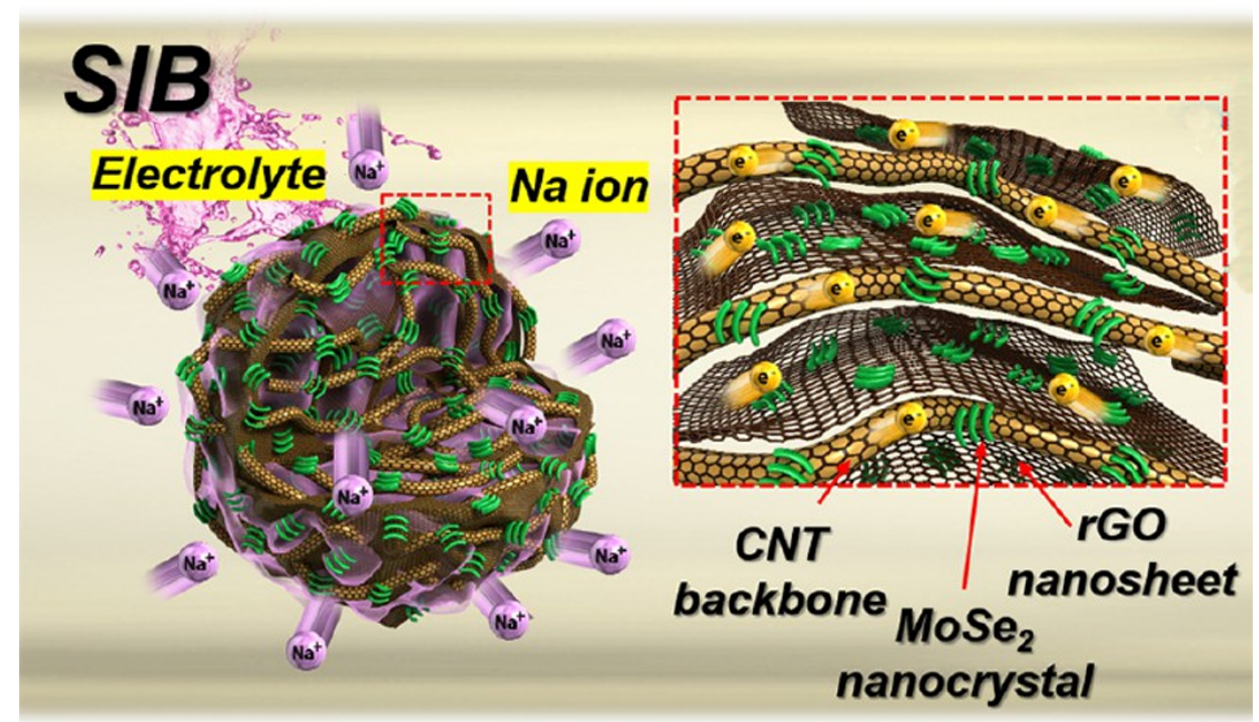

b)

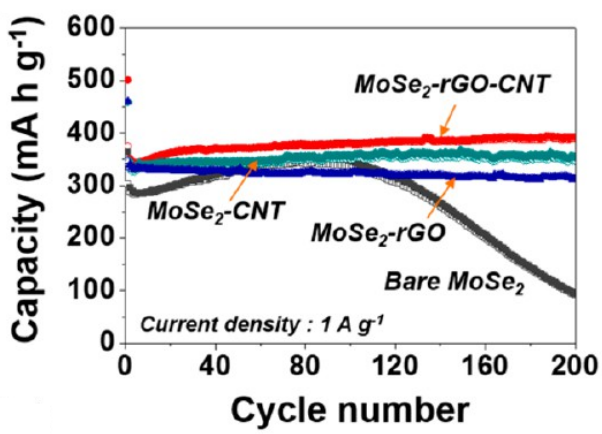

d)

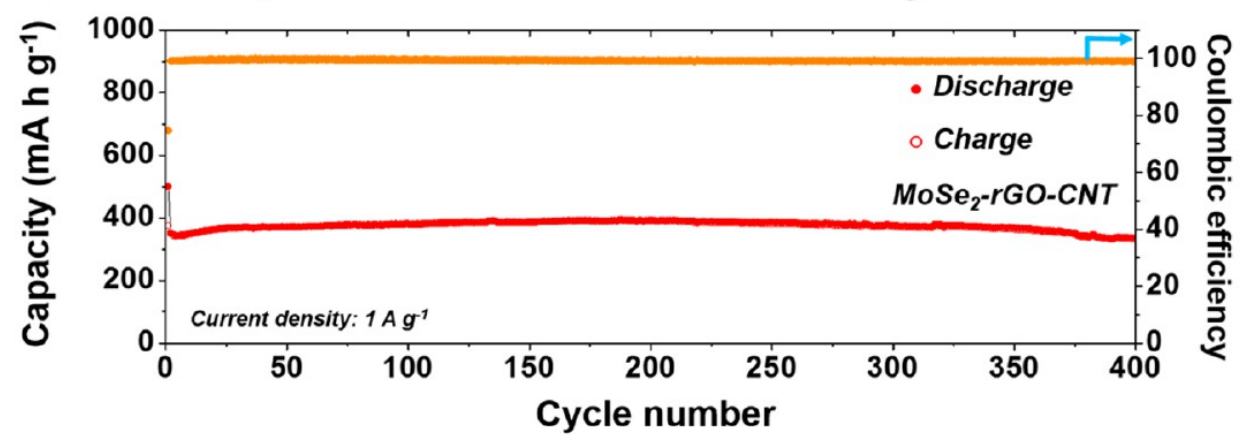

Fig. 14. (a) Schematic illustration of the highly porous $\mathrm{MoSe}_{2}-\mathrm{rGO}-\mathrm{CNT}$ composite by spray pyrolysis for superior Na-ion storage. Electrochemical properties of $\mathrm{MoSe}_{2}-\mathrm{rGO}-\mathrm{CNT}, \mathrm{MoSe}_{2}-\mathrm{rGO}, \mathrm{MoSe}_{2}-\mathrm{CNT}$, and bare $\mathrm{MoSe}_{2}$ powders: (b) cycling performances, (c) rate performances, and (d) long-term cycling performance and Coulombic efficiency of $\mathrm{MoSe}_{2}$-rGO-CNT. Reproduced from Ref. [209] with permission of American Chemical Society. 


\subsubsection{Free-standing $\mathrm{MoSe}_{2}$ electrodes}

For the attractive next-generation flexible electrode design [120,193], carbon cloth and graphene with porous $3 \mathrm{D}$ structure is a highly desirable flexible and robust substrate $[219,220]$. For example, a flexible $\mathrm{MoSe}_{2} / \mathrm{N}-\mathrm{CNF}$ dual anode material utilized for Na-ion storage can deliver a reversible capacity of $347 \mathrm{~mA} \mathrm{~h} \mathrm{~g}^{-1}$ after 100 cycles at $100 \mathrm{~mA} \mathrm{~g}^{-1}$ without the detectable decay, and showed a robust long-term cycling performance with a maintained capacity of $234 \mathrm{~mA} \mathrm{~h} \mathrm{~g}^{-1}$ (a retention rate of $88.9 \%$ compared to that of $2^{\text {nd }}$ cycle) after 1500 cycles at $1.0 \mathrm{~A} \mathrm{~g} \mathrm{~g}^{-1}[140]$. A robust and flexible $\mathrm{MoSe}_{2} / \mathrm{CF}$ composite electrode was fabricated by Du's group via solvothermal synthesis of thin $\mathrm{MoSe}_{2}$ nanosheets (thickness of $20 \mathrm{~nm}$ ) uniformly grown on carbon fiber (CF) cloth [219]. This binder-free SIB anode demonstrated a stable specific capacity of $453 \mathrm{~mA} \mathrm{~h} \mathrm{~g}{ }^{-1}$ and kept a $85.5 \%$ retention after 100 cycles at $200 \mathrm{~mA} \mathrm{~g}^{-1}$ and high rate capability, which makes it a promising flexible electrode for advanced SIBs. Tu and coworkers further developed a self-supported sandwiched vertical graphene $(\mathrm{VG}) / \mathrm{MoSe}_{2} / \mathrm{N}$-doped carbon $(\mathrm{N}-\mathrm{C})$ composite arrays (Fig. 15a-d) via a combined hydrothermal and polymerization method [221]. The flexible ternary core/shell electrode with high electrical conductivity, robust mechanical stability, and large porosity exhibited a high reversible Na-ion storage capacity of $534 \mathrm{~mA} \mathrm{~h} \mathrm{~g}^{-1}$ at $200 \mathrm{~mA} \mathrm{~g}^{-1}$ over 400 cycles, and enhanced high-rate capability with longterm cycling stability, i.e., 398 and $298 \mathrm{~mA} \mathrm{~h} \mathrm{~g}^{-1}$ after 1000 cycles at 1.0 and $2.0 \mathrm{~A} \mathrm{~g}^{-1}$ (Fig. 15e), respectively. Overall, the smart hybridization of active materials into tailored flexible electrode with dual conductive carbon networks provides a general method for high-performance electrochemical energy storage devices. 

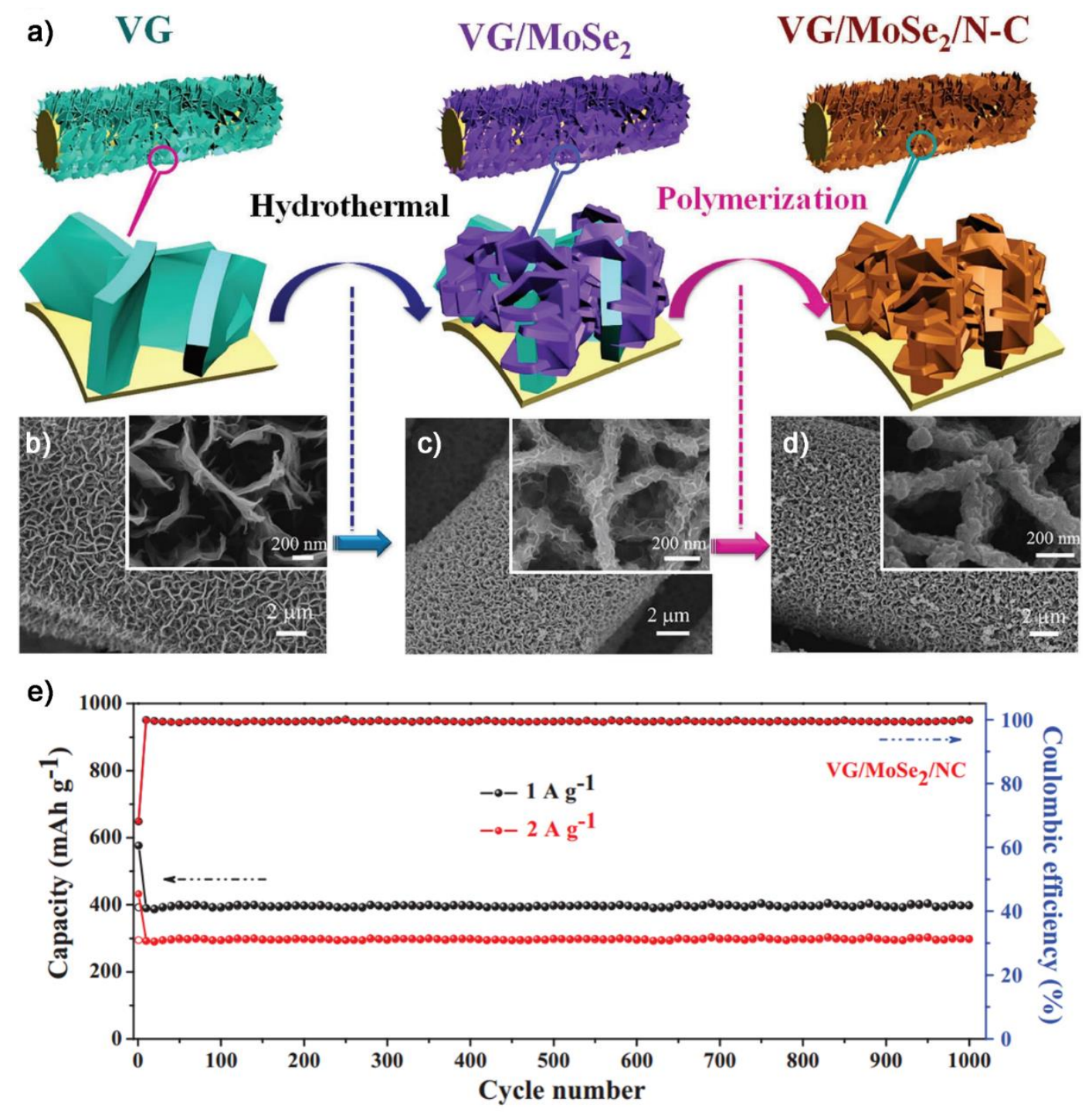

Fig. 15. (a-d) Schematic illustration of the synthesis of self-supported (vertical graphene and N-doped carbon) sandwiched VG/MoSe $/ \mathrm{N}-\mathrm{C}$ ternary core/shell arrays. (e) Cycling stability of VG/MoSe $/ \mathrm{N}-\mathrm{C}$ electrodes for SIBs at 1 and $2 \mathrm{~A} \mathrm{~g}^{-1}$, respectively. Reproduced from Ref. [221] with permission of Wiley-VCH.

\section{3. $\mathrm{WSe}_{2}$ for sodium-ion batteries}

Amongst TMDs, $\mathrm{WSe}_{2}$ has received increasing attention due to its specific features such as highly hydrophobic surface, ultralow thermal conductivity, and efficient p-type field-effect properties. However, little attention was paid to their energy storage applications, partially because of the difficulties in the synthesis and the intuitive expectation that TMDs containing heavier elements may 
not show advantages for high specific capacities [179,222,223]. After some highlights on the similarities and differences between the conversion reactions for $\mathrm{MoS}_{2}, \mathrm{WS}_{2}$, and $\mathrm{WSe}_{2}$, the low overpotential and better volumetric capacity of $\mathrm{WSe}_{2}$ manifest itself as a candidate material for nextgeneration SIB anode materials [179,222,223]. For example, Yang et al. synthesized a 2D WSe 2 hexagonal nanoplate material. When used as SIB anodes, it showed an excellent cycling performance of $384 \mathrm{~mA} \mathrm{~h} \mathrm{~g}^{-1}$ after 50 cycles at $400 \mathrm{~mA} \mathrm{~g}^{-1}$ and a high rate capacity of $317 \mathrm{~mA} \mathrm{~h} \mathrm{~g}^{-1}$ at $2.0 \mathrm{~A} \mathrm{~g}^{-1}$ after 40 cycles [179]. Taking the gravimetric density of $\mathrm{WSe}_{2}\left(9.32 \mathrm{~g} \mathrm{~cm}^{-3}\right)$ into consideration, it may afford a quite high volumetric energy density, a more important characteristic than gravimetric energy density for practical applications due to the limited battery packing space. The further ex situ XRD and Raman spectroscopy characterizations revealed that $\mathrm{WSe}_{2}$ reacted with $\mathrm{Na}^{+}$more easily and thoroughly than $\mathrm{Li}^{+}$, and it showed difference from the traditional conversion mechanism for LIBs. The $\mathrm{Na}_{2} \mathrm{Se}$ in the sodiated state is oxidized to amorphous Se during the subsequent charge process rather than reverting to $\mathrm{WSe}_{2}$ as in the $\mathrm{Li}$ storage mechanism. Zhang et al. synthesized a $\mathrm{WSe}_{2} / \mathrm{C}$ nanocomposite with crystal $\mathrm{WSe}_{2}$ nanoparticles uniformly distributed in a carbon matrix using a simple solid-state reaction of $\mathrm{W}, \mathrm{Se}$, and Super $\mathrm{P}$ carbon black powder. This hybrid nanomaterial demonstrated a high initial discharge capacity of $467 \mathrm{~mA} \mathrm{~h}^{-1}$ and an enhanced cycling stability with a reversible capacity of $270 \mathrm{~mA} \mathrm{~h} \mathrm{~g}^{-1}$ after 50 cycles at $200 \mathrm{~mA} \mathrm{~g}^{-1}$ without any notable loss. While pure $\mathrm{WSe}_{2}$ nanoplate anode underwent an apparent capacity decline during the initial 20 cycles and decreased to $81 \mathrm{~mA} \mathrm{~h} \mathrm{~g}^{-1}$. The improved cycling and rate performances should be ascribed to the buffering effect from carbon matrix for accommodating volume changes and high electric conductivity for fast charge transfer [222]. 


\section{Conclusions and future perspectives}

In this review, we summarize the recent advances in thedevelopment of graphene-like layered metal dichalcogenides $\mathrm{WS}_{2}, \mathrm{MoSe}_{2}, \mathrm{WSe} \mathrm{e}_{2}$ and their composites beyond $\mathrm{MoS}_{2}$ as the electrode materials in Li-ion and Na-ion batteries. The abovementionedhybrid materials have seen remarkableachievements made to date, however, there still are many challenges need to be addressed inthe future.

The performance of TMDs at high current drain is constrained by their limited electronicconductivity limiting the affordable power density. Compared to the most studied TMD $\mathrm{MoS}_{2}$, the layered $\mathrm{WS}_{2}, \mathrm{MoSe}_{2}$, and $\mathrm{WSe}_{2}$ possess a well-defined layered structure and higher intrinsic electronic conductivity. They have beenrecently studied as an attractive class of anode material for Liion and Na-ion batteries especially for high rate applications despite their lower theoretical capacity. However, the research on $\mathrm{WS}_{2}, \mathrm{MoSe}_{2}$, and $\mathrm{WSe}_{2}$-based carbon and other advanced hybrids still in their infancy. Researchers should pay attention to solve the problem of poorcycling stability due to large volume changes during ions insertion and extractionprocesses. Further study should focus on the electrochemical operating mechanism, optimizing the electrode preparation process, improving the phase and structural stability of electrode materials, enhancing the electrochemical cycle stability. And some vital technological applications of the aforementioned TMDs are also of great concern.

i) The mechanism for the intercalation and conversion processes should be further studied to clarify the debatable transformation behaviors of these transition metals, and the reversible process thereof.

ii) The capacity fading mechanism for TMDs and the impact of shuttle effect need to be further investigated. 
iii) The incorporation of TMDs with carbon matrix with more active sites especially for graphene improves the energy and power densities, but also reduces the initial Coulombic efficiency (ICE). An annealing/calcination post-treatment of these hybrid materials will greatly enhance the ICE and benefit the application in full cells or batteries, which is among several useful strategies to minimize the irreversible capacity including pre-lithium/sodium intercalation and electrolyte improvement.

iv) Doping or intercalation by heteroatoms including $\mathrm{S}, \mathrm{Se}, \mathrm{C}$ is favorable for enhancing the conductivity and expanding interlayer spacing, thus improves the electrochemical performances.

v) Heterostructures combining merits of different layered TMDs will be good candidates for rational design of advanced electrodes based on 2D materials for superior and tunable electrochemical performances.

vi) For flexible electrodes, the mechanical properties of electrospun or freeze-dried composite electrodes for example need to be further improved for practical application.

vii) The relatively high potential of TMDs is a double-edged sword, but generally speaking, TMDs could be safely utilized as anode materials especially for power batteries because of the excellent rate capability and superior cycling stability which would make up the shortcomings although it simultaneously avoids the danger for safety derived from dendrites.

Although there are still some significant challenges for the practical utilization of advanced energy storage devices based on the abovementioned TMDs, great stride has been achieved during the past decade. It would be reasonable to believe that further fundamental understanding and exploration in this field will lead to more exciting achievements for novel high-performance rechargeable batteries.

\section{Acknowledgments}


This work was supported by the National Natural Science Foundation of China (Grant No. 51302079), and the Natural Science Foundation of Hunan Province (Grant No. 2017JJ1008).

\section{Supplementary materials}

Supplementary material associated with this article can be found, in the online version, at doi:10.1016/j.jechem.

\section{References}

[1] J. Lu, Z. Chen, Z. Ma, F. Pan, L.A. Curtiss, K. Amine, Nat. Nanotechnol. 11 (2016) 1031-1038.

[2] B. Dunn, H. Kamath, J.M. Tarascon, Science 334 (2011) 928-935.

[3] P.J. Hall, E.J. Bain, Energy Policy 36 (2008) 4352-4355.

[4] J. Xu, J. Ma, Q. Fan, S. Guo, S. Dou, Adv. Mater. 29 (2017) 1606454.

[5] W. Luo, F. Shen, C. Bommier, H. Zhu, X. Ji, L. Hu, Acc. Chem. Res. 49 (2016) 231-240.

[6] J. Mao, T. Zhou, Y. Zheng, H. Gao, H.k. Liu, Z. Guo, J. Mater. Chem. A 6 (2018) 3284-3303.

[7] J. Xu, Y. Dou, Z. Wei, J. Ma, Y. Deng, Y. Li, H. Liu, S. Dou, Adv. Sci. 4 (2017) 1700146.

[8] N.S. Choi, Z.H. Chen, S.A. Freunberger, X.L. Ji, Y.K. Sun, K. Amine, G. Yushin, L.F. Nazar, J. Cho, P.G. Bruce, Angew. Chem. Int. Ed. 51 (2012) 9994-10024.

[9] P. Simon, Y. Gogotsi, Acc. Chem. Res. 46 (2013) 1094-1103.

[10] W. Li, J. Liu, D. Zhao, Nat. Rev. Mater. 1 (2016) 16023.

[11] R. Raccichini, A. Varzi, S. Passerini, B. Scrosati, Nat. Mater. 14 (2015) 271-279.

[12] F. Bonaccorso, L. Colombo, G. Yu, M. Stoller, V. Tozzini, A.C. Ferrari, R.S. Ruoff, V. Pellegrini, Science 347 (2015) 1246501.

[13] E. Pomerantseva, Y. Gogotsi, Nat. Energy 2 (2017) 17089.

[14] P.G. Bruce, B. Scrosati, J.M. Tarascon, Angew. Chem. Int. Ed. 47 (2008) 2930-2946.

[15] C. Liu, F. Li, L.P. Ma, H.M. Cheng, Adv. Mater. 22 (2010) E28-E62.

[16] W. Choi, N. Choudhary, G.H. Han, J. Park, D. Akinwande, Y.H. Lee, Mater. Today 20 (2017) 116-130.

[17] X. Duan, J. Xu, Z. Wei, J. Ma, S. Guo, H. Liu, S. Dou, Small Methods 1 (2017) 1700156.

[18] C. Tan, X. Cao, X.-J. Wu, Q. He, J. Yang, X. Zhang, J. Chen, W. Zhao, S. Han, G.-H. Nam, M. Sindoro, H. Zhang, Chem. Rev. 117 (2017) 6225-6331.

[19] X. Wang, Q. Weng, Y. Yang, Y. Bando, D. Golberg, Chemical Society Reviews 45 (2016) 4042-4073.

[20] D.L. Duong, S.J. Yun, Y.H. Lee, ACS Nano 11 (2017) 11803-11830.

[21] Z. Wei, L. Wang, M. Zhuo, W. Ni, H. Wang, J. Ma, J. Mater. Chem. A 6 (2018) 12185-12214.

[22] J. Shi, Q. Ji, Z. Liu, Y. Zhang, Adv. Energy Mater. 6 (2016) 1600459.

[23] C. Guerrero-Bermea, L.P. Rajukumar, A. Dasgupta, Y. Lei, Y. Hashimoto, S. Sepulveda-Guzman, R. CruzSilva, M. Endo, M. Terrones, Carbon 125 (2017) 437-453.

[24] S. Wu, Y. Du, S. Sun, Chem. Eng. J. 307 (2017) 189-207.

[25] M. Pumera, Z. Sofer, A. Ambrosi, J. Mater. Chem. A 2 (2014) 8981-8987.

[26] C.N.R. Rao, H.S.S.R. Matte, U. Maitra, Angew. Chem. Int. Ed. 52 (2013) 13162-13185. 
[27] M. Samadi, N. Sarikhani, M. Zirak, H. Zhang, H.-L. Zhang, A.Z. Moshfegh, Nanoscale Horizons 3 (2018) 90-204.

[28] W. Kang, Y. Wang, J. Xu, J. Mater. Chem. A 5 (2017) 7667-7690.

[29] C. Tan, H. Zhang, Chem. Soc. Rev. 44 (2015) 2713-2731.

[30] X. Cao, C. Tan, X. Zhang, W. Zhao, H. Zhang, Adv. Mater. 28 (2016) 6167-6196.

[31] Y.-P. Gao, X. Wu, K.-J. Huang, L.-L. Xing, Y.-Y. Zhang, L. Liu, CrystEngComm 19 (2017) 404-418.

[32] S. Balendhran, S. Walia, H. Nili, J.Z. Ou, S. Zhuiykov, R.B. Kaner, S. Sriram, M. Bhaskaran, K. Kalantarzadeh, Adv. Funct. Mater. 23 (2013) 3952-3970.

[33] Z. Hai, S. Zhuiykov, Adv. Mater. Interfaces 5 (2018) 1701385.

[34] M. Chhowalla, H.S. Shin, G. Eda, L.-J. Li, K.P. Loh, H. Zhang, Nat. Chem. 5 (2013) 263-275.

[35] M. Velický, P.S. Toth, Appl. Mater. Today 8 (2017) 68-103.

[36] Z. Wang, C. Zhao, R. Gui, H. Jin, J. Xia, F. Zhang, Y. Xia, Coord. Chem. Rev. 326 (2016) 86-110.

[37] A. Eftekhari, J. Mater. Chem. A 5 (2017) 18299-18325.

[38] N. Choudhary, M.A. Islam, J.H. Kim, T.-J. Ko, A. Schropp, L. Hurtado, D. Weitzman, L. Zhai, Y. Jung, Nano Today 19 (2018) 16-40.

[39] M.K. Jana, C.N.R. Rao, Philos. Trans. R. Soc. A 374 (2016) 20150318.

[40] J.R. Brent, N. Savjani, P. O'Brien, Prog. Mater. Sci. 89 (2017) 411-478.

[41] A. Eftekhari, Appl. Mater. Today 8 (2017) 1-17.

[42] X. Hu, W. Zhang, X. Liu, Y. Mei, Y. Huang, Chem. Soc. Rev. 44 (2015) 2376-2404.

[43] S. Fan, X. Zou, H. Du, L. Gan, C. Xu, W. Lv, Y.-B. He, Q.-H. Yang, F. Kang, J. Li, J. Phys. Chem. C 121 (2017) 13599-13605.

[44] R. Schmuch, R. Wagner, G. Hörpel, T. Placke, M. Winter, Nat. Energy 3 (2018) 267-278.

[45] Editorial, Nat. Energy 3 (2018) 245-245.

[46] A. Kwade, W. Haselrieder, R. Leithoff, A. Modlinger, F. Dietrich, K. Droeder, Nat. Energy 3 (2018) 290300.

[47] X. Xu, W. Liu, Y. Kim, J. Cho, Nano Today 9 (2014) 604-630.

[48] C.M. Julien, Mater. Sci. Eng. R 40 (2003) 47-102.

[49] M. Zheng, H. Tang, Q. Hu, S. Zheng, L. Li, J. Xu, H. Pang, Adv. Funct. Mater. 28 (2018) 1707500.

[50] H. Pan, Y.-S. Hu, L. Chen, Energy Environ. Sci. 6 (2013) 2338-2360.

[51] L. Peng, Y. Zhu, D. Chen, R.S. Ruoff, G. Yu, Adv. Energy Mater. 6 (2016) 1600025.

[52] M.Á. Muñoz-Márquez, D. Saurel, J.L. Gómez-Cámer, M. Casas-Cabanas, E. Castillo-Martínez, T. Rojo, Adv. Energy Mater. 7 (2017) 1700463.

[53] M. Lao, Y. Zhang, W. Luo, Q. Yan, W. Sun, S.X. Dou, Adv. Mater. 29 (2017) 1700622.

[54] S.W. Kim, D.H. Seo, X. Ma, G. Ceder, K. Kang, Adv. Energy Mater. 2 (2012) 710-721.

[55] X. Zhang, Z. Lai, C. Tan, H. Zhang, Angew. Chem. Int. Ed. 55 (2016) 8816-8838.

[56] H. Li, Y. Shi, M.-H. Chiu, L.-J. Li, Nano Energy 18 (2015) 293-305.

[57] X.Y. Yu, L. Yu, X.W. Lou, Small Methods 1 (2017) 1600020.

[58] Z. Lei, J. Zhan, L. Tang, Y. Zhang, Y. Wang, Adv. Energy Mater. 8 (2018) 1703482.

[59] C. Zhu, X. Mu, P.A. van Aken, Y. Yu, J. Maier, Angew. Chem. Int. Ed. 53 (2014) 2152-2156.

[60] L. Yang, S. Wang, J. Mao, J. Deng, Q. Gao, Y. Tang, O.G. Schmidt, Adv. Mater. 25 (2013) 1180-1184.

[61] Y.M. Chen, X.Y. Yu, Z. Li, U. Paik, X.W.D. Lou, Sci. Adv. 2 (2016) e1600021.

[62] Y. Wang, L. Yu, X.W.D. Lou, Angew. Chem. Int. Ed. 55 (2016) 7423-7426.

[63] X.-Y. Yu, L. Yu, X.W. Lou, Adv. Energy Mater. 6 (2016) 1501333. 
[64] Y.Y. Lee, G.O. Park, Y.S. Choi, J.K. Shon, J. Yoon, K.H. Kim, W.-S. Yoon, H. Kim, J.M. Kim, RSC Adv. 6 (2016) 14253-14260.

[65] Y. Ge, C. Wang, Y. Zhao, Y. Liu, Y. Chao, T. Zheng, G.G. Wallace, Small 14 (2018) 1703096.

[66] Y. Chao, R. Jalili, Y. Ge, C. Wang, T. Zheng, K. Shu, G.G. Wallace, Adv. Funct. Mater. 27 (2017) 1700234.

[67] Y. Wang, D. Kong, W. Shi, B. Liu, G.J. Sim, Q. Ge, H.Y. Yang, Adv. Energy Mater. 6 (2016) 1601057.

[68] R. Chen, T. Zhao, W. Wu, F. Wu, L. Li, J. Qian, R. Xu, H. Wu, H.M. Albishri, A.S. Al-Bogami, D.A. ElHady, J. Lu, K. Amine, Nano Lett. 14 (2014) 5899-5904.

[69] W. Yang, J. Wang, C. Si, Z. Peng, J. Frenzel, G. Eggeler, Z. Zhang, J. Mater. Chem. A 3 (2015) 1781117819.

[70] D. Chen, G. Ji, B. Ding, Y. Ma, B. Qu, W. Chen, J.Y. Lee, Nanoscale 5 (2013) 7890-7896.

[71] P.D. Antunez, D.H. Webber, R.L. Brutchey, Chem. Mater. 25 (2013) 2385-2387.

[72] W.-H. Ryu, H. Wilson, S. Sohn, J. Li, X. Tong, E. Shaulsky, J. Schroers, M. Elimelech, A.D. Taylor, ACS Nano 10 (2016) 3257-3266.

[73] Y.L. Ding, P. Kopold, K. Hahn, P.A. van Aken, J. Maier, Y. Yu, Adv. Mater. 28 (2016) 7774-7782.

[74] J. Zou, C. Liu, Z. Yang, C. Qi, X. Wang, Q. Qiao, X. Wu, T. Ren, ChemElectroChem 4 (2017) 2232-2236.

[75] T. Wang, C. Sun, M. Yang, L. Zhang, Y. Shao, Y. Wu, X. Hao, Electrochim. Acta 259 (2018) 1-8.

[76] X. Zeng, Z. Ding, C. Ma, L. Wu, J. Liu, L. Chen, D.G. Ivey, W. Wei, ACS Appl. Mater. Interfaces 8 (2016) 18841-18848.

[77] C. Wu, X. Zeng, P. He, L. Chen, W. Wei, Adv. Mater. Interfaces 5 (2018) 1701080.

[78] Y. Liu, W. Wang, H. Huang, L. Gu, Y. Wang, X. Peng, Chem. Commun. 50 (2014) 4485-4488.

[79] H. Liu, D. Su, G. Wang, S.Z. Qiao, J. Mater. Chem. 22 (2012) 17437-17440.

[80] J. Zhou, J. Qin, L. Guo, N. Zhao, C. Shi, E.-z. Liu, F. He, L. Ma, J. Li, C. He, J. Mater. Chem. A 4 (2016) 17370-17380.

[81] X. H. Zhang, H. Tan, Z. Fan, M. Z. Ge, X. Ye, M.Q. Xue, Chalcogenide Lett. 14 (2017) 419-423.

[82] X. Fang, C. Hua, C. Wu, X. Wang, L. Shen, Q. Kong, J. Wang, Y. Hu, Z. Wang, L. Chen, Chem. Eur. J. 19 (2013) 5694-5700.

[83] C. Feng, L. Huang, Z. Guo, H. Liu, Electrochem. Commun. 9 (2007) 119-122.

[84] G.X. Wang, S. Bewlay, J. Yao, H.K. Liu, S.X. Dou Electrochem. Solid-State Lett. 7 (2004) A321-A323.

[85] R. Bhandavat, L. David, G. Singh, J. Phys. Chem. Lett. 3 (2012) 1523-1530.

[86] J. Qian, Z. Peng, P. Wang, X. Fu, ACS Appl. Mater. Interfaces 8 (2016) 16876-16884.

[87] J.w. Seo, Y.w. Jun, S.w. Park, H. Nah, T. Moon, B. Park, J.G. Kim, Y.J. Kim, J. Cheon, Angew. Chem. Int. Ed. 46 (2007) 8828-8831.

[88] J. Jamnik, J. Maier, Phys. Chem. Chem. Phys. 5 (2003) 5215-5220.

[89] Z.-Q. Duan, Y.-C. Sun, Y.-T. Liu, X.-M. Xie, X.-D. Zhu, RSC Adv. 4 (2014) 41543-41550.

[90] L. Zhou, S. Yan, L. Pan, X. Wang, Y. Wang, Y. Shi, Nano Res. 9 (2016) 857-865.

[91] D.K. Nandi, U.K. Sen, A. Dhara, S. Mitra, S.K. Sarkar, RSC Adv. 6 (2016) 38024-38032.

[92] W. Lv, J. Xiang, F. Wen, Z. Jia, R. Yang, B. Xu, D. Yu, J. He, Z. Liu, Electrochim. Acta 153 (2015) 4954.

[93] J. Huang, X. Wang, J. Li, L. Cao, Z. Xu, H. Wei, J. Alloys Compd. 673 (2016) 60-66.

[94] S.H. Choi, S.J. Boo, J.-H. Lee, Y.C. Kang, Sci. Rep. 4 (2014) 5755.

[95] S. Yu, J.-W. Jung, I.-D. Kim, Nanoscale 7 (2015) 11945-11950.

[96] Q. Pang, Y. Gao, Y. Zhao, Y. Ju, H. Qiu, Y. Wei, B. Liu, B. Zou, F. Du, G. Chen, Chem. Eur. J. 23 (2017) 7074-7080.

[97] J. Li, X. Shi, J. Fang, J. Li, Z. Zhang, ChemNanoMat 2 (2016) 997-1002. 
[98] Z. Yuan, Q. Jiang, C. Feng, X. Chen, Z. Guo, J. Electron. Mater. 47 (2018) 251-260.

[99] Y. Liu, W. Wang, Y. Wang, X. Peng, Electrochim. Acta 148 (2014) 73-78.

[100] B. Kartick, S.K. Srivastava, S. Mahanty, J. Nanosci. Nanotechnol. 14 (2014) 3758-3764.

[101] X. Li, J. Zhang, Z. Liu, C. Fu, C. Niu, J. Alloys Compd. 766 (2018) 656-662.

[102] S. Liu, B. Shen, Y. Niu, M. Xu, J. Colloid Interface Sci. 488 (2017) 20-25.

[103] X. Xu, C.S. Rout, J. Yang, R. Cao, P. Oh, H.S. Shin, J. Cho, J. Mater. Chem. A 1 (2013) 14548-14554.

[104] Y. Du, X. Zhu, L. Si, Y. Li, X. Zhou, J. Bao, J. Phys. Chem. C 119 (2015) 15874-15881.

[105] D.H. Youn, C. Jo, J.Y. Kim, J. Lee, J.S. Lee, J. Power Sources 295 (2015) 228-234.

[106] S. Lin, Z. Yang, H. Yue, D. He, Mater. Lett. 158 (2015) 9-12.

[107] L. Zhou, S. Yan, Z. Lin, Y. Shi, Mater. Chem. Phys. 171 (2016) 16-21.

[108] L. Yu, H.B. Wu, X.W.D. Lou, Acc. Chem. Res. 50 (2017) 293-301.

[109] L. Zhou, Z. Zhuang, H. Zhao, M. Lin, D. Zhao, L. Mai, Adv. Mater. 29 (2017) 1602914.

[110] L. Yu, H. Hu, H.B. Wu, X.W. Lou, Adv. Mater. 29 (2017) 1604563.

[111] G. Huang, H. Liu, S. Wang, X. Yang, B. Liu, H. Chen, M. Xu, J. Mater. Chem. A 3 (2015) 24128-24138.

[112] H. Li, K. Yu, H. Fu, B. Guo, X. Lei, Z. Zhu, Phys. Chem. Chem. Phys. 17 (2015) 29824-29833.

[113] K. Shiva, H.S.S. Ramakrishna Matte, H.B. Rajendra, A.J. Bhattacharyya, C.N.R. Rao, Nano Energy 2 (2013) 787-793.

[114] S. Stankovich, D.A. Dikin, G.H.B. Dommett, K.M. Kohlhaas, E.J. Zimney, E.A. Stach, R.D. Piner, S.T. Nguyen, R.S. Ruoff, Nature 442 (2006) 282-286.

[115] Y. Wang, J.W. Shan, G.J. Weng, J. Appl. Phys. 118 (2015) 065101.

[116] Z.S. Wu, W.C. Ren, L. Xu, F. Li, H.M. Cheng, ACS Nano 5 (2011) 5463-5471.

[117] X.L. Li, H.L. Wang, J.T. Robinson, H. Sanchez, G. Diankov, H.J. Dai, J. Am. Chem. Soc. 131 (2009) 15939-15944.

[118] Y. Song, S. Bai, L. Zhu, M. Zhao, D. Han, S. Jiang, Y.-N. Zhou, ACS Appl. Mater. Interfaces 10 (2018) 13606-13613.

[119] D. Chen, G. Ji, B. Ding, Y. Ma, B. Qu, W. Chen, J.Y. Lee, Ind. Eng. Chem. Res. 53 (2014) 17901-17908. [120] W. Liu, M.S. Song, B. Kong, Y. Cui, Adv. Mater. 29 (2017) 1603436.

[121] Y. He, B. Matthews, J. Wang, L. Song, X. Wang, G. Wu, J. Mater. Chem. A 6 (2018) 735-753.

[122] X. Guo, S. Zheng, G. Zhang, X. Xiao, X. Li, Y. Xu, H. Xue, H. Pang, Energy Storage Mater. 9 (2017) 150-169.

[123] M. Yousaf, H.T.H. Shi, Y. Wang, Y. Chen, Z. Ma, A. Cao, H.E. Naguib, R.P. Han, Adv. Energy Mater. 6 (2016) 1600490.

[124] X. Wang, X. Lu, B. Liu, D. Chen, Y. Tong, G. Shen, Adv. Mater. 26 (2014) 4763-4782.

[125] L. Li, Z. Wu, S. Yuan, X.-B. Zhang, Energy Environ. Sci. 7 (2014) 2101-2122.

[126] H. Gwon, J. Hong, H. Kim, D.-H. Seo, S. Jeon, K. Kang, Energy Environ. Sci. 7 (2014) 538-551.

[127] S. Zhou, J. Chen, L. Gan, Q. Zhang, Z. Zheng, H. Li, T. Zhai, Sci. Bull. 61 (2016) 227-235.

[128] L. Zhang, W. Fan, T. Liu, Nanoscale 8 (2016) 16387-16394.

[129] D. Kong, X. Qiu, B. Wang, Z. Xiao, X. Zhang, R. Guo, Y. Gao, Q.-H. Yang, L. Zhi, Sci. China Mater. 61 (2018) 671-678.

[130] J. Ren, Z. Wang, F. Yang, R.-P. Ren, Y.-K. Lv, Electrochim. Acta 267 (2018) 133-140.

[131] L. Pan, Y.T. Liu, X.M. Xie, X.Y. Ye, Small 12 (2016) 6703-6713.

[132] J. Liu, H. Cao, B. Jiang, Y. Xue, L. Fu, Sci. China Mater. 59 (2016) 459-474.

[133] Y. Liu, W. Wang, Y. Wang, X. Peng, Nano Energy 7 (2014) 25-32. 
[134] Y.V. Lim, Z.X. Huang, Y. Wang, F.H. Du, J. Zhang, T.P. Chen, L.K. Ang, H.Y. Yang, RSC Adv. 6 (2016) 107768-107775.

[135] F. Béguin, F. Chevallier, C. Vix-Guterl, S. Saadallah, V. Bertagna, J.N. Rouzaud, E. Frackowiak, Carbon 43 (2005) 2160-2167.

[136] B. Zhao, F. Chen, Z. Wang, S. Huang, Y. Jiang, Z. Chen, Nanoscale 9 (2017) 17922-17932.

[137] Y. Shi, C. Hua, B. Li, X. Fang, C. Yao, Y. Zhang, Y.S. Hu, Z. Wang, L. Chen, D. Zhao, G.D. Stucky, Adv. Funct. Mater. 23 (2013) 1832-1838.

[138] J. Morales, J. Santos, J.L. Tirado, Solid State Ionics 83 (1996) 57-64.

[139] T. Xiang, S. Tao, W. Xu, Q. Fang, C. Wu, D. Liu, Y. Zhou, A. Khalil, Z. Muhammad, W. Chu, Z. Wang, H. Xiang, Q. Liu, L. Song, ACS Nano 11 (2017) 6483-6491.

[140] M. Zhu, Z. Luo, A. Pan, H. Yang, T. Zhu, S. Liang, G. Cao, Chem. Eng. J. 334 (2018) 2190-2200.

[141] Y. Liu, M. Zhu, D. Chen, J. Mater. Chem. A 3 (2015) 11857-11862.

[142] X. Yang, Z. Zhang, Y. Fu, Q. Li, Nanoscale 7 (2015) 10198-10203.

[143] L. Ma, X. Zhou, L. Xu, X. Xu, L. Zhang, W. Chen, J. Power Sources 285 (2015) 274-280.

[144] Y. Yang, S. Wang, J. Zhang, H. Li, Z. Tang, X. Wang, Inorg. Chem. Front. 2 (2015) 931-937.

[145] M.Q. Xue, Chalcogenide Lett. 13 (2016) 73-78.

[146] S. Zhang, G. Wang, J. Jin, L. Zhang, Z. Wen, J. Yang, ACS Nano 12 (2018) 4010-4018.

[147] N. Tian, A.-m. Qin, L. Liao, K.-y. Zhang, M.-p. Wang, Key Eng. Mater. 727 (2017) 645-652.

[148] W. Tang, D. Xie, T. Shen, X. Wang, D. Wang, X. Zhang, X. Xia, J. Wu, J. Tu, Chem. Eur. J. 23 (2017) 12924-12929.

[149] C. Zheng, C. Chen, L. Chen, M. Wei, J. Mater. Chem. A 5 (2017) 19632-19638.

[150] L. Wu, P. Tan, Y. Liu, X. Xiong, J. Pan, ChemistrySelect 2 (2017) 8101-8107.

[151] J. Wang, C. Peng, L. Zhang, Y. Fu, H. Li, X. Zhao, J. Zhu, X. Wang, Electrochim. Acta 256 (2017) 1927.

[152] B. Mendoza-Sánchez, J. Coelho, A. Pokle, V. Nicolosi, Electrochim. Acta 192 (2016) 1-7.

[153] J. Yao, B. Liu, S. Ozden, J. Wu, S. Yang, M.-T.F. Rodrigues, K. Kalaga, P. Dong, P. Xiao, Y. Zhang, R. Vajtai, P.M. Ajayan, Electrochim. Acta 176 (2015) 103-111.

[154] Z. Luo, J. Zhou, L. Wang, G. Fang, A. Pan, S. Liang, J. Mater. Chem. A 4 (2016) 15302-15308.

[155] H. Wang, X. Wang, L. Wang, J. Wang, D. Jiang, G. Li, Y. Zhang, H. Zhong, Y. Jiang, J. Phys. Chem. C 119 (2015) 10197-10205.

[156] S. Xin, Y.G. Guo, L.J. Wan, Acc. Chem. Res. 45 (2012) 1759-1769.

[157] H. Nishihara, T. Kyotani, Adv. Mater. 24 (2012) 4473-4498.

[158] G.Y. Zheng, S.W. Lee, Z. Liang, H.W. Lee, K. Yan, H.B. Yao, H.T. Wang, W.Y. Li, S. Chu, Y. Cui, Nat. Nanotechnol. 9 (2014) 618-623.

[159] W. Ni, Y. Wang, R. Xu, Part. Part. Syst. Charact. 30 (2013) 873-880.

[160] X. Yang, Z. Zhang, X. Shi, J. Alloys Compd. 686 (2016) 413-420.

[161] L. Wu, P. Tan, Y. Liu, Y. Shang, W. Liu, X. Xiong, J. Pan, J. Colloid Interface Sci. 491 (2017) 279-285.

[162] C. Zhao, H. Song, Q. Zhuang, Q. Ma, J. Liang, H. Peng, C. Mao, Z. Zhang, G. Li, Inorg. Chem. Front. 5 (2018) 1026-1032.

[163] P. Ge, H. Hou, C.E. Banks, C.W. Foster, S. Li, Y. Zhang, J. He, C. Zhang, X. Ji, Energy Storage Mater. 12 (2018) 310-323.

[164] Z. Zhang, Y. Fu, X. Yang, Y. Qu, Z. Zhang, ChemNanoMat 1 (2015) 409-414.

[165] J. Yang, J. Zhu, J. Xu, C. Zhang, T. Liu, ACS Appl. Mater. Interfaces 9 (2017) 44550-44559.

[166] T. Niu, A. Li, Prog. Surf. Sci. 90 (2015) 21-45. 
[167] D. Wang, L.-M. Liu, S.-J. Zhao, Z.-Y. Hu, H. Liu, J. Phys. Chem. C 120 (2016) 4779-4788.

[168] T. Li, A. Wang, X. Li, J. Wang, J. Zhang, G. Fu, L. Xu, D. Sun, Y. Tang, Adv. Mater. Interfaces 5 (2018) 1701604.

[169] W. Kang, Y. Wang, D. Cao, Z. Kang, D. Sun, J. Alloys Compd. 743 (2018) 410-418.

[170] X. Zhao, J. Sui, F. Li, H. Fang, H. Wang, J. Li, W. Cai, G. Cao, Nanoscale 8 (2016) 17902-17910.

[171] H. Wu, Y. Wu, X. Chen, Y. Ma, M. Xu, W. Wei, J. Pan, X. Xiong, RSC Adv. 6 (2016) 23161-23168.

[172] S. Wang, B. Liu, G. Zhi, X. Gong, Z. Gao, J. Zhang, Electrochim. Acta 268 (2018) 424-434.

[173] F. Ersan, G. Gökoğlu, E. Aktürk, J. Phys. Chem. C 119 (2015) 28648-28653.

[174] X. Chen, Z. Wang, Y. Qiu, J. Zhang, G. Liu, W. Zheng, W. Feng, W. Cao, P. Hu, W. Hu, J. Mater. Chem. A 4 (2016) 18060-18066.

[175] R. Jin, X. Liu, L. Yang, G. Li, S. Gao, Electrochim. Acta 259 (2018) 841-849.

[176] R. Jin, Y. Cui, Q. Wang, G. Li, J. Colloid Interface Sci. 508 (2017) 435-442.

[177] J. Wang, L. Chen, L. Zeng, Q. Wei, M. Wei, ACS Sustainable Chem. Eng. 6 (2018) 4688-4694.

[178] F. Chen, J. Wang, B. Li, C. Yao, H. Bao, Y. Shi, Mater. Lett. 136 (2014) 191-194.

[179] W. Yang, J. Wang, C. Si, Z. Peng, Z. Zhang, Nano Res. 10 (2017) 2584-2598.

[180] E. Vasilyeva, A. Nasibulin, O. Tolochko, A. Rudskoy, A. Sachdev, X. Xiao, Z. Phys. Chem. 229 (2015) 1429-1437.

[181] X. Rui, H. Tan, Q. Yan, Nanoscale 6 (2014) 9889-9924.

[182] J. Stejskal, M. Mrlík, T. Plachý, M. Trchová, J. Kovářová, Y. Li, React. Funct. Polym. 120 (2017) 30-37. [183] X. Wang, J. Huang, J. Li, L. Cao, W. Hao, Z. Xu, Q. Kang, J. Alloys Compd. 696 (2017) 22-27.

[184] Y.V. Lim, Y. Wang, D. Kong, L. Guo, J.I. Wong, L.K. Ang, H.Y. Yang, J. Mater. Chem. A 5 (2017) 10406-10415.

[185] X. Wang, J. Huang, J. Li, L. Cao, W. Hao, Z. Xu, Q. Kang, Electrochim. Acta 222 (2016) 1724-1732.

[186] Y. Liu, N. Zhang, H. Kang, M. Shang, L. Jiao, J. Chen, Chem. Eur. J. 21 (2015) 11878-11884.

[187] X. Wang, J. Huang, J. Li, L. Cao, W. Hao, Z. Xu, ACS Appl. Mater. Interfaces 8 (2016) 23899-23908.

[188] B.Y. Xia, Y. Yan, N. Li, H.B. Wu, X.W.D. Lou, X. Wang, Nat. Energy 1 (2016) 15006.

[189] H. Wang, D. Kong, P. Johanes, J.J. Cha, G. Zheng, K. Yan, N. Liu, Y. Cui, Nano Lett. 13 (2013) 34263433.

[190] D. Kong, H. Wang, J.J. Cha, M. Pasta, K.J. Koski, J. Yao, Y. Cui, Nano Lett. 13 (2013) 1341-1347.

[191] D. Su, S. Dou, G. Wang, Chem. Commun. 50 (2014) 4192-4195.

[192] S.H. Choi, Y.C. Kang, Nanoscale 7 (2015) 3965-3970.

[193] H.G. Wang, W. Li, D.P. Liu, X.L. Feng, J. Wang, X.Y. Yang, X.B. Zhang, Y. Zhu, Y. Zhang, Adv. Mater. 29 (2017) 1703012.

[194] Y. Wang, D. Kong, S. Huang, Y. Shi, M. Ding, Y. Von Lim, T. Xu, F. Chen, X. Li, H.Y. Yang, J. Mater. Chem. A 6 (2018) 10813-10824.

[195] C. Zhu, P. Kopold, W. Li, P.A. van Aken, J. Maier, Y. Yu, J. Mater. Chem. A 3 (2015) 20487-20493.

[196] H. Liu, H. Guo, B. Liu, M. Liang, Z. Lv, K.R. Adair, X. Sun, Adv. Funct. Mater. 28 (2018) 1707480.

[197] G. Jia, H. Wang, D. Chao, H. He, N.H. Tiep, Y. Zhang, Z. Zhang, H.J. Fan, Nanotechnology 28 (2017) 42LT01.

[198] H. Wang, X. Lan, D. Jiang, Y. Zhang, H. Zhong, Z. Zhang, Y. Jiang, J. Power Sources 283 (2015) 187194.

[199] Z.T. Shi, W. Kang, J. Xu, L.L. Sun, C. Wu, L. Wang, Y.Q. Yu, D.Y.W. Yu, W. Zhang, C.S. Lee, Small 11 (2015) 5667-5674. 
[200] J. Zhang, W. Kang, M. Jiang, Y. You, Y. Cao, T.-W. Ng, D.Y.W. Yu, C.-S. Lee, J. Xu, Nanoscale 9 (2017) 1484-1490.

[201] J. Zhang, M. Wu, T. Liu, W. Kang, J. Xu, J. Mater. Chem. A 5 (2017) 24859-24866.

[202] H. Wang, L. Wang, X. Wang, J. Quan, L. Mi, L. Yuan, G. Li, B. Zhang, H. Zhong, Y. Jiang, J. Electrochem. Soc. 163 (2016) A1627-A1632.

[203] Y.N. Ko, S.H. Choi, S.B. Park, Y.C. Kang, Nanoscale 6 (2014) 10511-10515.

[204] B. Mao, D. Guo, J. Qin, T. Meng, X. Wang, M. Cao, Angew. Chem. Int. Ed. 57 (2018) 446-450.

[205] Y. Tang, Z. Zhao, Y. Wang, Y. Dong, Y. Liu, X. Wang, J. Qiu, ACS Appl. Mater. Interfaces 8 (2016) 32324-32332.

[206] J.-S. Park, Y. Chan Kang, J. Mater. Chem. A 5 (2017) 8616-8623.

[207] J. Li, H. Hu, F. Qin, P. Zhang, L. Zou, H. Wang, K. Zhang, Y. Lai, Chem. Eur. J. 23 (2017) 14004-14010. [208] J. Liu, S.Z. Qiao, J.S. Chen, X.W. Lou, X. Xing, G.Q. Lu, Chem. Commun. 47 (2011) 12578-12591.

[209] G.D. Park, J.H. Kim, S.-K. Park, Y.C. Kang, ACS Appl. Mater. Interfaces 9 (2017) 10673-10683.

[210] Z. Zhang, X. Yang, Y. Fu, K. Du, J. Power Sources 296 (2015) 2-9.

[211] S.H. Choi, Y.C. Kang, Nanoscale 8 (2016) 4209-4216.

[212] D. Chen, W. Chen, L. Ma, G. Ji, K. Chang, J.Y. Lee, Mater. Today 17 (2014) 184-193.

[213] X. Zhao, H.-E. Wang, Y. Yang, Z.G. Neale, R.C. Massé, J. Cao, W. Cai, J. Sui, G. Cao, Energy Storage Mater. 12 (2018) 241-251.

[214] X. Zhao, W. Cai, Y. Yang, X. Song, Z. Neale, H.-E. Wang, J. Sui, G. Cao, Nano Energy 47 (2018) 224234.

[215] Z. Liu, Y. Zhang, H. Zhao, N. Li, Y. Du, Sci. China Mater. 60 (2017) 167-177.

[216] F. Niu, J. Yang, N. Wang, D. Zhang, W. Fan, J. Yang, Y. Qian, Adv. Funct. Mater. 27 (2017) 1700522.

[217] D. Xie, W. Tang, Y. Wang, X. Xia, Y. Zhong, D. Zhou, D. Wang, X. Wang, J. Tu, Nano Res. 9 (2016) 1618-1629.

[218] C. Cui, G. Zhou, W. Wei, L. Chen, C. Li, J. Yue, J. Alloys Compd. 727 (2017) 1280-1287.

[219] Y. Zhang, Z. Liu, H. Zhao, Y. Du, RSC Adv. 6 (2016) 1440-1444.

[220] G. Jia, D. Chao, N.H. Tiep, Z. Zhang, H.J. Fan, Energy Storage Mater. 14 (2018) 136-142.

[221] D. Xie, X. Xia, Y. Zhong, Y. Wang, D. Wang, X. Wang, J. Tu, Adv. Energy Mater. 7 (2017) 1601804.

[222] Z. Zhang, X. Yang, Y. Fu, RSC Adv. 6 (2016) 12726-12729.

[223] K. Share, J. Lewis, L. Oakes, R.E. Carter, A.P. Cohn, C.L. Pint, RSC Adv. 5 (2015) 101262-101267. 